\title{
Metal Oxide Nanoparticles: The Importance of Size, Shape, Chemical Composition, and Valence State in Determining Toxicity
}

\author{
Katherine Dunnick
}

Follow this and additional works at: https://researchrepository.wvu.edu/etd

\section{Recommended Citation}

Dunnick, Katherine, "Metal Oxide Nanoparticles: The Importance of Size, Shape, Chemical Composition, and Valence State in Determining Toxicity" (2015). Graduate Theses, Dissertations, and Problem Reports. 5516.

https://researchrepository.wvu.edu/etd/5516

This Dissertation is protected by copyright and/or related rights. It has been brought to you by the The Research Repository @ WVU with permission from the rights-holder(s). You are free to use this Dissertation in any way that is permitted by the copyright and related rights legislation that applies to your use. For other uses you must obtain permission from the rights-holder(s) directly, unless additional rights are indicated by a Creative Commons license in the record and/ or on the work itself. This Dissertation has been accepted for inclusion in WVU Graduate Theses, Dissertations, and Problem Reports collection by an authorized administrator of The Research Repository @ WVU.

For more information, please contact researchrepository@mail.wvu.edu. 


\title{
Metal Oxide Nanoparticles: The Importance of Size, Shape, Chemical Composition, and Valence State in Determining Toxicity
}

\author{
Katherine Dunnick \\ Dissertation submitted \\ to the School of Pharmacy \\ at West Virginia University \\ in partial fulfillment of the requirements for the degree of \\ Doctor in Philosophy in \\ Pharmaceutical and Pharmacological Sciences
}

\author{
Stephen Leonard, Ph.D., Advisor \\ Yon Rojanasakul, Ph.D., Chair \\ Vincent Castranova, Ph.D. \\ Timothy Nurkiewicz, Ph.D. \\ James Antonini, Ph.D. \\ Department of Pharmaceutical and Pharmacological Sciences
}

Morgantown, West Virginia

2015

Keywords: Metal Oxides, Nanoparticles, Tungstate, Cerium Oxide, Reactive Oxygen Species, Cytotoxicity Copyright 2015 Katherine Dunnick 


\section{ABSTRACT \\ Metal Oxide Nanoparticles: The Importance of Size, Shape, Chemical Composition, and Valence State in Determining Toxicity}

\section{Katherine Dunnick}

Nanoparticles, which are defined as a structure with at least one dimension between 1 and 100 $\mathrm{nm}$, have the potential to be used in a variety of consumer products due to their improved functionality compared to similar particles of larger size. Their small size is associated with increased strength, improved catalytic properties, and increased reactivity; however, their size is also associated with increased toxicity in vitro and in vivo. Numerous toxicological studies have been conducted to determine the properties of nanomaterials that increase their toxicity in order to manufacture new nanomaterials with decreased toxicity. Data indicates that size, shape, chemical composition, and valence state of nanomaterials can dramatically alter their toxicity profile. Therefore, the purpose of this dissertation was to determine how altering the shape, size, and chemical composition of various metal oxide nanoparticles would affect their toxicity. Metal oxides are used in variety of consumer products, from spray-sun screens, to food coloring agents; thus, understanding the toxicity of metal oxides and determining which aspects affect their toxicity may provide safe alternatives nanomaterials for continued use in manufacturing. Tungstate nanoparticles toxicity was assessed in an in vitro model using RAW 264.7 cells. The size, shape, and chemical composition of these nanomaterials were altered and the effect on reactive oxygen species and general cytotoxicity was determined using a variety of techniques. Results demonstrate that shape was important in reactive oxygen species production as wires were able to induce significant reactive oxygen species compared to spheres. Shape, size, and chemical composition did not have much effect on the overall toxicity of these nanoparticles in RAW 264.7 cells over a 72 hour time course, implicating that the base material of the nanoparticles was not toxic in these cells. To further assess how chemical composition can affect toxicity, cerium oxide nanoparticles were chemically modified using a process known as doping, to alter their valence state. The size and shape of the cerium oxide nanoparticles remained constant. Overall, results indicated that cerium oxide was not toxic in both RLE-6TN and NR8383 pulmonary rat cells, however, chemically modifying the valence state of the nanomaterial did affect the antioxidant potential. To determine if this trend was measureable in vivo, rats were exposed to various cerium oxide nanoparticles via intratracheal instillation and damage, changes in pulmonary cell differentials, and phagocytic cell activity were assessed. Results implicate that chemically modifying the nanoparticles had an effect on the overall damage induced by the material but did not dramatically affect inflammatory potential or phagocytic cell activity. Overall the data from these studies imply that size, shape, chemical composition, and valence state of nanomaterials can be manipulated to alter their toxicity. 


\section{DEDICATION}

To my mother and Dan: without your continued support, pep-talks, and love this would not have been possible. 


\section{ACKNOWLEDGEMENTS}

I would like to acknowledge and thank my mentor Dr. Stephen Leonard for his continued assistance during graduate school and advice with my dissertation. Thank you for always assisting me through the toughest aspects of my project and teaching me that negative data is still important! Further, I would like to thank each of my committee members, Dr. Yon Rojanasakul, Dr. Vincent Castranova, Dr. Timothy Nurkiewicz, and Dr. James Antonini who provided me with great suggestions and advice throughout graduate school and always had ideas for ways to improve my work.

I would like to acknowledge and thank Dr. Melissa Badding who acted as an unofficial co-advisor the past 3 years, but more importantly was a great friend and someone I could rely on during the most difficult times of graduate school. I would also like to thank Kimmi Alonge and Carrie Long for continued support and the great friendships we developed while at WVU.

I would also like to thank Dr. Stan Wong, Dr. Ed Sabolsky, Dr. Aleks Stefaniak, Dr. Rajalekshmi Pillai, and Ms. Kelly Pisane, without whom the production and characterization of the nanomaterials used for my dissertation would not have been possible. I would like to thank Dr. Nikki Marshall who taught me how to do flow cytometry and was always able to help me with the inflammatory aspects of my dissertation. I would like to Michael Wolfarth for his assistance with dynamic light scattering, Matthew Duling for his assistance with determining the surface area of the nanoparticles, Dr. Donna Davidson for insightful discussion about cerium oxide nanoparticle toxicity, Diane Schwegler-Berry for her assistance with electron microscopy, and Anna Morris for technical assistance.

Lastly, I would like to thank Dan Thomas for his continued love and support during the ups and downs of graduate school and sitting through the many practice seminars, and my sister 
and mom for always listening to me discuss my project and the stresses of being a graduate student. 


\section{Table of Contents}

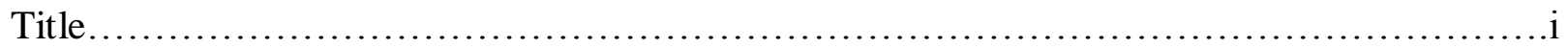

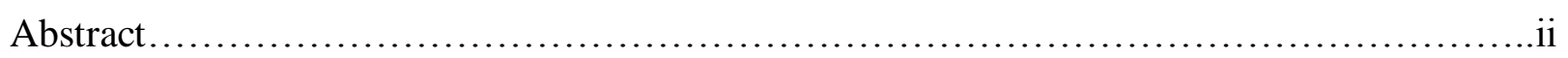

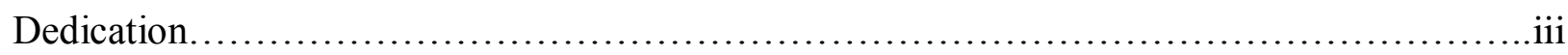

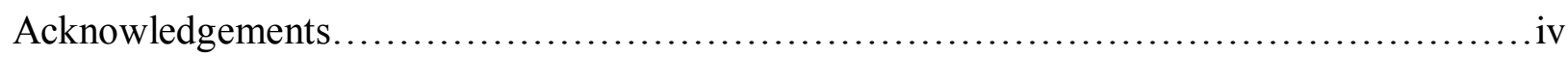

Table of Contents.................................................................

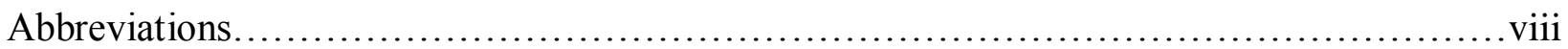

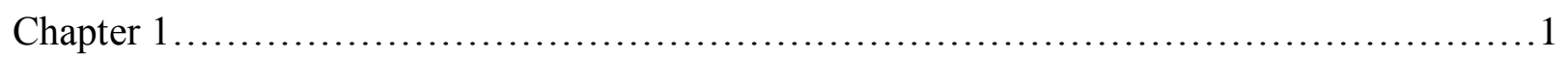

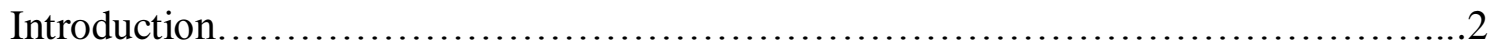

Types of Nanomaterials...................................................

Exposure Routes.......................................................6

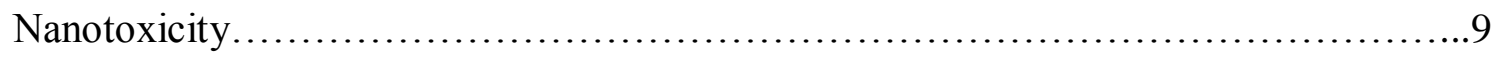

Nano characteristics....................................................13

Dissertation............................................................... 19

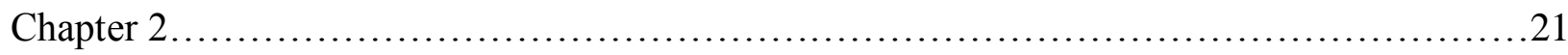

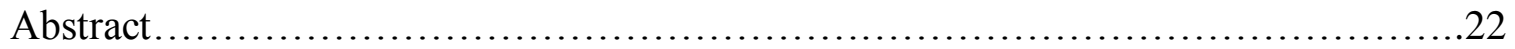

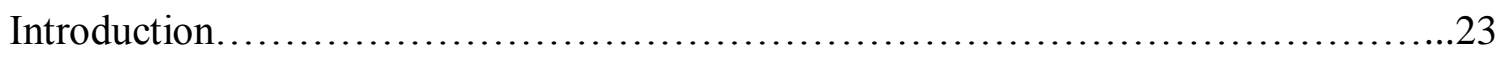

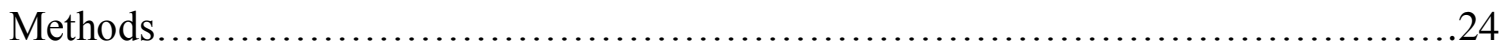

Results.................................................................... 32

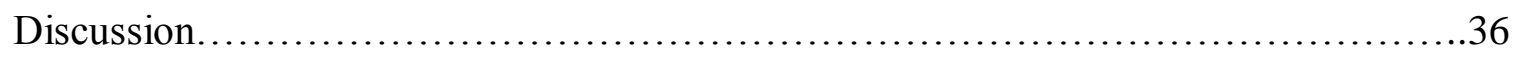

Figures and Tables......................................................42

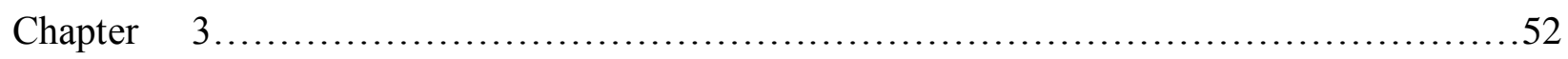

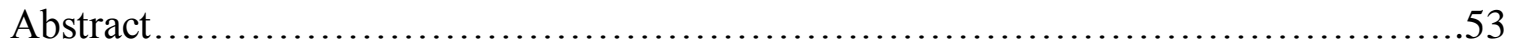


Introduction.

Methods................................................................ 55

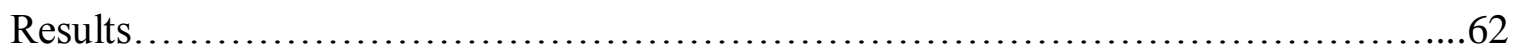

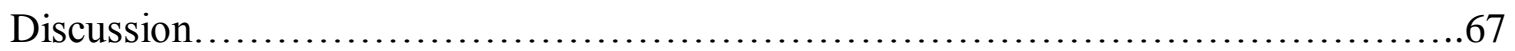

Figures and Tables..................................................... 71

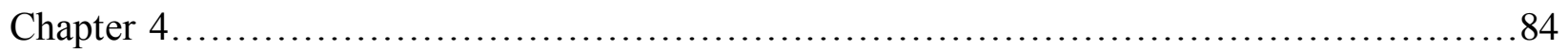

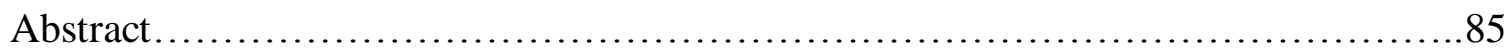

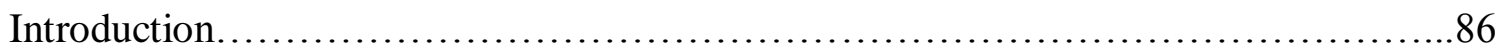

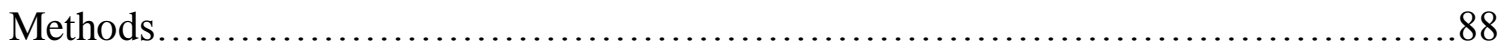

Results..................................................................... 94

Discussion.................................................................... 97

Figures and Tables..................................................... 102

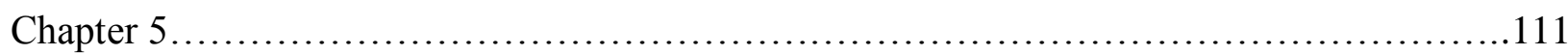

Conclusions............................................................ 112

Future Studies....................................................... 115

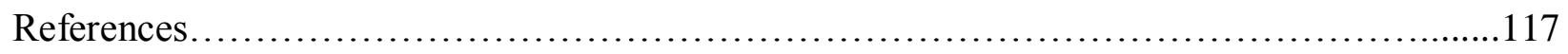

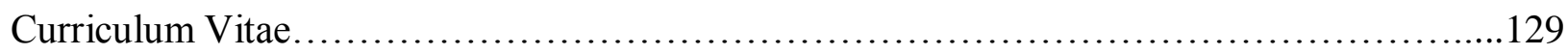




\section{ABBREVIATIONS}

$\begin{array}{ll}\text { Particulate Matter } & \text { PM }\end{array}$

Carbon nanotubes

CNTs

Single-walled carbon nanotubes

SWCNTs

Multi-walled carbon nanotubes

MWCNTs

Carbon nanofibers

CNFs

Zinc oxide

$\mathrm{ZnO}$

Titanium dioxide

$\mathrm{TiO}_{2}$

Reactive Oxygen Species

ROS

Copper oxide

$\mathrm{CuO}$

Cerium Oxide

$\mathrm{CeO}_{2}$

Superoxide

$\mathrm{O}_{2}^{--}$

Hydroxyl radical

$\mathrm{OH}$

Superoxide dismutase

SOD

Glutathione reductase

$\mathrm{GSH}$

Electron paramagnetic resonance

EPR

X-ray diffraction

XRD

Scanning electron microscopy

SEM

Energy-dispersive X-ray spectroscopy

EDS

Dynamic light scattering

DLS

Phosphate buffered saline

PBS

Immunocytochemistry

ICC

Transmission electron microscopy

TEM 
Hexavalent chromium

Body weight

BW

Permissible Exposure Limit

PEL

Bronchoalveolar lavage

BAL

Lactate dehydrogenase

LDH

Chemiluminescence

CL

Lipid peroxidation

LPO

Enzyme-like immunosorbent assay

ELISA

Polymorphonuclear leukocytes

PMN

Alveolar macrophages

AM

Hematoxylin and Eosin

$\mathrm{H} \& \mathrm{E}$ 


\section{Chapter 1}

Nanomaterials 


\subsection{What are Nanoparticles?}

Nanoparticles, or ultrafine particles, are a form of particulate matter (PM) defined as structures with at least one dimension between 1 and $100 \mathrm{~nm}$, that have unique characteristics not found in bulk material of the same composition [2]. PM, is a complex mixture of particles and liquid droplets. Depending on the size of the particles in the PM determines the detrimental health effects. Thus, ultrafine particles may have more negative effects due to their increased reactivity and surface area compared to coarse $(>2.5 \mu \mathrm{m})$ or fine $(<2.5 \mu \mathrm{m})$ PM [3]. Specifically, their small size, large surface area-to-volume ratio, strength, chemical composition, surface structure, and shape allow for the use of nanomaterials in a variety of commercial and industrial products, including batteries, sporting goods, cosmetics, electronics, and even sun-screens [1, 4-7]. Due to this versatility, their use in manufacturing and commercial applications has drastically increased into a multi-billion dollar industry $[1,8]$.

Nanoparticles are typically grouped into two categories: incidental and engineered. Incidental nanoparticles are those produced as a result of an industrial of combustion process, typically unintentionally, such as soot as a product of fossil fuel combustion. Alternatively, engineered nanomaterials are materials that are intentionally created with specific attributes for use in manufacturing, engineering, and consumer products [9]. There are numerous categories of engineered nanomaterials currently being produced, ranging from carbon- to metal-based nanomaterials, and their potential uses appear endless. This review will discuss 5 common nanomaterials, their uses, their potential toxicity, and potential mechanisms to alter toxicity while improving function. 


\subsection{Various Types of Nanomaterials}

\section{Carbon-based nanomaterials}

Typically, carbon-based nanomaterials are in the shape of tubes, known as carbon nanotubes (CNTs), or hollow spheres, known as fullerenes. These materials are often used in electronics, energy storage devices, industrial catalysts, and nanomedicine as a result of their unique shape, and large surface area-to-size ratio [10]. The most commonly studied and used carbon-based materials are single-walled CNTs (SWCNTs), which are a single layer of carbon in a fibrous form, multi-walled CNTs (MWCNTs), which are multiple layers of SWCNTs wrapped together, and fullerene C60, which resembles a soccer ball and consists of 60 carbon atoms [11, 12]. While their overall uses are plentiful, their use in consumer products may be limited due to previous studies indicating severe toxicity and asbestos-like pathogenicity observed in animal models induced following CNT exposure [13-16].

\section{Polymer-based nanomaterials}

Other nanomaterials that have uses in nanomedicine are polymer-based nanomaterials. These can consist of materials from plastics to proteins and DNA and show promise for quick drug delivery due to easy cell entry. Further, polymer-based nanomaterials are useful in food packaging as they can improve the barrier and antimicrobial properties of the packaging as well as be used as sensors to monitor the condition of the food [17]. Unlike many other nanomaterials available, polymer-based materials are relatively inert and often biodegradable [18, 19]. 


\section{Ceramic-based nanomaterials}

Ceramic-based nanomaterials are highly sought for use in engineering, due to their improved physical and mechanical properties, compared to their bulk-sized counterparts. For instance, magnesium aluminum can be used in harsh conditions due to an improved melting point and is ideal for lenses due to enhanced optical properties [20]. Further, they are useful as bioactive coatings on prosthetics and are important in tissue repair and implants [21]. Unfortunately, like many nanomaterials, their toxicity is not fully understood, but due to their degradation potential, the potential to cause damage is likely $[8,22]$.

\section{Metal-based nanomaterials}

Metal-based nanomaterials have received a lot of attention over the years, mainly nanosilver, which is known to act as an antibacterial agent and is estimated to have the greatest number of commercial applications. Currently these nanomaterials are used in a variety of medical applications, such as contraceptives and are used to treat burns and wounds [8]. They are also being added to various household products such as paint, tooth paste, fabrics, and toys for their antimicrobial properties [23]. Other metal-based nanomaterials commonly used are quantum dots and nanogold. Nanogold has found use in immunolabeling as well as tumor imaging due to increased penetration into tissues, greater sensitivity, and improved labeling [24, 25]. The toxicity of metal-based nanomaterials has been heavily studied with many studies concluding that both silver and gold nanomaterials induce only mild toxicity [26]. 


\section{Metal oxide-based nanomaterials}

Metal oxide-based nanomaterials, such as zinc oxide $(\mathrm{ZnO})$ and titanium dioxide $\left(\mathrm{TiO}_{2}\right)$, are currently used in a variety of consumer products, such as sunscreen or in donuts and cosmetics for coloring [4]. Metal oxide-based nanomaterials are also useful for a variety of engineering purposes, such as use in circuits, fuel cells, catalysts, and sensors [27]. Unlike metal-based and ceramic-based nanomaterials, metal oxide nanomaterials are typically very toxic, induce high levels of reactive oxygen species (ROS) and inflammation, and pose significant health risks [2830]. This is due to the effect of size on electronic properties of the metal oxide. While the decrease in size is beneficial for stability, it can affect the electronic properties and reactivity of the nanomaterial, resulting in new, unstudied toxicological outcomes [27]. The effect of size on metal oxide nanoparticles reactivity has been studied in depth and it was determined that a change in band gap, or the difference in charge between the tissue and the nanomaterials, had a profound effect on toxicity of the materials [31]. 


\subsection{Possible Exposure Routes}

As a result of the varying types of engineered nanomaterials and the products in which they are manufactured in, the potential routes of human exposure can differ greatly. However, the common routes of exposure are gastric, dermal, intravenous, or inhalation.

\section{Gastric Exposure}

Exposures to nanomaterials via the gastrointestinal tract represents a likely exposure route due to the use of various nanomaterials in both food and food containers. Further, following inhalation of nanomaterials, the materials may be indirectly ingested following movement up the mucociliary escalator and into pharynx where it is then swallowed. Silver nanoparticles are one material that has potential to be exposed via gastric routes due to its use in agriculture as a replacement for growth-promoting antibiotics [32]. Further, $\mathrm{TiO}_{2}$ nanomaterials are used in a variety of consumer products for pigmentation, often for food coloration, providing a direct path for ingestion of the nanomaterials. Fortunately, studies have implicated that nanomaterials exposed through gastrointestinal routes typically result in mild toxicity and relatively high concentrations [33].

\section{Dermal Exposure}

Use of nanomaterials in consumer products, such as make-up and sunscreens provides a direct route of exposure for nanomaterials to enter biological systems via the skin. Further, dermal exposure represents a risk for workers during the manufacturing of products containing nanomaterials. $\mathrm{TiO}_{2}$ nanoparticle studies have presented data that these nanomaterials are able to penetrate rodent skin and even result in organ damage. [34]. However, this effect was not 
measured in humans [35]. Further, studies implicate that nanoparticles administered in the dermis migrated toward lymph nodes, which may result in immunomodulation. In general, studies indicate that unless lesions are present within the dermal layer, human health hazards to dermal nanoparticle penetration are limited.

\section{Intravenous Exposure}

As a result of nanomaterials potential use in medicine, intravenous exposure (IV) is another

prospective exposure route of interest. Silica based nanomaterials have been studied following IV exposure as this material is emerging as a promising candidate for biomedical applications. Research has indicated that overall silica nanomaterials have low toxicity potential via IV exposure routes [36]. Further, CNTs, which have potential uses in cancer treatment and drug delivery, accumulate in various organs but induce mild damage following IV exposure in mice [37]. In general, IV exposure results in nanomaterial organ accumulation but mild toxicity.

\section{Inhalation Exposure}

The most likely route of exposure humans are likely to contact nanomaterials in through an inhalation route, due to properties of the materials that allow them to disperse readily in air [38]. Further, occupational environments in which nanomaterials are used for consumer products provides a likely scenario for nanoparticle inhalation. Studies have indicated that various nanomaterials cause significant toxicity in vivo following inhalation exposures, resulting in cellular influx, inflammation, and changes in lung structure and function [22, 39, 40]. For this reason, as well as a lack of toxicity data for most nanomaterials, understanding the potential 
toxic effects of various metal oxides in an inhalation model was studied and is presented in this dissertation. 


\subsection{Toxic Potential of Nanomaterials}

Nanomaterials provide numerous benefits for the engineering and consumer product industries, yet their potential human health effects are still under investigation to ensure safe manufacturing of nano containing products. While some nanomaterials cause little to no toxicity in vitro and in vivo at physiologically relevant doses, many nanomaterials have significant adverse effects, such as inflammation, genotoxicity, ROS production, and cell death.

\section{Inflammation}

Inflammation, which is typically associated with cytokine activation, changes in physiological environment, and changes in cellular composition, is a common endpoint induced by nanoparticles both in vitro and in vivo $[22,40]$. In animal models, persistent inflammation is known to promote fibrotic changes and induce permanent pulmonary damage [41]. Metal oxide nanomaterials, such as $\mathrm{ZnO}$, are typically strong inducers of inflammation, as measured by cytokine production [42]. Further, silica nanoparticles are able to induce pro-inflammatory markers in both monocyte-derived macrophages (RAW 264.7) and mice following single exposures [22]. Following inhalation exposures to $\mathrm{TiO}_{2}$, mice presented with emphysema-like lung injury, likely in response to inflammatory pathway activation [43].

\section{Genotoxicity}

In addition to promoting inflammation, studies have also been conducted to understand the genetic damage nanomaterials can induce. A strong inducer of genotoxicity in vitro are various metal oxide-based nanomaterials, such as copper oxide $(\mathrm{CuO})$ and $\mathrm{ZnO}$, which have been shown to induce genotoxicity in various cell lines, such as human lung epithelial cells and human 
epidermal cells $[44,45]$. Further, cerium oxide $\left(\mathrm{CeO}_{2}\right)$ nanoparticles has been shown to induce genotoxicity in human dermal fibroblasts, likely as a result of ROS production while $\mathrm{TiO}_{2}$ research has presented evidence that these nanomaterials cause genotoxic damage in mice [4648]. While metal oxide-based nanomaterials are typically inducers of genotoxicity, various other nanomaterials such as nickel nanoparticles and carbon-based nanomaterials have also been shown to cause genetic damage $[49,50]$.

\section{ROS Production}

ROS is often measured to determine the extent of nanoparticle toxicity. This is due to the idea that nanoparticles have a large surface area-to-size ratio, creating a more reactive surface. Further, the use of transition metals often creates electron donor and acceptor active sites on the material which induces superoxide $\left(\mathrm{O}_{2}{ }^{-}\right)$production. $\mathrm{O}_{2}{ }^{-}$is the main ROS produced in vivo and has strong reducing and oxidizing properties. In addition, $\mathrm{O}_{2}^{--}$production can lead to amplified free radical generation and downstream damage due to the production of hydroxyl radicals $(\cdot \mathrm{OH})$ (Figure 1.1) [1, 51].

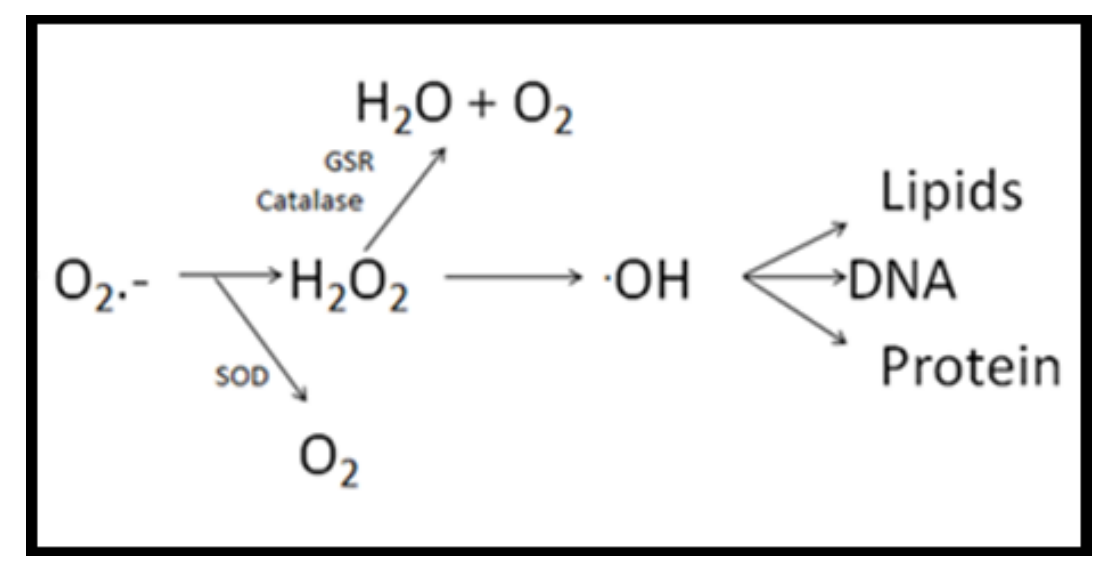

Figure 1.1 Schematic showing effect of superoxide production on downstream hydroxyl radical production and subsequent damage to lipids, DNA, and proteins. 
Numerous studies have provided evidence that $\mathrm{ZnO}$ nanoparticles induce significant $\mathrm{ROS}$ in various cell lines and in animals, possibly due to the dissolution properties exhibited by these nanoparticles [29, 52, 53]. Further, $\mathrm{CuO}$ nanoparticles are also known to induce significant ROS production by overwhelming cellular antioxidant systems [54]. Conversely, studies have also implicated that certain nanomaterials, such as platinum and $\mathrm{CeO}_{2}$, may have antioxidant-like effects, acting similar to superoxide dismutase (SOD), glutathione reductase (GSH), or catalase, preventing ROS induced damage from other chemicals [55, 56].

\section{Cell Death}

To determine the extent of nanoparticle toxicity beyond inflammatory potential or ROS production, cell death is commonly studied to determine toxic doses of nanomaterials. While many nanomaterials induce ROS or inflammation, this is not always correlated with cell death due to protective cellular mechanisms, such as antioxidant systems [57]. Therefore, to understand nanoparticle toxicity, various concentrations are tested in vitro and in vivo to determine the dose at which nanomaterials become harmful. Two typical methods of cell death are induced by nanomaterials: apoptosis and necrosis (Figure 1.2). Apoptosis is a normal process that occurs during cell turnover, is typically tightly controlled, and is considered a type of programmed cell death, which requires specific signals to be promoted [58]. Alternatively, cells can undergo necrotic cell death which is considered to be energy-independent and a result of severe toxic insult. Further, the cellular contents released during apoptotic cell death induce little to no inflammation, whereas the contents released following necrosis are highly inflammatory and can result in further downstream cellular damage. $\mathrm{ZnO}$ nanoparticles have been shown to typically induce apoptotic cell death whereas gold nanoparticles are implicated in 
necrotic cell death [59-61]. Alternatively, some nanomaterials, such as silver, have been implicated in both forms of cell death, likely due to changes in experimental conditions (tissue type, concentration, exposure time), as apoptotic cell death can transition toward necrotic cell death in response to intracellular ATP changes and decreased caspase activity [58,62, 63].

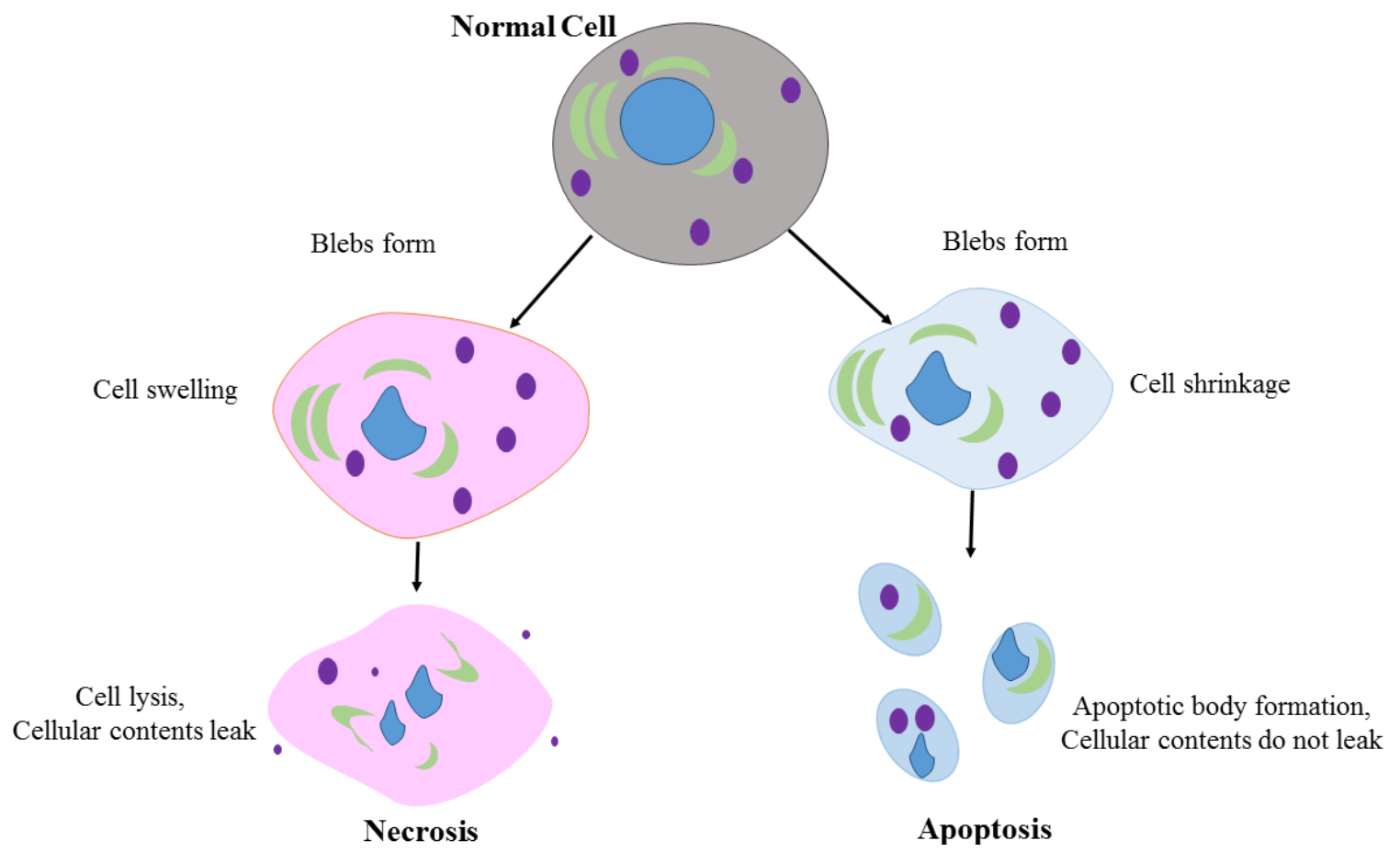

Figure 1.2 Schematic showing two common types of cell death: Necrosis and Apoptosis. Necrotic cells experience swelling due to a compromised cell membrane and eventually lyse, releasing cellular contents into the surrounding environment. Apoptotic cells shrink and begin to bleb, eventually forming apoptotic cell bodies which contain all of the cellular contents and are eventually phagocytosed by surrounding cells. 


\subsection{Characteristics of Nanoparticle Toxicity}

\section{Effect of Size on Nanoparticle Toxicity}

As noted, nanomaterials are any structure with at least one dimension between 1 and $100 \mathrm{~nm}$ [2].

While this feature improves the material's use in engineering, it can have dramatic effects on cytotoxicity and cellular uptake [64-66]. This is due to small changes in size leading to drastic changes in surface area and subsequent increases in the amount of cell-nanomaterial interaction

(Figure 1.3) [1].

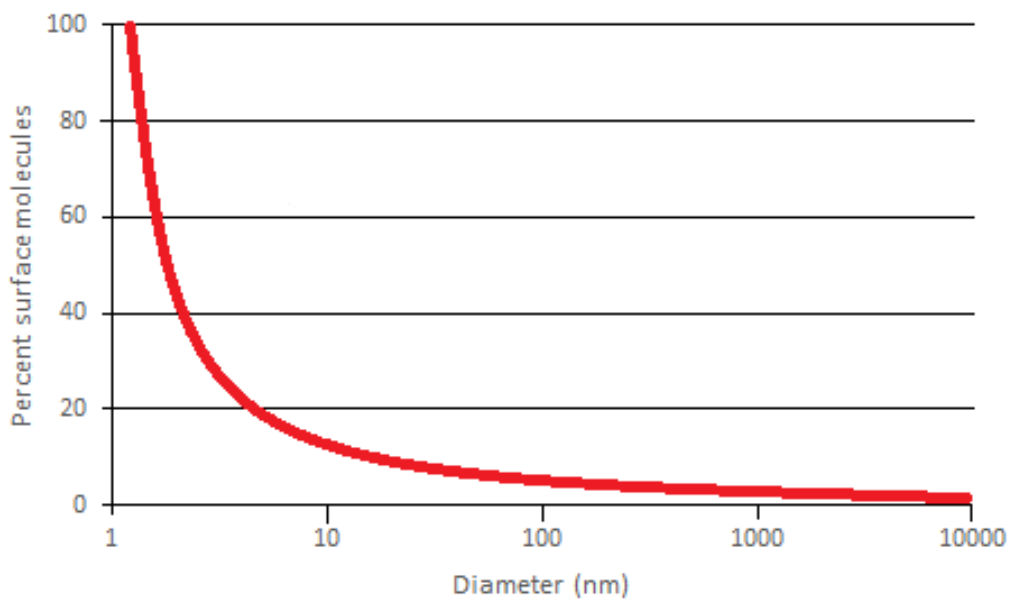

Figure 1.3 Inverse relationship between particle size and number of molecules displayed on the surface, showing that as nanoparticle size decreases the amount of molecules on the surface increases. For example, $30 \mathrm{~nm}$ particles have about $10 \%$ of the molecules expressed whereas a $3 \mathrm{~nm}$ particle has approximately $50 \%$ of the molecules expressed on the surface (Adapted from [1]).

A study completed by Park et al. (2011) implicated that smaller silver nanoparticles (20 nm) were more toxic than their larger counterparts $(80$ and $113 \mathrm{~nm})$ in L929 fibroblasts as they induced greater inflammation, and had more pronounced effects on genotoxicity and developmental toxicity endpoints [67]. Studies have also indicated that nanoparticle size effects ROS formation. Specifically, $15 \mathrm{~nm}$ silver nanoparticles induced significant ROS production in NR8383 macrophages whereas $50 \mathrm{~nm}$ silver nanoparticles did not [68]. Similar data were collected in osteoblastic mouse MC3T3-E1 cells, and phaeochromocytoma-derived PC12 cells, 
as silver nanoparticle size decreased, the ability of the particles to induce apoptosis increased [69]. Further, A549 human epithelial cells exposed to various sized $\mathrm{ZnO}$ and titanium dioxide nanoparticles, showed a similar trend that as size increased, toxicity decreased [70].

Nanomaterial size not only affects cytotoxicity but can alter cell death pathways. Gold nanoparticles have been shown to induce either necrosis or apoptosis depending on size, and the larger the particles become, the less measureable the toxicity they produce [71]. Unfortunately, as with many in vitro toxicity studies, little unison is seen with size effects in vivo [72]. Zhang et al. (2011) presented data in which various PEG-coated gold nanoparticles were administered to mice via intraperitoneal injection. Unlike in vitro studies that have concluded the size of gold nanoparticles alters toxicity, data from this study were inconclusive in regards to the effect of size on nanoparticle toxicity [73]. $\mathrm{TiO}_{2}$ nanoparticles showed similar conflicting data in vivo, as increased particle size was associated with increased toxicity as opposed to decreased toxicity in vitro [74]. Larger silica nanoparticles have also been shown to induce greater inflammation in mice following intravenous injection than smaller silica nanoparticles [75]. While these results are conflicting, it is possible that due to the large surface area of the nanoparticles, they readily agglomerate in vivo, thus mitigating the expected effects of size on toxicity [66]. Based on previous studies and a need to further the understanding of how nanomaterial size alters reactivity, a comparison of different sized nanomaterials was assessed and is discussed in this dissertation.

\section{Effect of Shape on Nanoparticle Toxicity}

Nanomaterials can be made in a variety of shapes depending on their function and purpose, such as rods, spheres, cylinders, and cubes. These changes in shape, just like size, can affect cellular 
uptake and subsequent toxicity [64, 65]. Chithrani et al. (2006) determined that nano-sized spherical particles are taken up by cells more readily than nanorods [76]. A similar finding was presented by Heng et al. (2011) in which $\mathrm{ZnO}$ spheres associated with cells more readily compared to $\mathrm{ZnO}$ sheets [77]. Further, numerous studies have shown differences in reactivity of carbon-based nanomaterials. While these nanomaterials are composed of graphene, a honeycomb lattice of carbon atoms, the shape of the materials drastically alters toxicity. Jia et al (2005) presented in vitro toxicity data that $\mathrm{C}_{60}$ fullerenes were much less toxic compared to both SWCNTs and MWCNTs and had less effects on phagocytosis impairment in alveolar macrophages [78]. Studies comparing MWCNTs to carbon nanofibers (CNFs) also found differences in toxicity profiles, implicating that MWCNTs were less toxic than CNFs in various lung tumor cell lines [13]. Zhang et al. (2010) presented similar findings in PC12 rat cells where both graphene layers and SWCNTs induced toxicity, but the SWCNTs caused greater elevations in lactate dehydrogenase (LDH) levels [79].

Additionally, metal oxide nanoparticles are known to induce varying degrees of toxicity dependent on shape. Results from Hsiao and Huang (2011) showed that ZnO nanorods induced greater toxicity in A549 human lung epithelial cells compared to nanospheres when surface area and size were held constant. Further, results indicated that titanium dioxide nanoparticle shape was also important in toxicity and that amorphous $\mathrm{TiO}_{2}$ induced greater toxicity than both anatase or anatase/rutile nanoparticles [70]. Based on previous studies and a need to further the understanding of how nanomaterial shape alters reactivity, a comparison between sphere and wire toxicity was assessed and is discussed in this dissertation. 


\section{Effect of Chemical Composition on Nanoparticle Toxicity}

In addition to shape and size, changes in nanomaterial composition can also affect toxicity. A study completed by Limbach et al. (2007) compared the toxicity of silica nanoparticles containing various metals. The nanomaterials were of similar size, shape, and agglomeration, which allowed for assessment of importance of chemical composition on toxicity. Results demonstrate that alterations in solubility and catalytic potential of the nanomaterials could alter the intracellular effects [80]. Similar studies have been conducted comparing metal oxide nanoparticles of similar size and have implicated that toxicity is dependent on chemical composition [61]. Further, Mihalchik et al. (2015) presented evidence that altering the chemical composition of MWCNT with nitrogen affects reactivity. The addition of nitrogen to the MWCNT carbon lattice caused increased ROS production, possibly due to changes in surface reactivity [14]. Based on previous studies, the effect of chemical composition of nanoparticles was assessed and is discussed in this Dissertation.

\section{Effect of Valence State on Nanoparticle Toxicity}

While chemical composition can modify the toxicological profile of nanomaterials, altering the valence state of nanomaterials can also affect their cellular response. Valence state refers to the number of electrons an atom can use for bonding. Some transition and post-transition metals can have more than one valence state; depending on the specific valence state can affect the metals reactivity. For example, cerium $(\mathrm{Ce})$, a rare earth metal, can exist in a dual valence state of $3+$ and $4+$ due to the inner and outer electron shells nearly equal energy. Due to the similar energy levels, little energy is required to transition between the two different electronic levels allowing Ce to commonly be found as both $\mathrm{Ce}^{3+}$ and $\mathrm{Ce}^{4+}$ [81]. Interestingly, the valence state of this 
material has profound effects on its reactivity in vitro. Researchers have implicated that altering the valence state from $\mathrm{Ce}^{3+}$ to $\mathrm{Ce}^{4+}$ decreases the antioxidant-like effects of cerium oxide $\left(\mathrm{CeO}_{2}\right)$ nanoparticles as previously determined [82, 83]. Further, Auffan et al. (2008) presented data that the valence state of iron nanoparticles affected their toxicity toward Escherichia coli. Specifically, changes in valence state affected the generation of ROS and disturbed the electron transport train due to interaction with oxygen molecules on the nanoparticle surface [84]. Adjusting the valence state of nanoparticles may provide a mechanism to decease their toxic potential, thus, the effect of valence state on $\mathrm{CeO}_{2}$ nanoparticle toxicity was assessed in this dissertation using a process known as doping (Figure 1.4). 

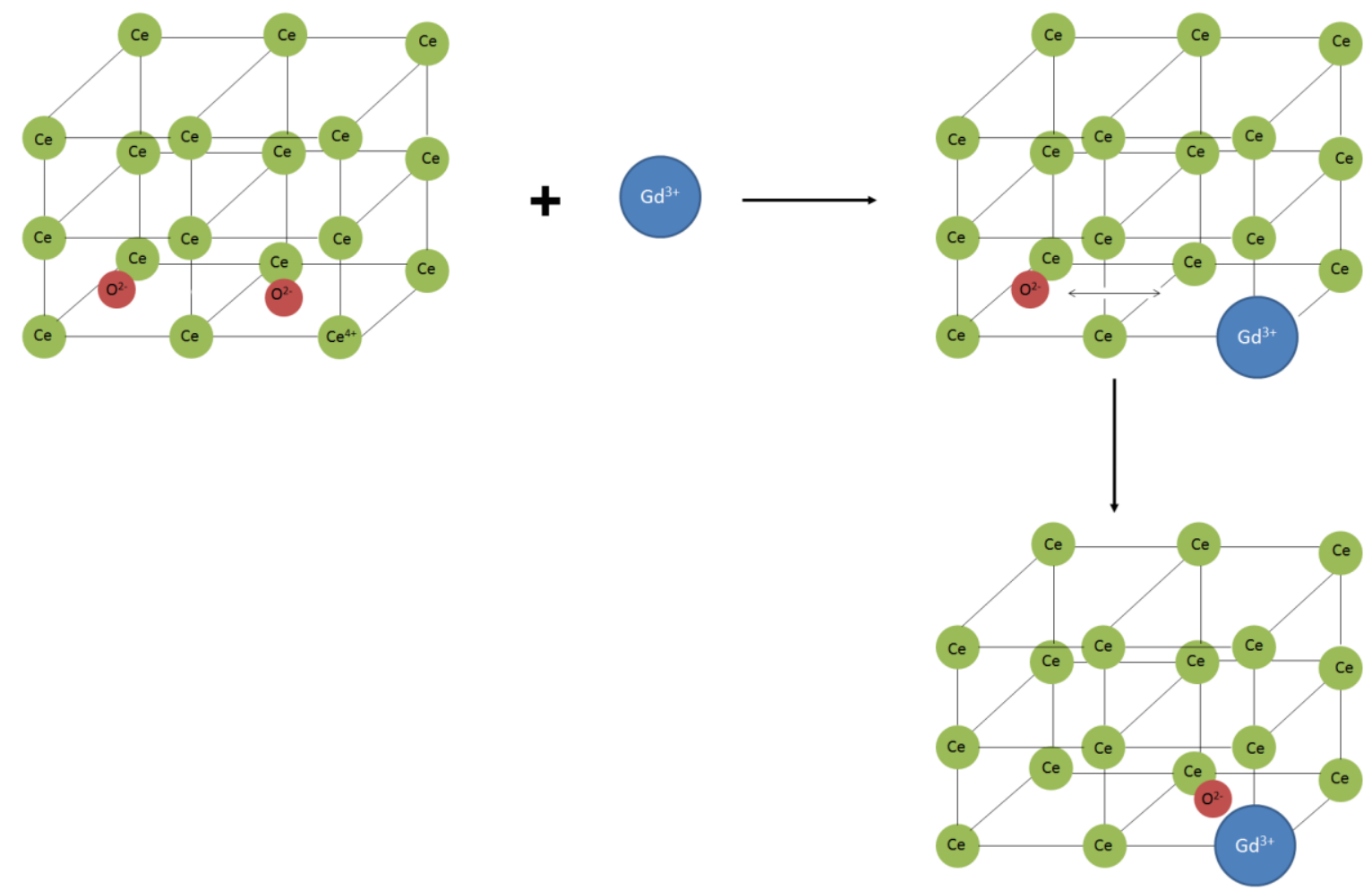

Figure 1.4. Diagram of the process of doping. In order to adjust the valence state of nanomaterials, often a technique known as doping is utilized. This is the process of adding impurities (i.e. gadolinium) into a pure substance to modulate the electrical properties. When impurities are added, the number of oxygen vacancies in the nanomaterial changes and the valence state is pushed toward that of the added impurity. By increasing the oxygen vacancies in the molecule, this improves electrical conductivity and oxygen storage ability [85], potentially increasing the reactivity of the nanomaterial with oxygen and ROS in vitro and in vivo. 


\subsection{Dissertation}

The purpose of this study was to investigate how, size, shape, chemical composition, and valence state alters various metal oxide nanoparticle toxicity.

\section{Chapter 2. Assess how size, shape, and chemical composition of tungstate nanoparticles} affects their toxicity in RAW 264.7 cells.

Tungstate nanoparticles, which can be used in fluorescent lighting and gas sensors [86], are a type of metal oxide nanoparticle that is predicted to increase in manufacturing. Therefore, to determine the toxicity of tungstate nanoparticles and develop safer tungstate containing materials, the shape, size, and chemical composition of the nanoparticles were altered. Using cytotoxicity assays and measurements of oxidative stress, the effects of size, shape, and chemical composition were assessed in RAW 264.7 cells.

Chapter 3. Assess how valence state of cerium oxide $\left(\mathrm{CeO}_{2}\right)$ nanoparticles alters reactivity in pulmonary rat cells.

The toxicity of $\mathrm{CeO}_{2}$ nanoparticles, which can be used in a variety of applications, including an additive to diesel fuel to decrease diesel admissions, is currently debated as some studies show mild to no toxicity and other studies implicate $\mathrm{CeO}_{2}$ induces severe toxicity $[83,87,88]$. Based on previous studies $[82,83]$, the hypothesis that $\mathrm{CeO}_{2}$ would have greater antioxidant-like effects in a pure, unmodified form was assessed using RLE-6TN rat alveolar epithelial cells and NR8383 rat alveolar macrophage cells. Various cytotoxicity and oxidative stress assays were utilized to determine how doping, a process which modifies the valence state of $\mathrm{CeO}_{2}$, would affect the reactivity of the nanoparticles. 
Chapter 4. Assess how valence state of cerium oxide $\left(\mathrm{CeO}_{2}\right)$ nanoparticles alters reactivity following intratracheal instillation in rats.

Previous research has implied that $\mathrm{CeO}_{2}$ causes adverse biological effects in rat models, inducing pulmonary PMN infiltration, cell death, and changes in collagen remodeling [39, 40, 89-91]. Based on these experiments, the hypothesis that pure $\mathrm{CeO}_{2}$ would induce greater toxic effects in vivo compared to doped $\mathrm{CeO}_{2}$ was tested. Cell differentials, cell death, oxidative damage, and pro-inflammatory markers were measured to assess toxicity and the effect of valence state on toxicity. 


\section{Chapter 2}

\section{The Effect of Tungstate Nanoparticles on Reactive Oxygen Species and Cytotoxicity in RAW 264.7 Mouse Monocyte Macrophage Cells}

Citation: Dunnick K, Badding M, Schwegler-Berry D, Patete J, Koenigsmann C, Wong S, and Leonard S. The effect of tungstate nanoparticles on reactive oxygen species and cytotoxicity in $R A W 264.7$ mouse monocyte macrophage cells. J Toxicol Env Heal A, 2015. 77 (20): 1251-1268. doi:10.1080/15287394.2014.897490

Adapted from Journal of Toxicology and Environmental Health Part A, 2014, 77 (20): 12511268 


\begin{abstract}
Due to their size, surface area, and chemical characteristics, nanoparticle use in consumer products has increased. However, the toxicity of nanoparticle exposure during the manufacturing process has not been fully assessed. Tungstate nanoparticles can be used in numerous products, including but not limited to scintillator detectors and fluorescent lighting. As with many nanoparticles, few toxicity studies have been completed. We tested the hypothesis that tungstate nanoparticle cellular exposure would result in reactive oxygen species (ROS) formation and cytotoxicity. We also hypothesized that differences in toxicity would occur based on tungstate nanoparticle size, shape (sphere vs. wire), and chemical characteristics. RAW 264.7 mouse monocyte macrophages were treated with tungstate nanoparticles and ROS formation was assessed via Electron Paramagnetic Resonance (EPR), and several assays (hydrogen peroxide, intracellular ROS, and Comet). Results showed ROS production induced by tungstate nanowire exposure and DNA damage induced by tungstate nanospheres. Cells were treated over 72 hours to assess cytotoxicity using an MTT assay. Results showed that differences in cell death between wires and spheres occurred at 24 hours but were minimal at both 48 and 72 hours. The present results imply that tungstate nanowires are capable of inducing ROS and cell death within 24 hours of exposure, whereas nanospheres do not, suggesting that differences in shape may affect reactivity. Although differences between spheres and wires were measured, after 24 hours, neither shape causes substantial cell death. Thus, tungstate nanoparticles may represent a safer alternative to other potentially more toxic metal oxides currently used in industry.
\end{abstract}

Key Words: Nanotoxicology, Metal Oxides, Reactive Oxygen Species, Cytotoxicity, Toxicity 


\section{Introduction}

Nanoparticles are defined as any structure with one dimension between 1 and $100 \mathrm{~nm}$ [2]. Their small size and large surface area-to-volume ratios offer physical and chemical properties not necessarily found in larger particles of similar chemical composition. For these reasons, increases in their manufacturing as well as in their commercial application and use have been rising dramatically. It is therefore important to understand potential risks associated with their use. Such activity may result in novel occupational exposures and potential health hazards that are dependent on the toxicity of the nanoparticle. For example, nanoscale zinc oxide $(\mathrm{ZnO})$ is currently being used in sunscreens to remove the unpleasant white-film commonly associated with sunscreen application [4]. Unfortunately, studies have shown that while nano-sized $\mathrm{ZnO}$ is useful in sunscreen coloring, the reduced size also may result in increased toxicity $[92,93]$. Due to the potential for toxicity, it is important to assess if the benefits of nanomaterials are indeed worth the health risks.

Nanoscale metal oxides represent one such material for which an increase in their usage has been noted. Currently they are incorporated as components of gas sensors, as they increase performance and reduce instabilities observed with their polycrystalline counterparts [5]. However, their unique properties have been speculated to be partly responsible for their biological toxicology. Metal oxides, for example, are widely known for their semi-conducting properties, allowing for passive electron transfer between the nanomaterial and aqueous environments. This passive electron transfer is thought to play a role in toxicity as it may occur between the metal oxides and the biological system, thereby promoting oxidative stress and inflammation [31]. Current research has shown that metal oxide nanoparticles are capable of inducing reactive oxygen species (ROS) formation which can result in oxidative stress, DNA 
damage, and down-stream health effects such as inflammatory responses [31, 93-95]. Studies have also shown metal oxides induce lactose dehydrogenase leakage and apoptosis at low doses and necrosis at high concentrations [61].

The growing use of nanomaterials in consumer products has resulted in increased industrial manufacturing. Tungstate nanoparticles, whose possible applications include fluorescent lighting, scintillator detectors, and gas sensors [7, 86], represent one such metal oxide that may be associated with increased manufacturing activity in the future. However, to date, limited studies have been performed on tungstate nanoparticle toxicity. Therefore, our study focused on assessing the toxicity of six different alkaline earth metal tungstate nanowires and six different nanospheres $\mathrm{AWO}_{4}(\mathrm{~A}=\mathrm{Ca}, \mathrm{Sr}, \mathrm{Ba})$ in an in vitro model. Further, research has shown that nanoparticles of similar or identical chemical composition can vary in toxicity based on size or shape [96]. Thus, we were intent on examining how differences in size, shape, and chemical composition would correlate with toxicity.

Based on previous studies that have shown metal oxide toxicity in RAW 264.7 cells [77, 97], we hypothesized that tungstate nanoparticle exposure would generate ROS and promote cell death. Further, we hypothesized that differences in size and shape of the nanoparticles would affect toxicity.

\section{Materials and Methods}

\section{Cell culture}

RAW 264.7 mouse monocyte macrophage cells (ATCC; Rockville, MD) were cultured following the ATCC recommended protocol. Cells were cultured in Dulbecco's Modified Eagle's Medium (DMEM) with $2 \mathrm{mM}$ L-glutamine, $10 \%$ fetal bovine serum, and $50 \mathrm{mg} / \mathrm{ml}$ penicillin/streptomycin (Thermo Scientific; Pittsburgh, PA). Cells were grown at $37^{\circ} \mathrm{C}$ in a $5 \%$ 
$\mathrm{CO}_{2}$ incubator and were passaged by scraping into medium. RAW 264.7 cells were chosen for these studies because they react with and engulf particles.

\section{Tungstate nanoparticle production and characterization}

Nanoparticle production and characterization were completed by Dr. Stanislaus Wong, Dr. Christopher Koenigsmann, and Dr. Johnathan Patete. Experimentally, a commercially available, track-etched polycarbonate membrane, possessing pores with an average diameter of $50 \mathrm{~nm}$, was mounted between two halves of a U-shaped reaction tube. Each half contained aqueous precursor solutions of defined chemical composition, which were allowed to diffuse towards each other, so as to control the resulting spatially confined growth of the corresponding anisotropic nanoparticles within the hollow membrane pore channels. For example, in a typical synthesis of tungstate nanowires, one of the two half cells was filled with $\mathrm{Na}_{2} \mathrm{WO}_{4}$ solution, and the other half cell contained a solution of the metal salt (either $\mathrm{CaCl}_{2}, \mathrm{SrCl}_{2}$, or $\mathrm{Ba}\left(\mathrm{NO}_{3}\right)_{2}$ ), to correspondingly generate $\mathrm{CaWO}_{4}, \mathrm{SrWO}_{4}$, and $\mathrm{BaWO}_{4}$ nanowires [86].

For the agglomerates of tungstate nanospheres, the synthesis was accomplished by solution phase precipitation of the appropriate alkali earth metal salt (either $\mathrm{CaCl}_{2}, \mathrm{SrCl}_{2}$, or $\left.\mathrm{Ba}\left(\mathrm{NO}_{3}\right)_{2}\right)$ and sodium tungstate $\mathrm{Na}_{2} \mathrm{WO}_{4}[98]$.

Purity was assessed using X-ray diffraction (XRD), and dimensions (diameter and length)

of the nanoparticles were determined using a field emission scanning electron microscopy (SEM) instrument [86]. To prepare XRD samples, the tungstate nanoparticles were rendered into slurries in ethanol, sonicated, and subsequently air dried as a film upon deposition onto glass slides. Multiple, replicate diffraction patterns were collected using a Scintag diffractometer (Scintag 
Inc.; Cupertino, CA), operating in the Bragg-Brentano configuration using $\mathrm{Cu} \mathrm{K} \alpha$ radiation $(\lambda=$ $1.54 \AA$ ) from $10^{\circ}$ to $80^{\circ}$ at a scanning rate of $2^{\circ}$ minutes.

The dimensions as well as morphology of as-prepared tungstate nanoparticles were characterized using a field emission scanning electron microscopy instrument (FE-SEM Leo 1550), operating at an accelerating voltage of $15 \mathrm{kV}$ and equipped with energy-dispersive $\mathrm{X}$-ray spectroscopy (EDS) capabilities. Samples for SEM were prepared by dispersing as-prepared tungstate nanoparticles in ethanol, sonicating for about 2 minutes, and then depositing a dilute solution of the sample onto either a conductive tape or a silicon wafer, attached to a SEM brass stub. All of these samples were then conductively coated with gold by sputtering for $15 \mathrm{~s}$ so as to minimize charging effects under SEM imaging conditions.

Agglomeration and size distribution of tungstate nanoparticles in a suspended state were assessed using dynamic light scattering (DLS). DLS analyzes the velocity distribution of suspended particles by detecting fluctuations of light scattering intensity caused by Brownian motion of the particles. This technique yields a hydrodynamic radius or diameter of the particles. Tungstate nanoparticles were prepared in dispersion media at concentrations of $100 \mu \mathrm{g} / \mathrm{ml}$ and a Nanotrac 252 (Microtrac; Montgomeryville, PA) was used to assess diameter and agglomeration.

\section{Determination of cellular interaction}

RAW 264.7 cells were grown on cleaned, autoclaved cover-glass until 60-80\% confluent (Chemglass Life Sciences; Vineland, New Jersey). Tungstate nanoparticles were prepared in dispersion media at a stock concentration of $1 \mathrm{mg} / \mathrm{ml}$, as previously described [99]. Cells were then treated with tungstate nanoparticles at a final concentration of $10 \mu \mathrm{g} / \mathrm{ml}$ for 5 minutes, 1 hour, 3 hours, and 7 hours in serum-free media. Following incubation, the media was removed 
and the cells were washed 3 times with warm phosphate buffered saline (PBS), fixed with 10\% formalin for 10 minutes, washed 3 times with PBS, mounted with Fluoromount G, and sealed with clear nail polish. Slides used for this experiment were purchased as clean cut slides to prevent excess silica particle residue, which results in excessive background during imaging (Schott Nexterion; Arlington, VA). Following mounting, images were acquired at $60 \mathrm{x}$ magnification using a Cytoviva enhanced darkfield microscopy system (Aetos Technologies; Inc., Auburn, AL) integrated into an Olympus BX41 upright optical microscope equipped with an Olympus DP73 digital camera (Olympus; Center Valley, PA). An enhanced darkfield microscope allows visualization of nano-sized particles that would otherwise not be visible under typical light microscopy [100]. Cellular interaction was determined as the number of cells associated with particles relative to the number of cells not associated with particles. The relative association is expressed as a percentage.

For SEM, RAW 264.7 cells were grown on cleaned, autoclaved cover-glass until 60-80\% confluent (Chemglass Life Sciences; Vineland, New Jersey). Tungstate nanoparticles were prepared in dispersion media at a stock concentration of $1 \mathrm{mg} / \mathrm{ml}$ and cells were treated at a final concentration of $10 \mu \mathrm{g} / \mathrm{ml}$ tungstate nanoparticles in serum-free media for 3 hours. Following exposure, cells were washed 3 times with warm PBS to remove unbound particles. The samples were fixed in formalin and post-fixed in osmium tetroxide. They were dehydrated in an ethanol series, dried using hexamethyldisalizane, mounted onto aluminum stubs, and sputter-coated with gold/palladium so as to render them conductive. The samples were then imaged on a Hitachi S4800 field emission scanning electron microscope (Hitachi High Technologies America; Inc., Clarksburg, MD). Elemental analysis was performed on samples to ensure particles associated with cells were tungstate nanoparticles using an energy dispersive system attachment. The 
electron beam was pointed at the area of the sample to be analyzed, resulting in an X-ray spectra of characteristic of the elemental composition of the sample. Only elements present within the area will be emitted and recorded on the spectral graph.

\section{Determination of cellular engulfment}

Transmission electron microscopy (TEM) was completed by Mrs. Diane Schwegler-Berry. For TEM, RAW 264.7 cells were grown in 6 well dishes until confluent. Cells were treated with tungstate nanoparticles at $50 \mu \mathrm{g} / \mathrm{ml}$ for 3 hours in serum-free media. Following exposure, media was removed and cells were scraped into $1 \mathrm{ml}$ PBS, and centrifuged at 500xG for 5 minutes. The samples were then fixed in Karnovsky's (2.5\% gluteraldehyde, $2.5 \%$ paraformaldehyde in $0.1 \mathrm{M}$ Sodium Cacodylic buffer) fixative, post-fixed in osmium tetroxide, mordanted in $1 \%$ tannic acid, and stained en bloc in $0.5 \%$ uranyl acetate. The pellets were embedded in epon, sectioned, and stained with Reynold's lead citrate and uranyl acetate. The sections were imaged on a JEOL 1220 transmission electron microscope (Jeol; Peabody, MA).

\section{Electron Paramagnetic Resonance (EPR)}

A spin trap technique was used to form long-lived free radicals that could be detected by EPR through addition of DMPO (5,5'-dimethylpyrroline N-oxide). EPR measurements were collected using a flat cell assembly and Brüker EMX spectrometer (Billerica, MA). Tungstate nanoparticles were incubated at a final concentration of $1 \mathrm{mg} / \mathrm{ml}$ with $1 \mathrm{mM} \mathrm{H}_{2} \mathrm{O}_{2}$ and $100 \mathrm{mM}$ DMPO (Sigma Chemical Co.; St. Louis, MO) for 3 minutes as previously described [101]. Samples were run in triplicates. Signal intensity (peak height) is used to measure the relative amount of hydroxyl radicals produced and is measured in $\mathrm{mm}$. 
For cellular EPR, tungstate nanoparticles at a final concentration of $1 \mathrm{mg} / \mathrm{ml}$ were incubated with RAW 264.7 cells at $2 \times 10^{6}$ cells $/ \mathrm{ml}$ and $200 \mathrm{mM} \mathrm{DMPO}$ for 5 minutes at $37^{\circ} \mathrm{C}$ [101]. Peak heights represent relative amounts of hydroxyl radicals produced, and are measured in $\mathrm{mm}$.

\section{Hydrogen peroxide production}

RAW 264.7 cells were seeded at $1 \times 10^{5}$ cells per well in 96 well plates and allowed to grow for 24 hours until approximately $60 \%$ confluent. Assays were completed using recommended company protocol (OXIS International; Foster City, CA). Briefly, cells were treated with tungstate nanoparticles at a final concentration of $50 \mu \mathrm{g} / \mathrm{ml}$ for 5 minutes or 1 hour. Following treatment, $10 \mu \mathrm{l}$ media was removed from the centrifuged 96 well plate and combined with $90 \mu 1$ of working reagent. Following a 30 minute incubation, absorbance was measured at $560 \mathrm{~nm}$. Samples were run in triplicates and experiments were completed twice. Data reported as percentage absorbance compared to control.

\section{Intracellular ROS production}

RAW 264.7 cells were seeded at $5 \times 10^{4}$ cells per well in 96 well plates and allowed to grow for 24 hours until approximately $50 \%$ confluent. The assay was completed using the recommended company protocol (Cell Biolabs, Inc.; San Diego, CA). Briefly, 2', 7'-Dichlorodihydrofluorescin diacetate (DCFH-DA), diluted in serum-free medium, was added to cells following removal of media and 3 washes with PBS and incubated for 45 minutes at $37^{\circ} \mathrm{C}$. Following incubation, the media was removed, cells were washed with PBS, and serum-free media was added to wells with tungstate nanoparticles at a final concentration of $50 \mu \mathrm{g} / \mathrm{ml}$. Control wells were run containing 
only media and tungstate nanoparticles to measure potential auto-fluorescence, but none was detected above the fluorescence of the blank. Measurements were recorded every hour at $480 \mathrm{~nm}$ excitation/ $530 \mathrm{~nm}$ emission. Data reported in DCF fluorescence units.

\section{Comet assay}

RAW 264.7 cells were seeded at $1 \times 10^{5}$ in 24 well plates and grown until $50 \%$ confluent. Cells were treated with tungstate nanoparticles at a final concentration of $50 \mu \mathrm{g} / \mathrm{ml}$ for 1 or 3 hours. A comet assay was completed using an alkaline system as outlined by the company (Trevigen; Gaithersburg, MD). Briefly, cells were washed with PBS, combined with pre-heated agarose, and placed on comet slides. Samples were lysed, treated with an unwinding solution, and electrophoresed at $21 \mathrm{~V}, 50 \mathrm{mAmps}$ for 50 minutes. Following fixation with $70 \%$ ethanol and an overnight drying stage, slides were treated with SYBR green and imaged using an Olympus AX70 microscope equipped with an Olympus DP73 digital camera (Olympus; Center Valley, PA). Experiments were completed in duplicate and a minimum of 50 comets were measured for percentage DNA in comet tails. These measurements were calculated using ImageJ software to compare the corrected nuclear region fluorescence to the corrected total cell fluorescence as previously described $[102,103]$. These values were converted to percentage of DNA in the “tail".

\section{MTT assay}

Cells were seeded at $2.5 \times 10^{4}$ cells per well in 96 well plates. Following 24 hours of growth, cells were treated with tungstate nanoparticles at a final concentration of $50 \mu \mathrm{g} / \mathrm{ml}$ for 24 , 48 , or 72 hours. Four hours prior to each time point, media was removed and replaced with $100 \mu$ phenol 
red-free medium containing $0.5 \mathrm{mg} / \mathrm{ml} \quad$ MTT (3-(4,5-dimethylthiazol-2-yl)-2,5diphenyltetrazolium bromide) (Invitrogen; Carlsbad, CA). At the various time points, $50 \mu 1$ of media was removed and replaced with $100 \mu \mathrm{l}$ dimethyl sulfoxide (DMSO) (Fisher Scientific; Pittsburgh, PA) to solubilize the formazan crystals, mixed, and incubated for 10 minutes at $37^{\circ} \mathrm{C}$. Absorbance was measured at $570 \mathrm{~nm}$. Data reported as percent absorbance compared to the control.

\section{Caspase 3/7 assay}

RAW 264.7 cells were seeded at $1 \times 10^{5}$ cells per well in 96 well plates. Following 24 hours growth, cells were treated with tungstate nanoparticles at a final concentration of $50 \mu \mathrm{g} / \mathrm{ml}$ for 24 hours. The caspase 3/7 assay was completed according to company protocol (Invitrogen; Carlsbad, CA). Thirty minutes prior to the 24 hour time point, $5 \mu \mathrm{M}$ caspase $3 / 7$ reagent was added to the wells and incubated at $37^{\circ} \mathrm{C}$. Fluorescence was measured at 502 excitation/ 530 emission. Data reported as percent fluorescence compared to control.

\section{Statistical Analysis}

All data are represented as the mean \pm standard deviation for each condition. To compare responses between groups, a one-way analysis of variance (ANOVA) and Tukey post-test were performed using GraphPad Prism 6 software (GraphPad Software; Inc., La Jolla, CA). Statistical significance is shown when $\mathrm{p}<0.05$ or $\mathrm{p}<0.001$. 


\section{Results}

\section{Tungstate Characteristics}

Analysis by XRD indicated that all 12 tungstate nanoparticle samples were pure and contained no detectable crystalline impurities, which is in agreement with previous reports [86]. SEM images provided length and size characteristics of the six different spheres and six different wires (Table 2.1, Figure 2.1). All six agglomerates of nanospheres were of different sizes, and the individual nanoparticles that comprise the nanospherical agglomerates were approximately 20 $\mathrm{nm}$ in diameter. Most notably, agglomerates of $\mathrm{BaWO}_{4}$ spheres measured greater than $1 \mu \mathrm{m}$ in diameter and $4 \mu \mathrm{m}$ in length while the remaining agglomerated spheres were less than $400 \mathrm{~nm}$ in diameter and less than $122 \mathrm{~nm}$ in length. All six nanowires were of similar diameter, approximately $100 \mathrm{~nm}$, and of similar length, approximately $2 \mu \mathrm{m}$. Although the measured diameters were found to be significantly larger than the nominal pore size of the template, expansion of the pore walls during nanowire growth is typical under U-tube conditions, particularly for polycarbonate membranes. The diameter of the nanowire is in agreement with previous reports [104-106].

DLS was used to assess particle size under the physiological treatment conditions used in cellular exposures. Results showed the nanospheres existed in 2 populations, large and small with the exception of $\mathrm{BaWO}_{4}$ and $\mathrm{Ca}_{7} \mathrm{Sr}_{3} \mathrm{WO}_{4}$ nanospheres, which dispersed into a single size population (Figure 2.1A). In suspension, $\mathrm{BaWO}_{4}$ population size was smaller than that measured under dry conditions, possibly a result of the non-spherical shape. DLS cannot accurately define the diameter of non-spherical nanoparticles, but provides a representative measurement of the wires relative sizes and provides an indication of dispersion state [107]. Results for nanowires showed that with the exception of $\mathrm{SrWO}_{4}$ and $\mathrm{BaWO}_{4}$, all other nanowires formed large 
agglomerations with diameters between $200 \mathrm{~nm}$ and $6000 \mathrm{~nm}$. On the other hand, $\mathrm{SrWO}_{4}$ and $\mathrm{BaWO}_{4}$ nanowires had diameters around $1 \mathrm{~nm}$, which implies they did not form large agglomerates (Figure 2.1).

\section{Cellular Interactions with Particles Show Accumulation Over Time}

To investigate potential tungstate nanoparticle cellular interactions, we used enhanced darkfield microscopy to visualize both spheres and wires with RAW 264.7 cells over a time course of 7 hours. Results showed that both spheres and wires accumulated on the cell surface over the time course (Figure 2.2). However, the wires associated with cells more rapidly as compared with the spheres as noted at 1 and 3 hour time points. Figure 2.2A shows that after 1 hour, $\mathrm{SrWO}_{4}$, $\mathrm{Ca}_{3} \mathrm{Sr}_{7} \mathrm{WO}_{4}, \mathrm{Ca}_{5} \mathrm{Sr}_{5} \mathrm{WO}_{4}$, and $\mathrm{Ca}_{7} \mathrm{Sr}_{3} \mathrm{WO}_{4}$ tungstate spheres were significantly associated with cells, relative to PBS vehicle-treated cells. Conversely, after 1 hour, all tungstate wires, with the exception of $\mathrm{BaWO}_{4}$, were significantly associated with cells relative to PBS vehicle control cells (Figure 2.2B).

\section{Cellular Engulfment of Tungstate Nanoparticles}

To study whether tungstate-cellular interactions were associated with engulfment of nanoparticles after 3 hours, TEM was implemented. Tungstate nanospheres were visualized within the cells, while nanowires were not. Images showed that the nanospheres were engulfed and possibly confined to cytoplasmic vacuoles rather than existing free in the cytoplasm (Figure 2.3). TEM images showed no engulfment of nanowires after 3 hours. Based on the lack of TEM confirmation of nanowire engulfment, SEM analysis was performed to determine if the wires

attach to and penetrate the cell surface. Only $\mathrm{Ca}_{3} \mathrm{Sr}_{7} \mathrm{WO}_{4}$, and $\mathrm{Ca}_{7} \mathrm{Sr}_{3} \mathrm{WO}_{4}$ wires could be 
verified as being associated with cells (Figure 2.4); however, examination of cells showed increased cellular debris following exposure to all tungstate nanowires suggesting the cells are likely reacting to the presence of wires. SEM showed that nanowires were either lying on top of the cells or were protruding into the cells. Elemental analysis was completed to confirm the particles associated with the cells were actually tungstate nanowires (Figure 2.4B).

\section{Hydroxyl Radical Production from Tungstate Nanoparticles}

Based on the visualization of particle-cellular interactions and previous studies highlighting metal oxide-induced ROS production [108], hydroxyl radical production was measured. To determine whether tungstate nanoparticles are capable of converting $\mathrm{H}_{2} \mathrm{O}_{2}$ to hydroxyl radicals, acellular Fenton reactions were carried out using EPR and a spin trap method. Both spheres and wires were capable of producing hydroxyl radicals in an acellular system, with $\mathrm{SrWO}_{4}$ wires producing significantly more hydroxyl radicals as compared with $\mathrm{SrWO}_{4}$ spheres (Figure 2.5A). Because hydroxyl radicals are highly reactive oxygen species, their production provides a basis for cellular damage, and thus cellular EPR was also completed. The data showed that the majority of the spheres yielded no hydroxyl radical production, whereas wires still produced hydroxyl radicals (Figure 2.5B). However, the hydroxyl radical peak height by wires decreased under cellular conditions relative to acellular production (e.g., $\mathrm{Ca}_{3} \mathrm{Sr}_{7} \mathrm{WO}_{4}: 57.8 \pm 5.0 \mathrm{~mm}$ for $\mathrm{H}_{2} \mathrm{O}_{2}$ versus $33.2 \pm 6.7 \mathrm{~mm}$ for cellular, mean $\pm \mathrm{SD}$ ).

\section{Tungstate Nanoparticles do not Cause Hydrogen Peroxide Release}

Based on the EPR results, we chose to examine $\mathrm{H}_{2} \mathrm{O}_{2}$ production as another means of measuring ROS. To assess the release of $\mathrm{H}_{2} \mathrm{O}_{2}$ from cells, media was measured after 5 minute and 1 hour 
treatments with tungstate nanoparticles. Figure 2.6 shows no $\mathrm{H}_{2} \mathrm{O}_{2}$ production at either time point following cellular treatment with both wires and spheres as compared with PBS controls.

\section{Tungstate Nanowires Induce Intracellular ROS}

To further explore ROS induction following tungstate nanoparticle exposure, intracellular ROS production was assessed using a cell permeable dye, DCFH-DA, which fluoresces in the presence of ROS. Cells were treated with tungstate nanoparticles (wires and spheres) and measurements were taken every hour for 7 hours. Out of all 6 spheres, only $\mathrm{Ca}_{7} \mathrm{Sr}_{3} \mathrm{WO}_{4}$ treatment with cells resulted in significantly increased intracellular ROS production as compared with PBS controls (PBS, 1610.5 $\pm 438.08, \mathrm{Ca}_{7} \mathrm{Sr}_{3} \mathrm{WO}_{4}, 3148.1 \pm 1332.2$ at 4 hours, Figure 2.7A). Wire-treated cells showed significant ROS production relative to PBS controls starting at 5 hours exposure with all 6 tungstate wires (Figure 2.7B).

\section{Tungstate Nanosphere Exposures Cause DNA Damage}

To measure potential DNA damage following nanoparticle exposure, an alkaline comet assay was used [109]. A comet assay uses an unwinding and electrophoresis process to produce comet 'tails', which are formed following nuclear DNA damage. Cells treated with spheres for 3 hours had slight but significant DNA damage as compared with respective PBS controls, whereas cells treated with wires for 3 hours had no significant DNA damage (Figure 2.8). Additionally, a time course study showed DNA damage to be highest at 3 hours of exposure, with no significant changes at 1 hour exposure. Basal levels of DNA damage in PBS control cells were higher in the wire exposed experiment compared to the sphere exposed treatment. 


\section{Tungstate Nanoparticle Treatments Result in Minimal Decreases in Cell Viability}

To measure overall cell viability following nanoparticle exposure, an MTT assay was used[96].

At 24 hours, cellular treatment with spheres showed a trend towards increased cell viability or potentially enhanced proliferation as compared with PBS-treated controls. In contrast, cellular exposure to wires showed a trend towards decreased viability as compared with PBS controls at the same time point (Figure 2.9A). At 48 hours, these changes in viability were no longer present with either wires or sphere-treated cells, with the exception of $\mathrm{Ca}_{3} \mathrm{Sr}_{7} \mathrm{WO}_{4}$ wires, which was significantly lower as compared with both PBS vehicle control cells and $\mathrm{Ca}_{3} \mathrm{Sr}_{7} \mathrm{WO}_{4}$ spheretreated cells (wire: $74.9 \pm 8.8 \%$, PBS control: $100.0 \pm 6.1 \%$, sphere: $111.6 \pm 23.0 \%$, Figure 2.9B). At 72 hours, cellular exposure to $\mathrm{Ca}_{3} \mathrm{Sr}_{7} \mathrm{WO}_{4}, \mathrm{Ca}_{5} \mathrm{Sr}_{5} \mathrm{WO}_{4}$, and $\mathrm{Ca}_{3} \mathrm{Sr}_{7} \mathrm{WO}_{4}$ wires caused slight but significant reductions in viability as compared with PBS vehicle control cells (Figure 2.9C). No significant differences were measured at 72 hours with sphere exposures. We wanted to determine if these slight decreases in viability at 24 hours treatment were due to apoptosis. Therefore we measured caspase 3/7 activation. Measurements showed no caspase 3/7 activation by cells treated with spheres and wires as compared with PBS controls (Figure 2.9D).

\section{Discussion}

Metal oxide nanoparticles are increasing in use due to their unique chemical properties. In response to this growth in manufacturing, there is concern for potential toxicity following exposure during processing. Decreased size and increased surface area have been implicated in nanoparticle toxicity, especially when compared with their larger counterparts as previously shown [94]. Therefore, this study focused on understanding how differences in shape and size 
could affect the toxicity of 6 different tungstate nanowires and 6 different tungstate nanospheres in an in vitro model.

The principal finding of the present study was that tungstate nanowires reacted with RAW 264.7 cells and resulted in ROS production and cell death after 24 hours at $50 \mu \mathrm{g} / \mathrm{ml}$, while nanospheres did not induce significant ROS or cell death at the same concentration (Figures 2.4, 2.6, and 2.8). These differences may be due to the increased surface area, inherent anisotropic character and the size of the wires relative to spheres [1, 110,111]. Size was also an important factor in the ability of nanoparticles to associate and interact with cells; agglomerates of $\mathrm{BaWO}_{4}$ spheres were the largest tungstate nanoparticles tested and had the least amount of cellular association over the 7 hour time course. $\mathrm{BaWO}_{4}$ spheres were not visualized by TEM within the cells either. Moreover, these spheres were also less reactive, implying that increased size and a lack of cellular association and engulfment may affect toxicity. Furthermore, Zhao et al. showed that increased cellular association with nanoparticles results in differences in ROS production [112]. Therefore, the increased cellular associations noted with wires compared to spheres, as visualized with enhanced darkfield microscopy (Figure 2.2), may be responsible for the differences in ROS production.

While enhanced darkfield imaging showed nanowire-cellular association, both SEM and TEM analyses could not confirm that all 6 wires were engulfed by or associated with cells. The intrinsic morphology of the cells rendered differentiation between wires and pseudopodia difficult. Additionally, the small size of the wires may have hindered spectral analysis. While SEM could only confirm that $\mathrm{Ca}_{3} \mathrm{Sr}_{7} \mathrm{WO}_{4}$ and $\mathrm{Ca}_{7} \mathrm{Sr}_{3} \mathrm{WO}_{4}$ wires were associated with cells and appear to be penetrating the cells, the presence of cellular debris in images of wire-treated cells implies that this treatment may cause some form of cellular damage (Figure 2.4). Large fiber or 
wire-like particles, such as asbestos, have previously been shown to lack full engulfment by cells. Rather, association typically results in frustrated phagocytosis, which can cause ROS production [113]. Given our finding that tungstate nanowires were more reactive than spheres and produced continued ROS over a 7 hour time course with cells, we speculate that the fiberlike shape contributes to cellular stress. The lengths of tungstate nanowires are shorter than typical fibers that result in frustrated phagocytosis [114] and therefore probably do not result in true frustrated phagocytosis. However, their protrusion into the cell and continued association rather than engulfment may cause similar cellular responses, such as ROS, as measured through EPR and an intracellular ROS assay. Based on the increased ROS generation by wires, we expected to see a significant increase in oxidative DNA damage by wires relative to spheres [96]. Unexpectedly, we observed minimal DNA damage following wire incubation with cells over a 3 hour time course. Further, we noted minimal but significant DNA damage following sphere incubation with cells at 3 hours. This indicates that tungstate nanoparticles do not induce longterm cellular oxidative injury, regardless of ROS production by cells exposed to wires (Figure 2.8).

Furthermore, a discrepancy in toxicity between wires and spheres was noted through an MTT assay. The spheres cause a trend towards increased viability and potential cell proliferation with 24 hours of treatment. Conversely, the cells treated with wires had decreased viability at 24 hours, which was significant compared to both vehicle control cells and spheres. This decrease in viability could be in response to the damaging ROS measured via both EPR and the intracellular ROS assay (Figures 2.4, 2.6). Studies have shown that ROS-induced damage can result in cytotoxicity through mitochondrial damage and the promotion of apoptosis [61]. Because we anticipated cell death was due to apoptosis, we measured caspase 3/7 levels following cellular 
interactions with wires or spheres. Based on ROS activity following cellular interactions with wires and decreased viability, we anticipated increased caspase 3/7 activation in wire-treated cells as compared with sphere-treated cells. However, caspase 3/7 activation was not detected in either sphere or wire treatments, implying that cell death was not in response to caspase signaling, but rather is occurring via a caspase-independent cell death pathway (Figure 2.9D). Surprisingly, at 48 hours of treatment, we observed neither cell death nor increased proliferation following wire and sphere treatment with cells, implying that the damage induced by tungstate nanoparticle exposure is short-term and manageable by the cells.

While our results showed minimal toxicity, there are numerous other endpoints of nanoparticle toxicity that are commonly measured, including cytokine production and inflammation which can propagate disease. For example, Heng et al. showed pro-inflammatory cytokine production following $\mathrm{ZnO}$ nanoparticle exposure, even with minimal cytotoxic effects [77]. Additionally, this group showed that the shape of $\mathrm{ZnO}$ nanoparticles played a role in $\mathrm{ROS}$ production and cytokine release. We thus predicted that perhaps the ROS generation in response to nanowire treatments would promote cytokine production by cells. However, there was no measurable production of IL-6, IL-8 or TNF- $\alpha$ (data not shown) following treatment, suggesting that the mild ROS production caused by tungstate nanowires does not result in an inflammatory response by macrophage cells in our toxicity model.

Previous studies have shown that treatment of cells with nanoparticles can result in ROS production, cellular toxicity, inflammatory responses, and apoptosis [93, 115]. While our study showed that tungstate nanowires are capable of producing mild ROS and inducing cytotoxicity within 24 hours, our studies in general provide evidence that tungstate nanoparticles may be 
unreactive in cell culture, unlike other previously-studied metal oxide nanoparticles [22, 93, 116, $117]$.

Due to dosages used in previous nanoparticle research [97], we expected tungstate nanoparticles to produce ROS when exposed to RAW 264.7 cells at a concentration of $50 \mu \mathrm{g} / \mathrm{ml}$. However, macrophage cells are capable of engulfing particles to limit the level of toxicity. Therefore RAW 264.7 cells appear to be capable of dealing with the toxic effects of tungstate nanoparticles at this concentration, such as ROS production and initial decreased viability following wire exposure. It is possible that at higher concentrations more negative toxic effects would be observed [118]. However, higher doses will no longer fall within the commonly accepted concentration range of $0.1-100 \mu \mathrm{g} / \mathrm{ml}$ used in nanotoxicology studies $[61,115]$. Additionally, longer exposures have been shown to result in greater toxicity, and thus increased toxicity may be seen in long-term cell culture [119]. However, our study was interested in acute exposures to examine the initial cellular responses to tungstate nanoparticles.

Prior to this study, little was known about the toxicity of tungstate nanoparticles. Our initial findings imply that at concentrations of $50 \mu \mathrm{g} / \mathrm{ml}$, tungstate nanoparticles result in mild, but repairable damage. Furthermore, these results show that shape and size play a major role in determining reactivity, as wires produced more ROS and decreased viability at 24 hours as compared with spheres, while chemical composition had minimal effects on differences in toxicity. Also, these results demonstrated that chemical characteristics and variability had little discernible effect on observed differences in cellular toxicity. The goal of this study was to assess whether tungstate nanoparticles would present a hazard that could be translated into occupational exposures. This research implies that in an in vitro model, the toxicity of tungstate 
nanoparticles is minimal. Thus, tungstate nanoparticles may serve as a safe alternative to other potentially more toxic metal oxides typically used in scintillator and gas sensors. 
Table 2.1.

Tungstate Nanoparticle Descriptive Characteristics

\begin{tabular}{|c|c|c|c|c|}
\hline \multirow[b]{2}{*}{ SAMPLE } & \multirow[b]{2}{*}{ MORPHOLOGY } & \multirow[b]{2}{*}{$\begin{array}{c}\text { DIAMETER } \\
(\mathbf{n m})\end{array}$} & \multicolumn{2}{|c|}{ LENGTH (nm) } \\
\hline & & & LARGE & SMALL \\
\hline $\mathrm{CaWO}_{4}$ & Spheres & $141+/-59$ & $\begin{array}{c}328+/- \\
144\end{array}$ & $85+/-36$ \\
\hline $\mathrm{SrWO}_{4}$ & Spheres & $356+/-111$ & $\begin{array}{c}804+/- \\
365\end{array}$ & $32+/-18$ \\
\hline $\mathrm{BaWO}_{4}$ & Spheres & $1495+/-609$ & $\begin{array}{c}4534+/- \\
2223\end{array}$ & N/A \\
\hline $\mathrm{Ca}_{3} \mathrm{Sr}_{7} \mathrm{WO}_{4}{ }^{*}$ & Spheres & $209+/-81$ & $278+/-99$ & $54+/-17$ \\
\hline $\mathrm{Ca}_{5} \mathrm{Sr}_{5} \mathrm{WO}_{4}{ }^{*}$ & Spheres & $229+/-90$ & $\begin{array}{c}320+/- \\
151\end{array}$ & $122+/-59$ \\
\hline $\mathrm{Ca}_{7} \mathrm{Sr}_{3} \mathrm{WO}_{4}{ }^{*}$ & Spheres & $394+/-195$ & $\begin{array}{c}394+/- \\
195\end{array}$ & $43+/-18$ \\
\hline $\mathrm{CaWO}_{4}$ & Nanowires & $109+/-31$ & $\begin{array}{c}2430+/- \\
672\end{array}$ & N/A \\
\hline $\mathrm{SrWO}_{4}$ & Nanowires & $119+/-26$ & $\begin{array}{c}2116+/- \\
1178\end{array}$ & N/A \\
\hline $\mathrm{BaWO}_{4}$ & Nanowires & $106+/-31$ & $\begin{array}{c}2006+/- \\
758\end{array}$ & N/A \\
\hline $\mathrm{Ca}_{3} \mathrm{Sr}_{7} \mathrm{WO}_{4}{ }^{*}$ & Nanowires & $99+/-20$ & $\begin{array}{c}2586+/- \\
1700\end{array}$ & N/A \\
\hline $\mathrm{Ca}_{5} \mathrm{Sr}_{5} \mathrm{WO}_{4}{ }^{*}$ & Nanowires & $96+/-16$ & $\begin{array}{c}1812+/- \\
1248\end{array}$ & $\mathrm{~N} / \mathrm{A}$ \\
\hline $\mathrm{Ca}_{7} \mathrm{Sr}_{3} \mathrm{WO}_{4}{ }^{*}$ & Nanowires & $97+/-17$ & $\begin{array}{c}2056+/- \\
1461\end{array}$ & N/A \\
\hline
\end{tabular}

*Note. 3, 5, and $7=0.03,0.05$, and 0.07, respectively. Data presented as mean \pm standard deviation. 


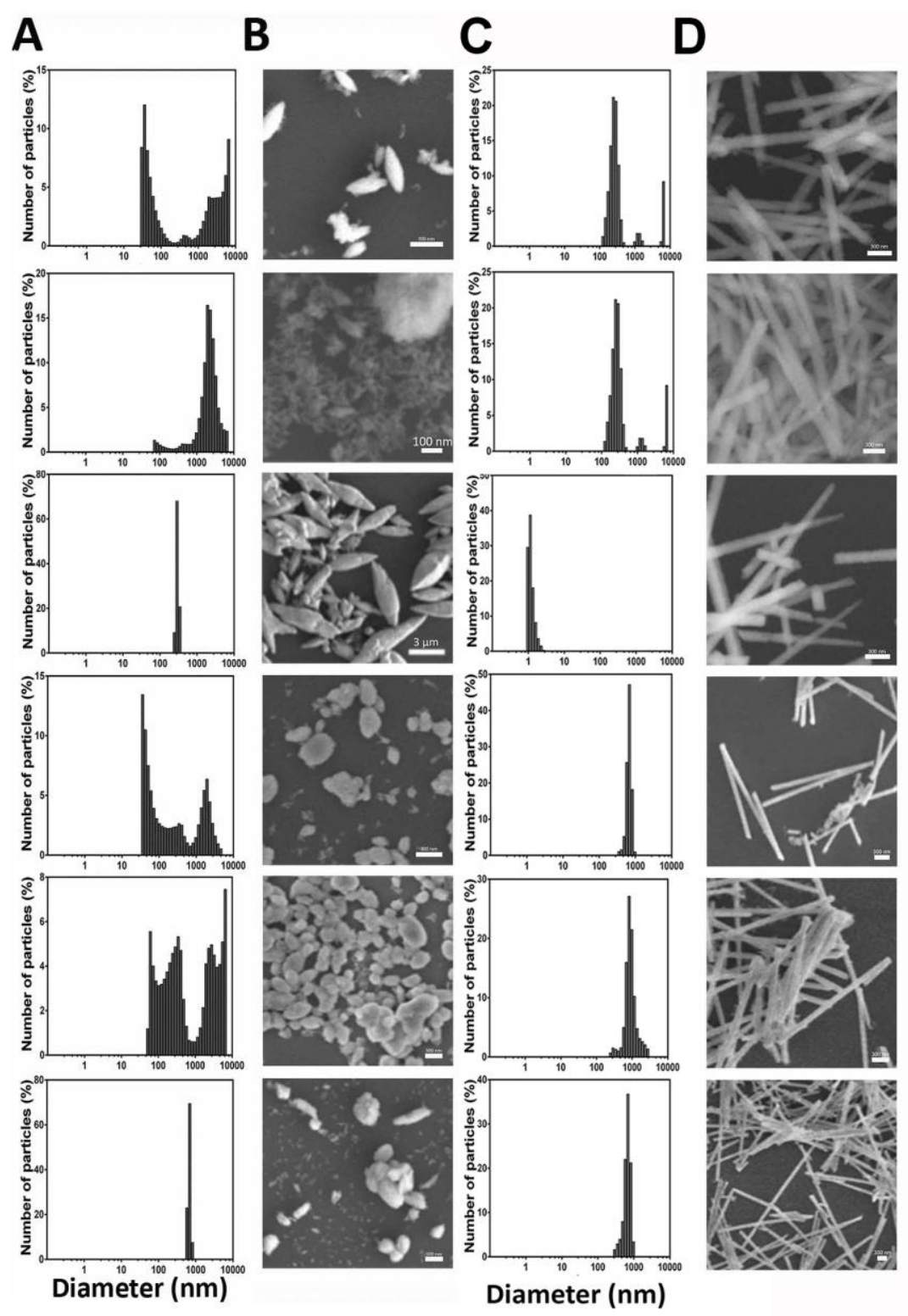

Figure 2.1. Tungstate nanoparticle Dynamic Light Scattering and Electron Microscopy

Images. A. DLS was completed on tungstate nanospheres to provide diameters of the spheres in a dispersed state. B. SEM was completed on tungstate nanospheres to provide length and size characteristics in a dry state. From top to bottom: $\mathrm{CaWO}_{4}, \mathrm{SrWO}_{4}, \mathrm{BaWO}_{4}, \mathrm{Ca}_{3} \mathrm{Sr}_{7} \mathrm{WO}_{4}$, $\mathrm{Ca}_{5} \mathrm{Sr}_{5} \mathrm{WO}_{4}, \mathrm{Ca}_{7} \mathrm{Sr}_{3} \mathrm{WO}_{4}$. C. As in $\mathbf{B}$ except $\mathrm{SEM}$ was completed on analogous tungstate nanowires. All scale bars, $300 \mathrm{~nm}$, except: B: second panel from top, $100 \mathrm{~nm}$, third panel from top, $3 \mu \mathrm{m}$. 


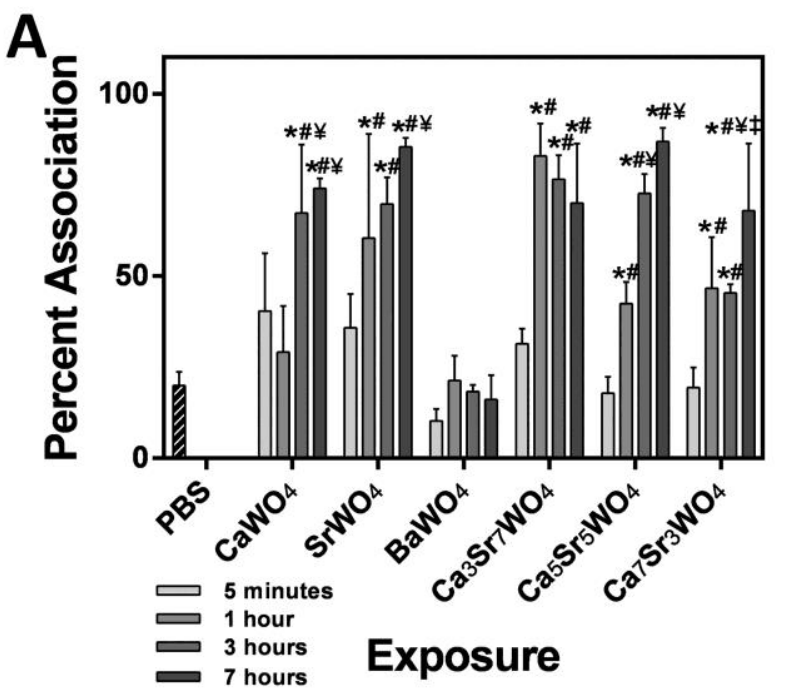

C
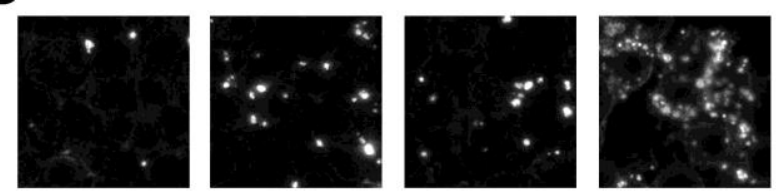

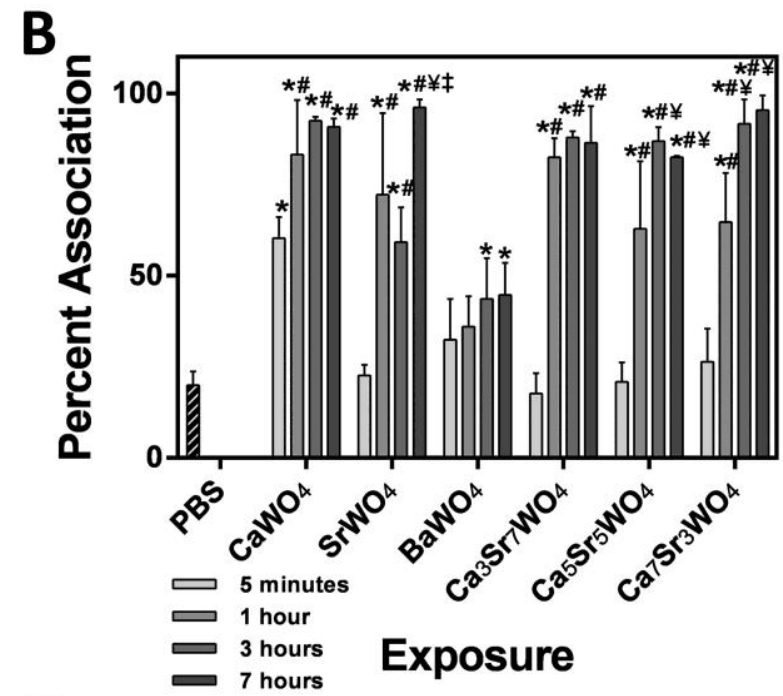

D
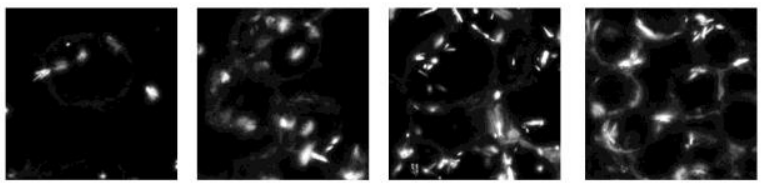

Figure 2.2. Raw 264.7 cells associate with tungstate nanoparticles over a time course. A. A

CytoViva enhanced darkfield microscopy system provides images of high-contrast tungstate nanoparticles (bright spots) against a dark background of cells. Experiments were completed in duplicate and a minimum of 50 cells were counted from 3 fields for each time point. Bars represent number of cells associated compared to number not associated as a percentage \pm standard deviation. *, $\mathrm{p}<0.001$ compared to PBS vehicle,,$+ \mathrm{p}<0.05$ compared to PBS vehicle, \#, $\mathrm{p}<0.05$ compared to 5 minutes, $¥, \mathrm{p}<0.05$ compared to one hour, $\$, \mathrm{p}<0.05$ compared to 3 hours. C. Representative images of cells treated with $\mathrm{Ca}_{3} \mathrm{Sr}_{7} \mathrm{WO}_{4}$ nanospheres over a 7 hour timecourse. B. As in A, except cells were treated with tungstate nanowires. D. As in C, except images represent cells treated with $\mathrm{CaWO}_{4}$ nanowires over a 7 hour time-course. Scale bar, 10 $\mu \mathrm{m}$. 

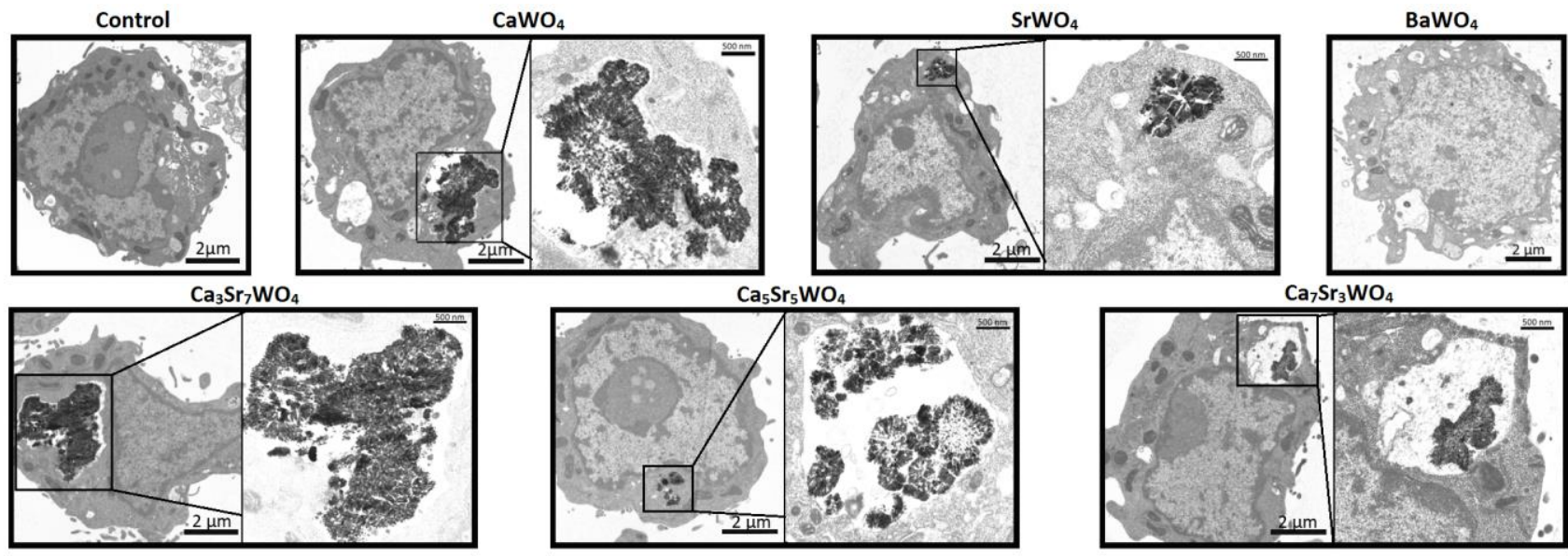

Figure 2.3. RAW 264.7 cells engulf tungstate nanospheres. TEM analysis of RAW 264.7 cells exposed to tungstate nanospheres for 3 hours. 


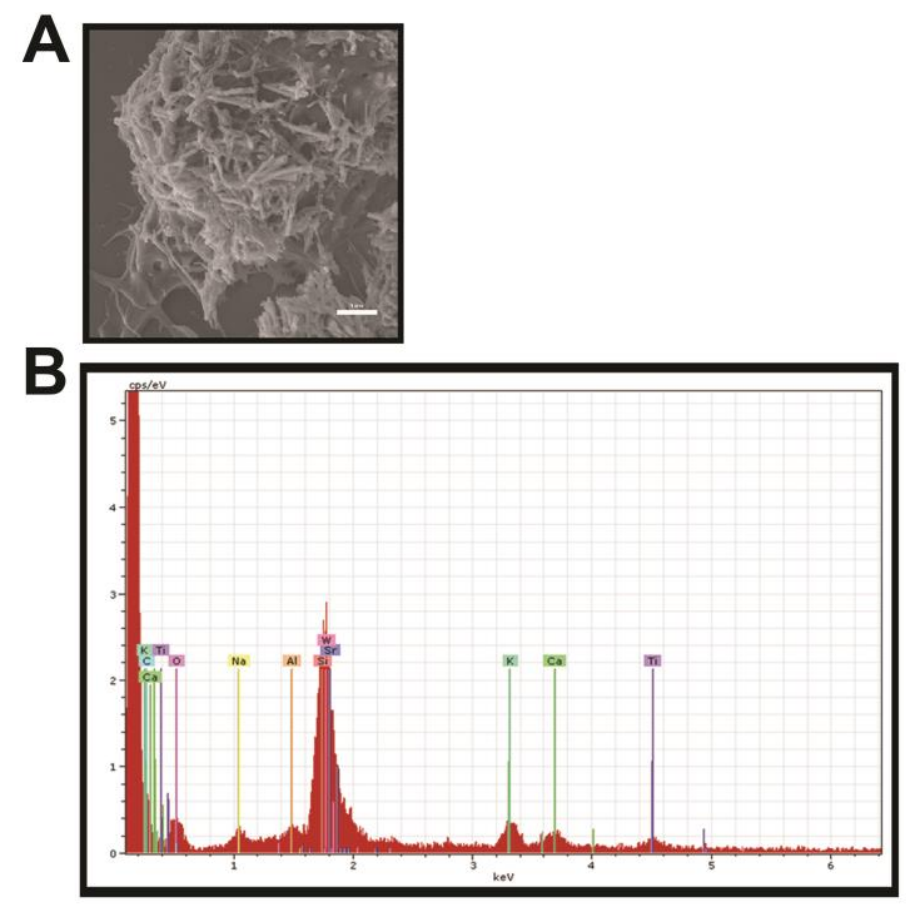

Figure 2.4. SEM analysis shows wire-cell interactions. A. RAW 264.7 cells were treated with $\mathrm{Ca}_{7} \mathrm{Sr}_{3} \mathrm{WO}_{4}$ tungstate nanowires for 3 hours. B. Elemental analysis was completed on $\mathrm{Ca}_{7} \mathrm{Sr}_{3} \mathrm{WO}_{4}$ wire treated cells. 


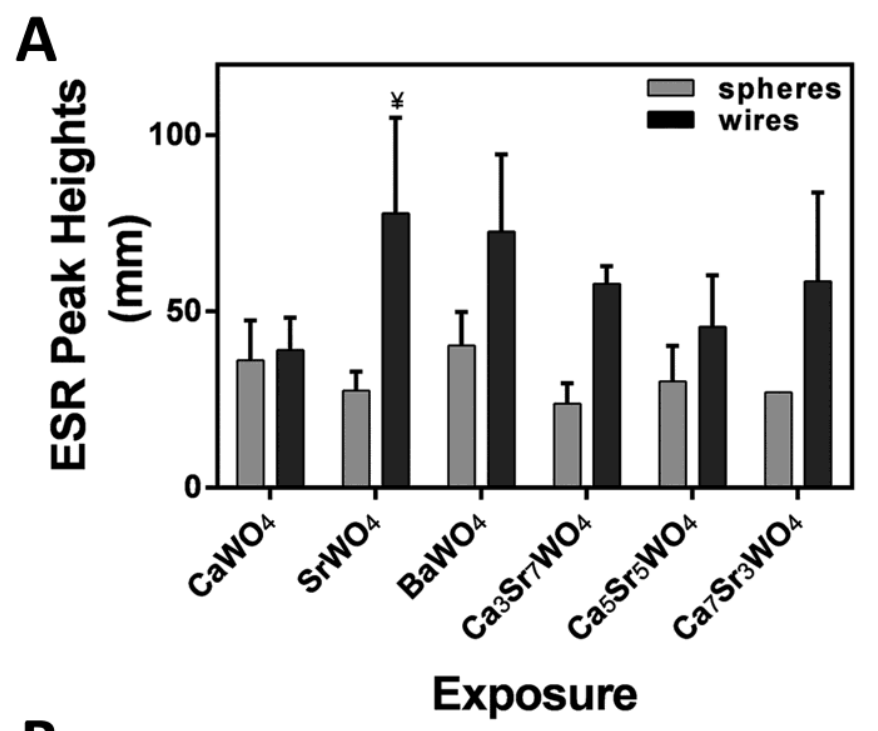

B

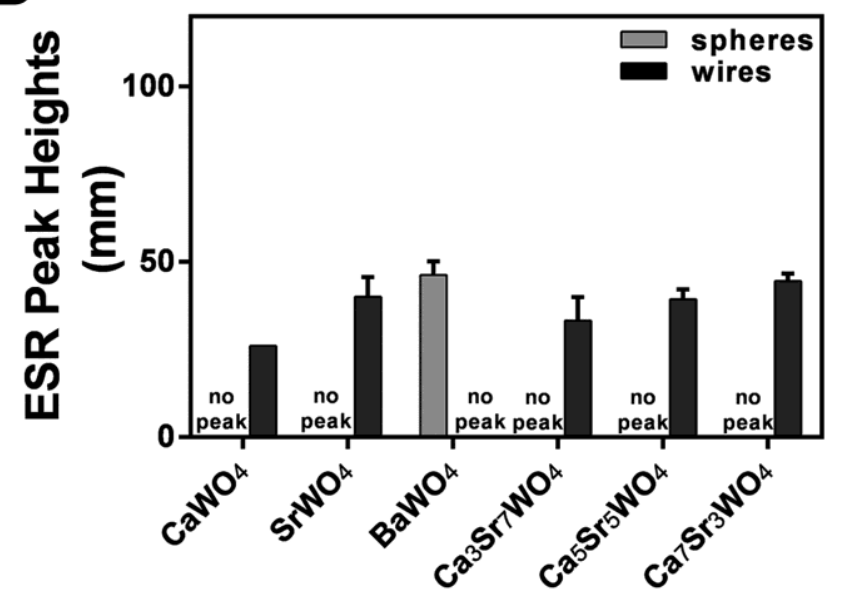

Exposure

Figure 2.5. Tungstate nanoparticles produce hydroxyl radicals after $\mathrm{H}_{2} \mathrm{O}_{2}$ exposure. A. EPR settings were: center field, $3385 \mathrm{G}$; scan width, $100 \mathrm{G}$; time constant, 0.25 seconds; modulation amplitude, 1G; receiver gain, $2.5 \times 10^{4}$; frequency, $9.424 \mathrm{GHz}$; and power, $50 \mathrm{~mW}$. Signal intensity was measured in $\mathrm{mm}$. Error bars represent the mean \pm standard deviation. $¥$, $\mathrm{p}<0.05$ compared to spheres. B. The same as in $\mathbf{A}$, except tungstate nanoparticles were combined with RAW 264.7 cells $\left(2 \times 10^{6}\right)$. EPR settings were: center field, $3475 \mathrm{G}$; scan width, $100 \mathrm{G}$; time constant, 0.41 seconds; modulation amplitude, 1G; receiver gain, 2.5x10 ${ }^{4}$; frequency, 9.748 GHz; and power, $126.6 \mathrm{~mW}$. Error bars represent the mean \pm standard deviation. 

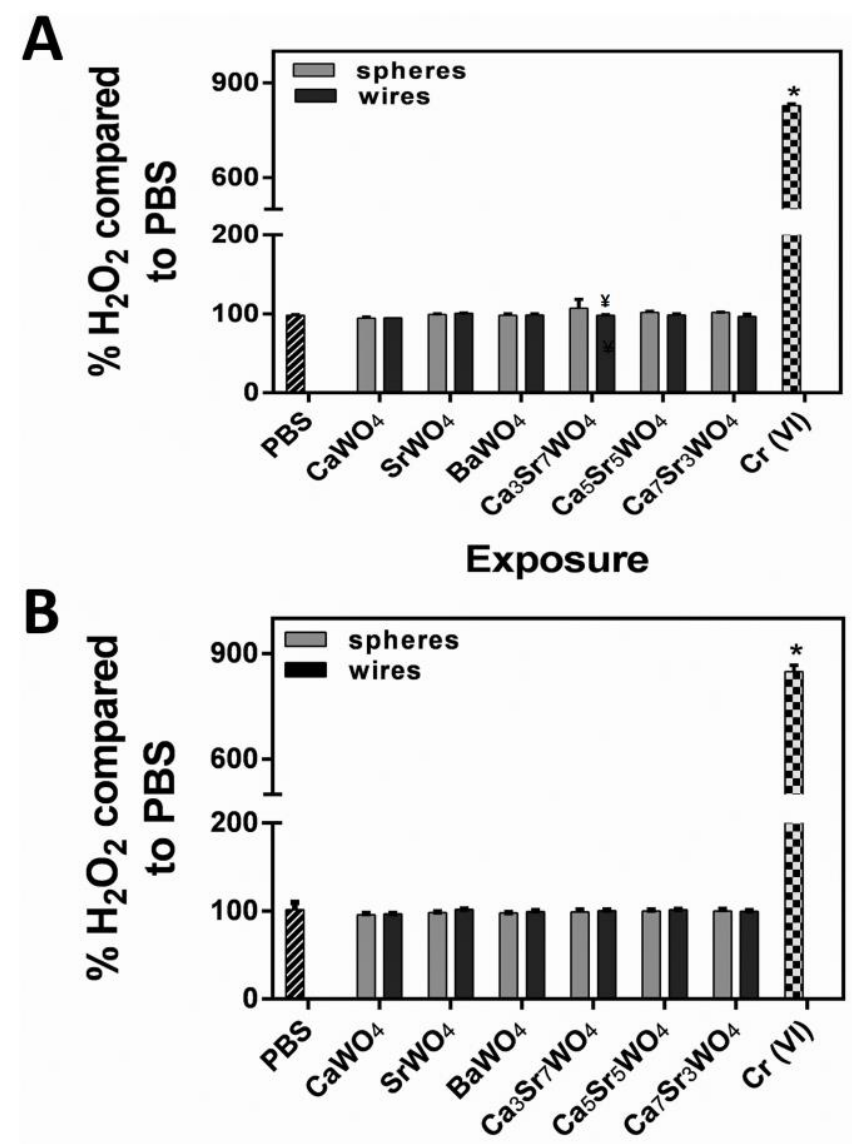

Exposure

Figure 2.6. Tungstate nanoparticles do not cause release of cellular $\mathbf{H}_{2} \mathbf{O}_{2}$. A. RAW 264.7 cells were treated with tungstate nanoparticles at $50 \mu \mathrm{g} / \mathrm{ml}$ for 5 minutes. Bars represent the percentage $\mathrm{H}_{2} \mathrm{O}_{2}$ production as compared with $\mathrm{PBS}$ control treated cells \pm standard deviation. *, $\mathrm{p}<0.05$ compared to PBS vehicle, $¥, \mathrm{p}<0.05$ compared to spheres, $\mathrm{n}=6$. Cr (VI) at $1 \mathrm{mM}$ was used as a positive control. B. Same as in A except cells were treated for 1 hour. 


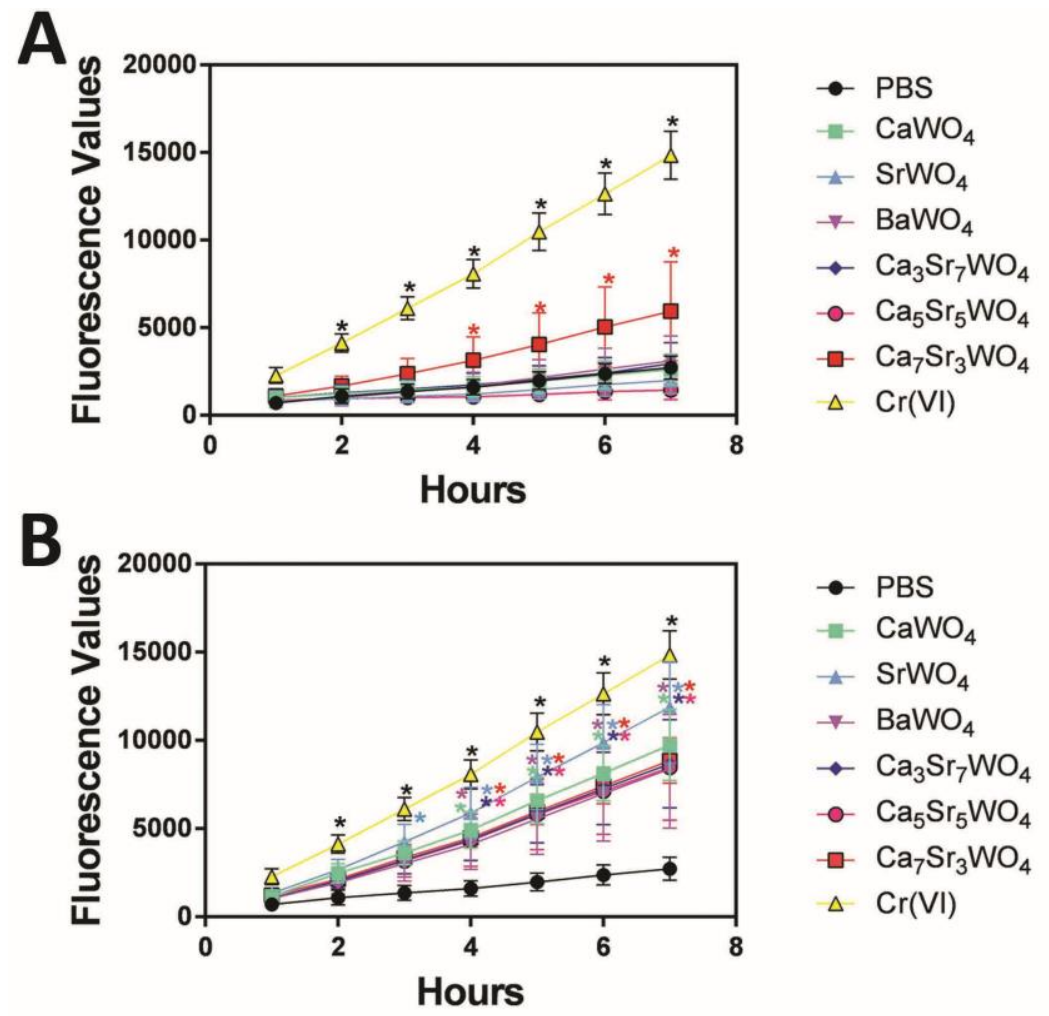

Figure 2.7. Tungstate nanowires produce intracellular ROS. A. RAW 264.7 cells were pretreated with DCFH-DA, then exposed to tungstate nanospheres at $50 \mu \mathrm{g} / \mathrm{ml}$ and incubated at $37^{\circ}$ $\mathrm{C}$ for 7 hours. Error bars represent mean \pm standard deviation. *, p $<0.05$ compared to PBS vehicle, $\mathrm{n}=6 . \mathrm{Cr}$ (VI) at $1 \mathrm{mM}$ was used as a positive control. B. Same as in A except cells were treated with tungstate nanowires. Error bars represent mean \pm standard deviation. 


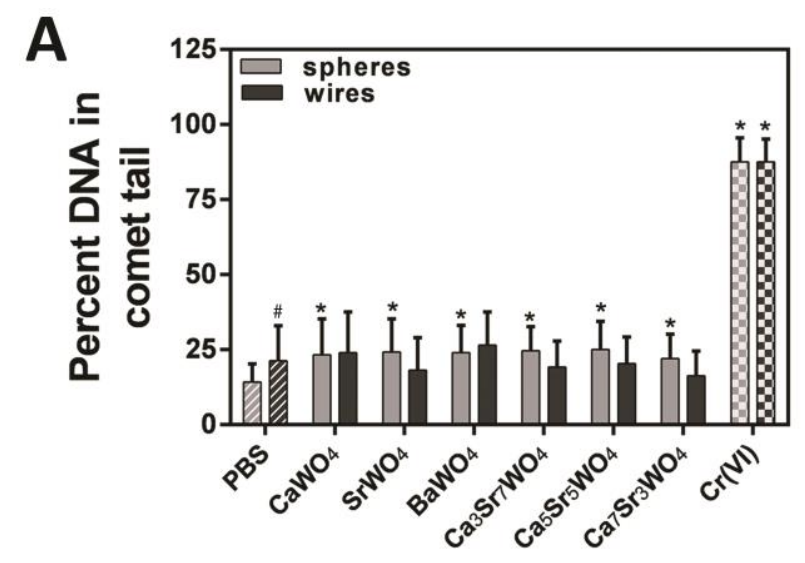

\section{Exposure}

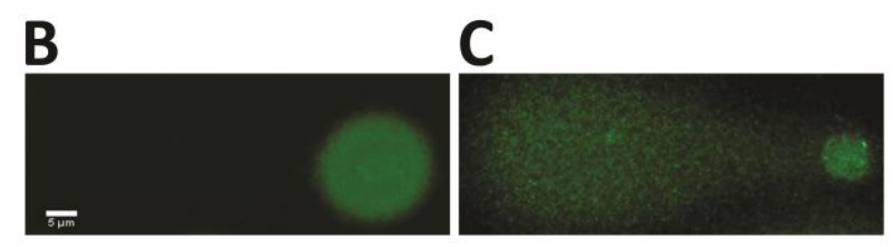

Figure 2.8. Tungstate nanospheres result in oxidative DNA damage at 7 hours. A. RAW 264.7 cells were treated with tungstate nanoparticles at $50 \mu \mathrm{g} / \mathrm{ml}$ for 7 hours. Percent DNA in the tail was measured by comparing nuclear fluorescence with total fluorescence from images. Error bars represent the mean \pm standard deviation. *, $\mathrm{p}<0.001$ compared to PBS vehicle, \#, $\mathrm{p}<0.05$ compared to PBS vehicle, $\mathrm{n}=6$. $\mathrm{Cr}(\mathrm{VI})$ at $1 \mathrm{mM}$ was used as a positive control. B. Representative control cell comet. Scale bar, $5 \mu \mathrm{m}$. C. Representative Cr (VI) treated comet. 
A

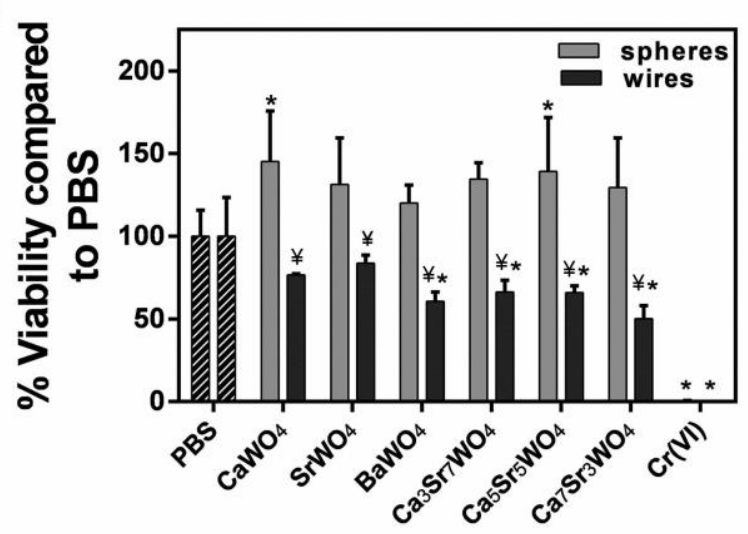

C

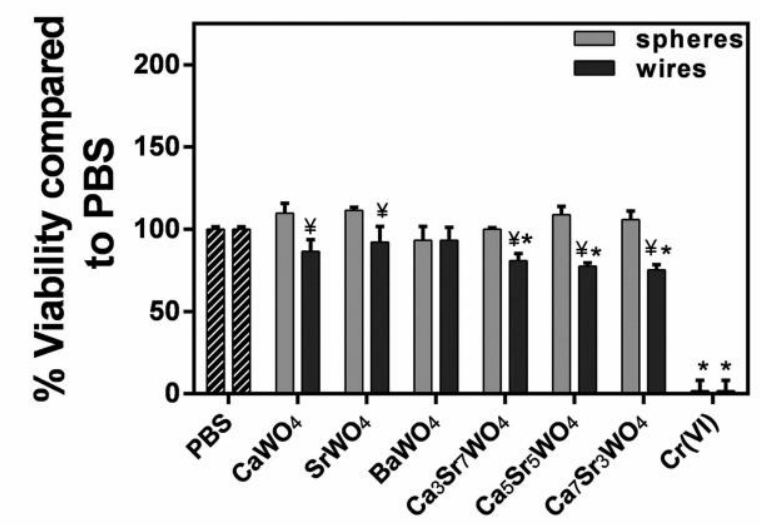

Exposure
B

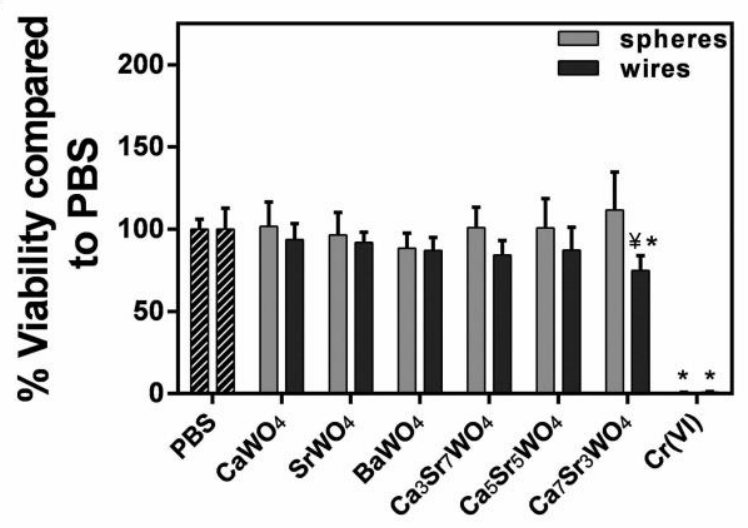

Exposure

D

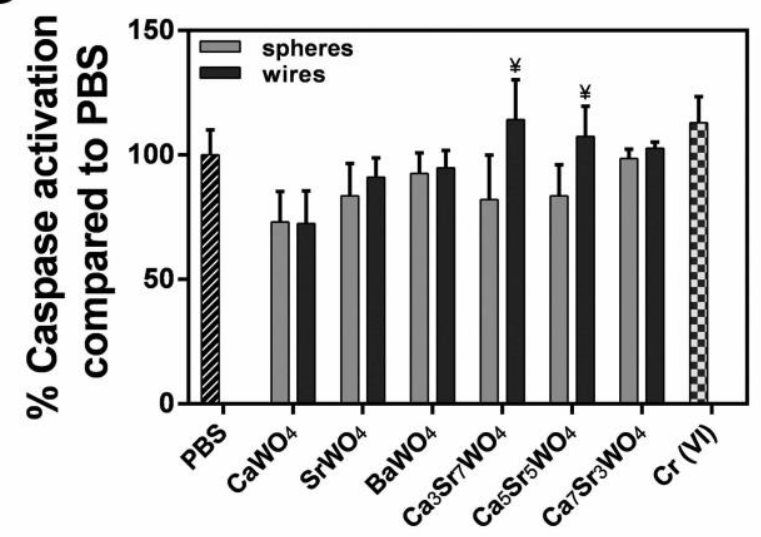

Exposure

Figure 2.9. Tungstate nanowires reduce cell viability at 24 hours. A. RAW 264.7 cells were treated with tungstate nanoparticles at $50 \mu \mathrm{g} / \mathrm{ml}$ for 24 hours, MTT was added 4 hours prior to time point, and absorbance measured. Error bars represent the mean \pm standard deviation. * $\mathrm{p}<0.05$ compared to PBS vehicle, $¥ \mathrm{p}<0.05$ compared spheres, $n=6$. B. As in A except cells were treated for 48 hours. C. As in A except cells were treated for 72 hours. D. RAW 264.7 cells were treated with tungstate nanoparticles at $50 \mu \mathrm{g} / \mathrm{ml}$ for 24 hours, $5 \mu \mathrm{M}$ Caspase-3/7 Green Detection Substrate was added, and fluorescence measured. Error bars represent the mean \pm standard deviation. $¥, \mathrm{p}<0.05$ compared to spheres. 


\section{Chapter 3}

\section{The Effect of Cerium Oxide Nanoparticle Valence State on Reactive Oxygen Species and Toxicity}

Citation: Dunnick, K., Pillai, R., Pisane, K., Stefaniak, A., Sabolsky, E., and Leonard, S. The effect of cerium oxide nanoparticle valence state on reactive oxygen species and toxicity. Biol Trace Elem Res, 2015. doi: $10.1007 / \mathrm{s} 12011-015-0297-4$

Adapted from Biological Trace Elements Research, 2015, 166 (1): 96-107 


\begin{abstract}
Cerium oxide $\left(\mathrm{CeO}_{2}\right)$ nanoparticles, which are used in a variety of products including solar cells, gas sensors, and catalysts, are expected to increase in industrial use. This will subsequently lead to additional occupational exposures, making toxicology screenings crucial. Previous toxicology studies have presented conflicting results as to the extent of $\mathrm{CeO}_{2}$ toxicity, which is hypothesized to be due to the ability of $\mathrm{Ce}$ to exist in both $\mathrm{a}+3$ and +4 valence state. Thus, to study whether valence state and oxygen vacancy concentration are important in $\mathrm{CeO}_{2}$ toxicity, $\mathrm{CeO}_{2}$ nanoparticles were doped with gadolinium to adjust the cation $(\mathrm{Ce}, \mathrm{Gd})$ and anion (O) defect states. The hypothesis that doping would increase toxicity and decrease antioxidant abilities as a result of increased oxygen vacancies and inhibition of +3 to +4 transition was tested. Differences in toxicity and reactivity based on valence state were determined in RLE-6TN rat alveolar epithelial and NR8383 rat alveolar macrophage cells using enhanced dark field microscopy, electron paramagnetic resonance (EPR), and annexin V/ propidium iodide cell viability stain. Results from EPR indicated that as doping increased, antioxidant potential decreased. Alternatively, doping had no effect on toxicity at 24 hours. The present results imply that as doping increases, thus subsequently increasing the $\mathrm{Ce}^{3+} / \mathrm{Ce}^{4+}$ ratio, antioxidant potential decreases, suggesting that differences in reactivity of $\mathrm{CeO}_{2}$ are due to the ability of $\mathrm{Ce}$ to transition between the two valence states and the presence of increased oxygen vacancies, rather than dependent on a specific valence state.
\end{abstract}

Key words: Cerium Oxide, Valence State, Nanotoxicology, Reactive Oxygen Species, Toxicity 


\section{Introduction}

Cerium oxide $\left(\mathrm{CeO}_{2}\right)$ nanoparticles are useful in a variety of applications, including polishing agents, solar cells, and catalysts; they have also found use as a diesel fuel additive $[120,121]$. Cerium (Ce), a rare earth metal of the lanthanide series, is the most abundant rare earth metal making research into the production and use of $\mathrm{CeO}_{2}$ nanoparticles desirable. When in the form of $\mathrm{CeO}_{2}$, the $\mathrm{Ce}$ atom can exist in both a trivalent $\left(\mathrm{Ce}^{3+}\right)$ and more stable tetravalent $\left(\mathrm{Ce}^{4+}\right)$ state, allowing the nanoparticles to store and release oxygen [122]. This ability has increased industrial interest into $\mathrm{CeO}_{2}$ and its potential use in catalysts [85]. In fact, production of $\mathrm{CeO}_{2}$ with increased oxygen storage and releasing properties is desirable in industry to increase its catalytic properties. This increased interest will result in growth in the industrial uses of $\mathrm{CeO}_{2}$ and consequently result in greater exposure risks, specifically inhalation risks, for individuals working in the manufacturing process. Therefore, to understand and limit potentially toxic inhalation exposures, investigation into the toxicity of $\mathrm{CeO}_{2}$ is crucial.

Studies of the toxicity of this nanomaterial have been completed using various cell types, including pulmonary epithelial cells, macrophages, lung fibroblasts, and endothelial cells, but there have been conflicting results. For example, in pulmonary epithelial cells (BEAS-2B and A549 cells), $\mathrm{CeO}_{2}$ can either exert toxicity mediated by reactive oxygen species (ROS) production [87, 88] and Nrf-2 signaling [123] or has antioxidant-like properties [93]. Additionally, $\mathrm{CeO}_{2}$ has antioxidant-like properties under induced oxidative stress in RAW 264.7 macrophage cells [93] and protective effects against induced apoptosis in U937 and Jurkat lymphocyte cells [83]. These conflicting findings have been hypothesized to be a result of the ability of $\mathrm{Ce}$ to transition between $\mathrm{Ce}^{3+}$ and $\mathrm{Ce}^{4+}$ valence states and the subsequent oxygen vacancies formed from this transition $[82,122]$. The reduction of $\mathrm{Ce}^{4+}$ to $\mathrm{Ce}^{3+}$ is thought to 
generate superoxide anions, which can produce damaging hydroxyl radicals. It is also postulated that $\mathrm{Ce}^{3+}$ can react with hydroxyl radicals and act as an antioxidant $[82,83,88,124]$. Thus, it is possible that the valence state of $\mathrm{Ce}$ affects whether $\mathrm{CeO}_{2}$ nanoparticles play a protective or toxic role in exposed cells. Based on previous research, we hypothesize valence state determines the extent of $\mathrm{CeO}_{2}$ toxicity and that when $\mathrm{CeO}_{2}$ exist in a greater $3+/ 4+$ ratio, it's toxicity will increase and antioxidant potential will decrease. To test this hypothesis and assess the effects of valence state, a technique known as doping was employed. Doping is the process of intentionally introducing impurities into a pure substance to modulate electrical properties. To modulate the oxygen storage and release capacity of $\mathrm{CeO}_{2}$ nanoparticles, rare earth metals ions with low valence states are typically used [85]. For this study, gadolinium (III) oxide $\left(\mathrm{Gd}_{2} \mathrm{O}_{3}\right)$ was used to produce increased oxygen vacancies in the $\mathrm{CeO}_{2}$ nanoparticle lattice [85] and force the valence state toward a greater $+3 /+4$ ratio. Two types of doped $\mathrm{CeO}_{2}$ nanoparticles were prepared and used for this study, a $10 \mathrm{~mol} \%$ and $20 \mathrm{~mol} \% \mathrm{Gd}$ in $\mathrm{CeO}_{2}$. In addition, pure $\mathrm{CeO}_{2}$ nanoparticles were tested. Previous studies have shown that $\mathrm{Gd}_{2} \mathrm{O}_{3}$ itself exhibits toxicity [125], therefore $\mathrm{Gd}_{2} \mathrm{O}_{3}$ controls were used throughout the study to ensure any differing effects between cerium compounds were due to valence state and transitional ability rather than the presence of $\operatorname{Gd}_{2} \mathrm{O}_{3}$. The effect of valence state and transitional ability of pure $\mathrm{CeO}_{2}$ nanoparticles and doped $\mathrm{CeO}_{2}$ nanoparticles on ROS and toxicity was assessed.

\section{Materials and Methods}

\section{Cell culture}

RLE-6TN rat alveolar type II cells (ATCC; Rockville, MD) were cultured following a modified ATCC recommended protocol. Cells were cultured in Ham's F12 medium with 5\% fetal bovine 
serum, and $50 \mathrm{mg} / \mathrm{ml}$ penicillin/streptomycin (Thermo Scientific; Pittsburgh, PA). Cells were grown at $37^{\circ} \mathrm{C}$ in a $5 \% \mathrm{CO}_{2}$ incubator and were passaged following trypsinization. RLE-6TN cells were chosen for these studies to represent the pulmonary alveolar region most likely to come into contact with nanoparticles. NR8383 rat macrophage cells (ATCC; Rockville, MD) were cultured following the ATCC recommended protocol. Cells were cultured in Ham's F12K medium with $15 \%$ fetal bovine serum, and $50 \mathrm{mg} / \mathrm{ml}$ penicillin/streptomycin. Cells were grown at $37^{\circ} \mathrm{C}$ in a $5 \% \mathrm{CO}_{2}$ incubator and were passaged by transferring floating cells to culture flasks.

\section{Immunocytochemistry staining of RLE-6TN cells}

Because alveolar type II cells act as the progenitor cells for alveolar type I cells in the pulmonary environment [126], immunocytochemistry (ICC) staining was completed to determine the phenotype of the cultured cells throughout the experiments. Briefly, cells were plated on autoclaved glass coverslips in 12 well plates at $1 \times 10^{5} /$ well and grown until $80 \%$ confluent. Media was the removed, cells were washed with PBS, then fixed with 3.7\% formaldehyde for 15 minutes. Cells were washed twice with cold PBS and immunofluorescence was carried out using primary antibodies against P180 (1:100, Abcam; Cambridge, MA) and Purinergic receptor P2X ligand-gated ion channel 7 (P2RX7) (1:200, Abcam; Cambridge, MA), and secondary Alexa 488 and 568 antibody conjugates (1:200, Invitrogen; Grand Island NY). Coverslips were mounted onto slides with Fluoromount G (eBioscience; San Diego, CA) and cells were imaged using an Olympus AX70 microscope equipped with an Olympus DP73 camera (Olympus; Center Valley, PA). 


\section{$\mathrm{CeO}_{2}$ Nanoparticle Production and Characterization}

Nanoparticle production and characterization were completed by Dr. Edward Sabolsky, Dr. Rajalekshmi Pillai, Ms. Kelly Pisane, and Dr. Aleksandr Stefaniak. Gd-doped $\mathrm{CeO}_{2}$ nano powder was prepared using a hydrothermal method [127] (Figure 3.1). For this process, two separate aqueous solutions $\left(5 \times 10^{-3} \mathrm{~mol} \mathrm{~L}^{-1}\right)$ of cerium (IV) ammonium nitrate $\left(\mathrm{Ce}\left(\mathrm{NH}_{4}\right)_{2}\left(\mathrm{NO}_{3}\right)_{6}, 99.9 \%\right.$ purity) and gadolinium nitrate hexa-hydrate $\left(\mathrm{Gd}\left(\mathrm{NO}_{3}\right)_{3} \cdot 6 \mathrm{H}_{2} \mathrm{O}\right)$ were prepared by dissolving the salts into deionized water at room temperature. The as-prepared solutions were mixed together under vigorous stirring. An aqueous solution of tetramethyl ammonium hydroxide (TMAH) was added drop by drop until the $\mathrm{pH}$ of the solution reached 10 . After 30 minutes of stirring, a white or yellowish gel-like precipitate was formed and settled rapidly. The supernatant of the solution was decanted and the resulting solid was rinsed several times with deionized water and hydrothermally treated at $240^{\circ} \mathrm{C}$ for 1 hour under autogenous pressure without stirring to obtain cerium (or Gd-doped cerium) oxide. The clear supernatant was decanted and the yellowish precipitate was washed with isopropanol and then dried at $80-85^{\circ} \mathrm{C}$ overnight.

An X'PERT PRO Panalytical X-ray diffractometer (Westborough, MA) was used to determine the phase of the prepared ceria powders using $\mathrm{Cu} \mathrm{Ka}$ radiation. Data was collected from $10^{\circ}-90^{\circ}$ angles $(2 \theta)$ with a step size of 0.02 increments at a rate of $1 \%$ minutes. Phase identification was achieved by X'PERT PRO software through the comparison of indexed powder diffraction files maintained by International Center for Diffraction Data. The morphology of the synthesized ceria powders was examined by scanning electron microscopy (SEM; JEOL 7600F; Peabody, MA). Energy-dispersive X-ray spectroscopy (EDS) was used to identify the elemental composition of the prepared powders. The X-ray photoelectron spectroscopy (XPS) measurements were carried out using a Physical Electronics, PHI 5000 
Versa Probe (XPS/UPS) spectrometer (Chanhassen, MN) with a monochromatic Al Ka source operated at $300 \mathrm{~W}$ and a base pressure of $5 \times 10^{-8}$ Torr. XPS is a surface sensitive technique that analyzes the top 25 to 50 angstroms of a particles exterior. The spectrometer was configured to operate at high resolution with energy of $100 \mathrm{eV}$. The acquisition time of the sample was kept low to minimize surface oxidation state changes during X-ray irradiation. The XPS analysis was performed to understand the changes in the valence state and binding energy of the constituent elements on powder surfaces. The work function of the instrument was calibrated to a binding energy of $83.96 \mathrm{eV}$ for the $\mathrm{Au} 4 \mathrm{f} 7 / 2$ line for metallic gold, and the dispersion of the spectrometer was adjusted to a binding energy of $932.62 \mathrm{eV}$. The powder samples were placed on the sample holder using a double-side conductive tape followed by 6 hour evacuation prior to analyses. Survey spectra were collected by $1.0 \mathrm{eV}$ steps at analyzer pass energy of $160 \mathrm{eV}$ and the high resolution analysis of small spectrum regions by $0.05 \mathrm{eV}$ steps and pass energy of $20 \mathrm{eV}$. The integrated area under the curve of each de-convoluted peak was used to calculate the concentration of $\mathrm{Ce}^{3+}$ ions as $[C e]=\frac{\left[A v_{0}+A v^{\prime}+A u_{0}+A u^{\prime}\right]}{\sum A_{i}}$ where $\mathrm{A}_{\mathrm{i}}$ is the integrated area for peak "i".

The size distributions of $\mathrm{CeO}_{2}$ and $\mathrm{Gd}$-doped $\mathrm{CeO}_{2}$ nanoparticles in a suspended state were assessed using dynamic light scattering (DLS). DLS analyzes the velocity distribution of suspended particles by detecting fluctuations of scattered light produced by Brownian motion of the particles and provides hydrodynamic radius or diameter of the particles. All measurements were performed using a Nano ZS90 instrument (Malvern Instruments; Worcestershire, UK). Prior to measurement, each sample cell was cleaned, rinsed with $0.02 \mu \mathrm{m}$-filtered water, and prewetted with dispersion media (DM). Suspensions of each material in DM was subjected to 
ultrasonic agitation using a probe tip for 10 to 20 minutes (delivered energy $=4500$ to $9000 \mathrm{~J}$ ) until a uniform dispersion appeared. An ice bath was used to cool the samples during sonication.

The zeta potentials of $\mathrm{CeO}_{2}$ and $\mathrm{Gd}$-doped $\mathrm{CeO}_{2}$ nanoparticles in a suspended state were assessed to describe the stability of the dispersions in DM. All measurements were performed using a Nano ZS90 instrument (Malvern Instruments; Worcestershire, UK). Prior to measurement, each sample cell was cleaned and rinsed with $0.02 \mu \mathrm{m}$-filtered water and ethanol. All dispersant media were filtered through a $0.02 \mu \mathrm{m}$ membrane prior to use as well. The viscosity of the dispersant was determined at room temperature using a VS-10 viscometer (Malvern Instruments) and measured values were used in the calculation of zeta potential. Each nanoparticle suspension was subjected to ultrasonic agitation for up to 10 minutes using a probe tip (delivered energy $=4400 \mathrm{~J}$ ). The Smoluchowski approximation of 1.5 was used for Henry's function and a $\mathrm{pH}$ of 7.51 was determined for the DM.

Nitrogen gas adsorption was used to determine powder-specific surface area (SSA) using a multipoint Brunauer, Emmett, and Teller (BET) instrument (ASAP2020 surface area analyzer; Micromeritics; Norcross, GA). Prior to analysis, powders were outgassed under vacuum $(0.013$ torr) for 3 hours at $150^{\circ} \mathrm{C}$ to remove moisture [128]. The transmission electron microscopy (TEM) samples were prepared by sonicating a mixture of $\mathrm{CeO}_{2}$ nanopowder and $\mathrm{DM}$ for 2 minutes to disperse the nanoparticles. Ethanol was added and the solution was sonicated for an additional 5 minutes. One drop of the resulting solution was placed on a carbon coated copper TEM grid for imaging on a JEOL JEM 2100 (Peabody, MA) TEM with a $\mathrm{LaB}_{6}$ filament operated at $200 \mathrm{kV}$. Regular micrographs were taken with a Gatan ES500W (Gatan; Pleasanton, CA) digital camera and high resolution images were obtained with an Orius SC1000 (Gatan; Pleasanton, CA) camera. 


\section{Determination of cellular interaction}

To visualize nanoparticles, which are not visible using typical light microscopy, enhanced darkfield microscopy was employed [100]. RLE-6TN and NR8383 cells were grown on cleaned, autoclaved cover-glass (Chemglass Life Sciences; Vineland, NJ) until 60-80\% confluent. $\mathrm{CeO}_{2}$, Gd-doped $\mathrm{CeO}_{2}$, and $\mathrm{Gd}_{2} \mathrm{O}_{3}$ nanoparticles were prepared in DM at a stock concentration of 1 $\mathrm{mg} / \mathrm{ml}$, as previously described [99]. Cells were then treated with $\mathrm{CeO}_{2}$ or $\mathrm{Gd}_{2} \mathrm{O}_{3}$ (SigmaAldrich; St. Louis, MO) nanoparticles at a final concentration of $10 \mu \mathrm{g} / \mathrm{ml}$ for 5 minutes, 1 hour, and 3 hours. Following incubation, the medium was removed and the cells were washed 3 times with warm phosphate buffered saline (PBS), fixed with $10 \%$ formalin for 10 minutes, washed three times with PBS, mounted with Fluoromount G (eBioscience; San Diego, CA), and sealed with clear nail polish. Slides used for this experiment were purchased as clean cut slides to avoid silica particle residue, which results in high background during imaging (Schott Nexterion, Arlington, VA). Following mounting, images were acquired at $60 \mathrm{x}$ magnification using a Cytoviva enhanced darkfield microscopy system (Aetos Technologies; Inc., Auburn, AL) integrated into an Olympus BX41 upright optical microscope equipped with an Olympus DP73 digital camera (Olympus; Center Valley, PA).

\section{Electron Paramagnetic Resonance (EPR)}

A spin trap technique was used to form long-lived free radicals that could be detected by EPR through addition of DEPMPO (5-(diethioxyphosphoyl)-5-methyl-1-pyrroline N-oxide) or DMPO (5,5'-dimethylpyrroline $\mathrm{N}$-oxide). EPR measurements were collected using a flat cell assembly

and Brüker EMX spectrometer (Billerica, MA). $\mathrm{CeO}_{2}$ and $\mathrm{Gd}$-doped $\mathrm{CeO}_{2}$ nanoparticles were incubated at a final concentration of $1 \mathrm{mg} / \mathrm{ml}$ with $50 \mathrm{mM}$ DEPMPO (Cayman Chemical, Ann 
Arbor, Michigan), $3.5 \mathrm{mM}$ xanthine and $2 \mathrm{U} / \mathrm{ml}$ xanthine oxidase (Sigma Aldrich) for 3 minutes to produce superoxide radicals. To induce hydroxyl radicals in an acellular system and assess antioxidant potential, $\mathrm{CeO}_{2}$ and $\mathrm{Gd}$-doped $\mathrm{CeO}_{2}$ were incubated at a final concentration of 1 $\mathrm{mg} / \mathrm{ml}$ with $100 \mathrm{mM}$ DMPO (Sigma Aldrich) and $1 \mathrm{mM} \mathrm{H}_{2} \mathrm{O}_{2}$, and then exposed to UV light for 1 minute. The mass of $\mathrm{Gd}_{2} \mathrm{O}_{3}$ powder was adjusted to achieve a final concentration of $179 \mu \mathrm{g} / \mathrm{ml}$, as this value represents the theoretical amount of elemental $\mathrm{Gd}$ in the $20 \mathrm{~mol} \% \mathrm{Gd}$-doped $\mathrm{CeO}_{2}$ nanoparticles. This reaction was also run in the absence of UV light to assess the ability of $\mathrm{CeO}_{2}$ and $\mathrm{Gd}$-doped $\mathrm{CeO}_{2}$ to produce hydroxyl radicals. Samples were run in triplicate and instrument settings are indicated under Results. Signal intensity (peak height) was used to measure the relative amount of superoxide radicals produced and is measured in $\mathrm{mm}$.

For cellular EPR, $\mathrm{CeO}_{2}$ and $\mathrm{Gd}$-doped $\mathrm{CeO}_{2}$ at final concentrations of $1 \mathrm{mg} / \mathrm{ml}$ or $\mathrm{Gd}_{2} \mathrm{O}_{3}$ at $179 \mu \mathrm{g} / \mathrm{ml}$ were incubated with either RLE-6TN or NR8383 cells at $2 \times 10^{6}$ cells $/ \mathrm{ml}$ and 200 $\mathrm{mM}$ DMPO for 3 minutes at $37^{\circ} \mathrm{C}[57,101]$. Reactions were run in triplicate. This reaction was repeated but $2 \mathrm{mM} \mathrm{Cr}$ (VI) was added to the system to induce hydroxyl radicals. Peak heights represent relative amounts of hydroxyl radicals produced and are measured in $\mathrm{mm}$.

\section{Annexin V/ Propidium Iodide}

The degree of apoptosis and necrosis induced by $\mathrm{CeO}_{2}$ and $\mathrm{Gd}$-doped $\mathrm{CeO}_{2}$ at 24 hours was determined by flow cytometry. RLE-6TN cells were seeded at $1 \times 10^{5}$ cells per well in 24 well plates and NR8383 cells were seeded at $3 \times 10^{5}$ cells per well. Following 24 hours of growth, cells were treated with $\mathrm{CeO}_{2}$ and $\mathrm{Gd}$-doped $\mathrm{CeO}_{2}$ at a final concentration of $10 \mu \mathrm{g} / \mathrm{ml}$ or 50 $\mu \mathrm{g} / \mathrm{ml}$ for 24 hours or treated with $\mathrm{Gd}_{2} \mathrm{O}_{3}$ at a final concentration of $1.79 \mu \mathrm{g} / \mathrm{ml}$ or $8.95 \mu \mathrm{g} / \mathrm{ml}$. The annexin V/ propidium iodide assay was completed according to company protocol 
(Trevigen; Gaithersburg, MD). Briefly, cell media were collected followed by trypsinization of cells for 2 minutes. Trypsinized cells were combined with media to ensure collection of viable, apoptotic, and necrotic cells. Following a washing step, cells were incubated for 15 minutes with $100 \mu 1$ annexin V/ propidium iodide stain then analyzed on a BD Biosciences LSR II flow cytometer. All data were analyzed using DIVA software and 10,000 events per sample were

collected. Samples were run three times in duplicate and are presented in graphical rather than scatter plot format.

\section{Statistical Analysis}

All data are represented as the mean \pm standard deviation for each condition. To compare responses between groups, a one-way analysis of variance (ANOVA) and Tukey post-test were performed using GraphPad Prism 6 software (GraphPad Software, Inc.; La Jolla, CA). Statistical significance is shown when $\mathrm{p}<0.05$.

\section{Results}

Immunocytochemistry staining of RLE-6TN cells

Immunocytochemistry was utilized to determine whether the RLE-6TN cells were type II or type I alveolar epithelial cells. Staining demonstrates that cells used for these studies were a mix of both population types, which more closely recapitulates the pulmonary environment (Figure 3.2). 


\section{$\mathrm{CeO}_{2}$ Characteristics}

The XRD diffraction peaks of the $\mathrm{CeO}_{2}$, which represent the crystalline plane (llll 111$),\left(\begin{array}{lll}2 & 0 & 0\end{array}\right),\left(\begin{array}{l}2 \\ 2\end{array}\right.$ 2 0) and (3 11 1), correspond to cubic fluorite crystal structure (JCPDS Data Card \# 88-2326), where $\mathrm{Ce}$ is in the $4+$ oxidation state [129]. The $\mathrm{XRD}$ pattern of $\mathrm{CeO}_{2} 10 \% \mathrm{Gd}$ and $\mathrm{CeO}_{2} 20 \%$ Gd showed no Gd oxide peaks, indicating the formation of $\mathrm{Gd}-\mathrm{CeO}_{2}$ solid solution [129] (data not shown). SEM was used to assess the agglomeration of the nanoparticles and indicated that the $\mathrm{CeO}_{2}$ and doped- $\mathrm{CeO}_{2}$ powders agglomerated and that there was a wide distribution of particle sizes. The EDS pattern of pure $\mathrm{CeO}_{2}$ (data not shown) did not reveal any impurities present in the powder.

Figure 3.3A. shows the wide scan XPS survey spectra for pure $\mathrm{CeO}_{2}, \mathrm{CeO}_{2} 10 \% \mathrm{Gd}$, and $\mathrm{CeO}_{2} 20 \% \mathrm{Gd}$. High resolution XPS spectra for Ce (3d), the fitted curve, and the corresponding de-convoluted peaks of $\mathrm{CeO}_{2}$ nanoparticles are shown in Figure 3.3B. The recorded XPS spectra were charge corrected with respect to the $\mathrm{C}(1 \mathrm{~s})$ peak at $284.6 \mathrm{eV}$. The peaks in the spectrum of Ce were de-convoluted using the multi pack software. The letter "v" marked in the spectra indicates the spin-orbit coupling $3 \mathrm{~d}_{5 / 2}$ and the letter " $\mathrm{u}$ " indicates spin orbit coupling $3 \mathrm{~d}_{3 / 2}$ of pure $\mathrm{CeO}_{2}$. The peaks denoted by $\mathrm{v}_{0}, \mathrm{v}^{\prime}, \mathrm{u}_{0}$ and $\mathrm{u}^{\prime}$ represent $\mathrm{Ce}^{3+}$ ions whereas those marked by $\mathrm{v}, \mathrm{v}^{\prime \prime}$, $\mathrm{v}^{\prime \prime \prime}, \mathrm{u}, \mathrm{u}^{\prime \prime}$ and $\mathrm{u}^{\prime \prime \prime}$ represent $\mathrm{Ce}^{4+}$ ions. It is evident that the de-convoluted $\mathrm{Ce}(3 \mathrm{~d})$ spectrum is relatively complex due to the presence of $\mathrm{Ce}$ in $3+$ and $4+$ oxidation states as well as multiple $\mathrm{d}-$ splitting. The spin orbit doublets for pure $\mathrm{CeO}_{2}, 3 \mathrm{~d}_{3 / 2}(885.3$ and $903.4 \mathrm{eV})$ and $3 \mathrm{~d}_{5 / 2}(881.9$ and $888.6 \mathrm{eV}$ ) are clearly evident for both valence states of $\mathrm{Ce}$, indicating that $\mathrm{Ce}$ is in mixed valence states of $3+$ and $4+[130]$. High resolution XPS spectra for Ce (3d), the fitted curve, and the corresponding de-convoluted peaks of pure $\mathrm{CeO}_{2}, \mathrm{CeO} 210 \% \mathrm{Gd}$, and $\mathrm{CeO}_{2} 20 \% \mathrm{Gd}$ are presented in Figure 3.3. Table 3.1 shows the binding energies, peak heights, peak areas and the 
concentrations of $\mathrm{Ce}^{3+}$ and $\mathrm{Ce}^{4+}$ atoms of pure $\mathrm{CeO}_{2}, \mathrm{CeO}_{2} 10 \% \mathrm{Gd}$ and $\mathrm{CeO}_{2} 20 \% \mathrm{Gd}$. The characteristic peaks of $\mathrm{Gd}^{3+} 3 \mathrm{~d}_{5 / 2}$ was observed in the region $1183.83 \pm 0.7 \mathrm{eV}$ and $1215.83 \pm 0.7$ $\mathrm{eV}$ in $\mathrm{CeO}_{2} 10 \% \mathrm{Gd}$ and $1187.07 \pm 0.7 \mathrm{eV}$ and $1219.07 \pm 0.7 \mathrm{eV}$ in $\mathrm{CeO}_{2} 20 \% \mathrm{Gd}$, indicating that $\mathrm{Gd}$ is in the 3+ oxidation state (Figure 3.3). It was observed that in both the peaks of $\mathrm{Gd}^{3+}$, there was a slight shift towards the lower binding energy, which can be attributed to the increase in valence electron density. From the table it may be seen that the addition of $\mathrm{Gd}$ increases the $\mathrm{Ce}^{3+}$ state. The ratios of $\mathrm{Ce}^{3+} / \mathrm{Ce}^{4+}$ were found to be $16.9,42.7$ and $43.9 \%$ for pure $\mathrm{CeO}_{2}, \mathrm{CeO}_{2} 10 \%$ $\mathrm{Gd}$ and $\mathrm{CeO}_{2} 20 \% \mathrm{Gd}$, respectively. The high value of $\mathrm{v}_{0} / \mathrm{u}_{0}$ and $\mathrm{v}^{\prime} / \mathrm{u}^{\prime}$ indicates that nano-sized ceria exhibits better catalytic activity due to the large amount of electronic and ionic defects, which include the presence of $\mathrm{Ce}^{3+}$ and $\mathrm{Gd}^{3+}$ atoms and the corresponding oxygen vacancies $\left(\mathrm{V}_{\mathrm{O}}{ }^{\prime \prime}\right) . \mathrm{Gd}$ is a lanthanide that can be used to modify the chemical, crystal structure, and defect state of ceria. The atomic radius and the electron negativity of Gd are close to that of the cerium atom, so the atom fits into the Ce-site within the fluorite structure. It must be noted, that as the amount of $\mathrm{Ce}^{3+}$ and $\mathrm{Gd}^{3+}$ states within the structure increases, the structure must compensate for these additions by increasing the positive charge within the material to retain charge neutrality. The material typically compensates for this ionic defect by releasing oxygen from the structure, resulting in an open anionic site within the structure (oxygen vacancy, $\mathrm{V}_{\mathrm{O}}{ }^{\prime)}$ ). The oxygen vacancies may be considered as open sites within the bulk and surface structure for the uptake of oxygen, and are critical for the efficient diffusion of oxygen ions within or on the surface of the ceria.

Hydrodynamic diameter and zeta potential were measured to assess particle agglomeration under physiological exposure conditions while TEM was used to observe particle size. The results demonstrated that the hydrodynamic diameters of all three $\mathrm{CeO}_{2}$ nanoparticle 
agglomerates $\left(\mathrm{CeO}_{2}, 875 \pm 58 ; \mathrm{CeO}_{2} 10 \% \mathrm{Gd}, 201 \pm 5 ; \mathrm{CeO}_{2} 20 \% \mathrm{Gd}, 176 \pm 8\right)$ (Table 3.2) were larger than the observed size under TEM $(\sim 5 \mathrm{~nm})$ (Figure 3.4). The zeta potential shows that the nanoparticle dispersions are likely to agglomerate in DM (Table 3.2) based on the stability categories developed by Riddick [131]. Thus the results show that the stability of the nanoparticle dispersions is fairly poor over time. The surface area results implicate that the pure $\mathrm{CeO}_{2}$ and $\mathrm{CeO}_{2} 10 \% \mathrm{Gd}$ were of similar surface area while the surface are of $\mathrm{CeO}_{2} 20 \% \mathrm{Gd}$ was substantially less (Table 3.2).

\section{Cellular Interactions with Particles Show Accumulation Over Time}

Enhanced darkfield microscopy was used to visualize $\mathrm{CeO}_{2}$ and $\mathrm{Gd}_{2} \mathrm{O}_{3}$ nanoparticle cellular interactions over a time course of 3 hours. The results demonstrated that all $\mathrm{CeO}_{2}$ nanoparticles and $\mathrm{Gd}_{2} \mathrm{O}_{3}$ accumulated with cells over time (Figure 3.5). Figure 3.5B illustrates that all nanoparticles associated with NR8383 cells more rapidly than RLE-6TN cells.

\section{Super Oxide Radical Scavenging with $\mathrm{CeO}_{2}$ Nanoparticles}

Studies have demonstrated that $\mathrm{CeO}_{2}$ has superoxide dismutase properties [124], thus the effect of doping and alteration in valence state on superoxide scavenging was assessed using a xanthine oxidase/xanthine reaction and spin trap technique. Results showed that all three $\mathrm{CeO}_{2}$ nanoparticles had significant scavenging properties in a 3 minute acellular system; however, the $\mathrm{Gd}_{2} \mathrm{O}_{3}$ positive control did not have this effect (Figure 3.6). 


\section{Hydroxyl Radical Scavenging with $\mathrm{CeO}_{2}$ Nanoparticles}

As a result of the rapid association of nanoparticles with cells (within 5 minutes) and previous studies indicate that $\mathrm{CeO}_{2}$ can induce or scavenge $\operatorname{ROS}[123,124,132]$, superoxide and hydroxyl radical production was measured. To determine whether $\mathrm{CeO}_{2}$ and $\mathrm{Gd}_{2} \mathrm{O}_{3}$ nanoparticles are capable of converting $\mathrm{H}_{2} \mathrm{O}_{2}$ into hydroxyl radicals, acellular Fenton-like reactions were carried out using EPR and a spin trap method. Neither $\mathrm{CeO}_{2}$ (pure and doped) nor $\mathrm{Gd}_{2} \mathrm{O}_{3}$ induced hydroxyl radicals in an acellular system (data not shown). Further, because previous studies have shown $\mathrm{CeO}_{2}$ has scavenging abilities [93], the ability of $\mathrm{CeO}_{2}$ to scavenge hydroxyl radicals was carried out using $\mathrm{H}_{2} \mathrm{O}_{2}$, UV light and a spin trap method. Results showed that pure $\mathrm{CeO}_{2}, \mathrm{CeO}_{2}$ $10 \% \mathrm{Gd}$, and $\mathrm{CeO}_{2} 20 \% \mathrm{Gd}$ had significant antioxidant effects, while $\mathrm{Gd}_{2} \mathrm{O}_{3}$ had no significant effects on induced hydroxyl radicals within 3 minutes in an acellular system (Figure 3.7).

While all three $\mathrm{CeO}_{2}$ nanoparticles did not generate hydroxyl radicals in an acellular system, previous studies have shown that $\mathrm{CeO}_{2}$ induces significant $\mathrm{ROS}$ in vitro $[88,123]$; thus, cellular EPR was completed. The results showed that in RLE-6TN cells, all three $\mathrm{CeO}_{2}$ nanoparticles significantly reduced the presence of hydroxyl radicals; however, in NR8383 cells, only pure $\mathrm{CeO}_{2}$ and $\mathrm{CeO}_{2} 10 \% \mathrm{Gd}$ significantly scavenged the free radicals. In both cell lines, the $\mathrm{Gd}_{2} \mathrm{O}_{3}$ control had no effect (Figures 3.8 and 3.9).

\section{$\mathrm{CeO}_{2}$ Nanoparticle Exposure Effects on Cell Viability}

To measure $\mathrm{CeO}_{2}$ effects on apoptosis and necrosis at 24 hours, an annexin V/ propidium iodide dual stain was used. At 24 hours, no $\mathrm{CeO}_{2}$ nanoparticle affected overall cell viability in RLE$6 \mathrm{TN}$ cells at either $10 \mu \mathrm{g} / \mathrm{ml}$ or $50 \mu \mathrm{g} / \mathrm{ml}$ doses. However, in the population of dead RLE-6TN cells, $\mathrm{CeO}_{2} 10 \% \mathrm{Gd}$ and $\mathrm{CeO}_{2} 20 \% \mathrm{Gd}$ at $10 \mu \mathrm{g} / \mathrm{ml}$ induced significant necrosis (PI positive) 
compared to control cells. Further, $\mathrm{Gd}_{2} \mathrm{O}_{3}$ induced significant apoptosis (annexin $\mathrm{V}$ positive) at $8.95 \mu \mathrm{g} / \mathrm{ml}$ compared to the control (Figure 3.10).

In NR8383 cells, pure $\mathrm{CeO}_{2}$, doped $\mathrm{CeO}_{2}$ and $\mathrm{Gd}_{2} \mathrm{O}_{3}$ nanoparticles had no significant effects on overall cell viability or development of necrosis. However, $\mathrm{Gd}_{2} \mathrm{O}_{3}$ significantly increased the number of cells undergoing apoptosis at a dose of $8.95 \mu \mathrm{g} / \mathrm{ml}$ compared to the control (Figure 3.11).

\section{Discussion}

As industrial interest in the use of $\mathrm{CeO}_{2}$ nanoparticles increases, so will manufacturing and worker exposures. While disagreements exist within the literature as to the nature of $\mathrm{CeO}_{2}$ toxicity, it is almost universally agreed upon that $\mathrm{CeO}_{2}$ affects $\mathrm{ROS}$, theoretically due to its exceptional redox potential. Therefore, this study focused on examining how altering the valence state of $\mathrm{CeO}_{2}$ nanoparticles through doping affects $\mathrm{CeO}_{2}$ toxicity, specifically its effects on ROS generation.

As predicted, the use of $\mathrm{Gd}_{2} \mathrm{O}_{3}$ as a dopant substantially altered the $\mathrm{Ce}^{3+}$ to $\mathrm{Ce}^{4+}$ ratio of the nanoparticles (Table 3.1) [85]. XPS analysis of powder surfaces indicated that doping with $\mathrm{Gd}_{2} \mathrm{O}_{3}$ increased the rate of reduction of $\mathrm{Ce}^{4+}$ to $\mathrm{Ce}^{3+}$, a rate that increased as the concentration of $\mathrm{Gd}_{2} \mathrm{O}_{3}$ increased. $\mathrm{CeO}_{2}$ containing $10 \mathrm{~mol} \% \mathrm{Gd}_{2} \mathrm{O}_{3}$-doped into the nanoparticles had a ratio shift from $16 \%$ to $42 \%$ compared to pure $\mathrm{CeO}_{2}$, while the $20 \mathrm{~mol} \% \mathrm{Gd}_{2} \mathrm{O}_{3}$-doped nanoparticles shifted the ratio from $16 \%$ to $44 \%$. Alternatively, a study completed by Celado et al., showed that doping with samarium $(\mathrm{Sm})$ decreased the amount of $\mathrm{Ce}^{3+}$ in the nanoparticles [83]. This difference in doping outcome may be a result of $\mathrm{Gd}_{2} \mathrm{O}_{3}$ to introduce more $\mathrm{Ce}^{3+}$ oxidation state into the nanoparticle compared to Sm as previously shown [133]. While the effects of doping 
observed in the two studies conflict, our results correlate with the general finding that as doping increases, antioxidant potential decreases. Thus, in conjunction with the works of Celado et al., it appears that the ratio of $\mathrm{Ce}^{3+} / \mathrm{Ce}^{4+}$ is not as crucial in determining antioxidant potential of $\mathrm{CeO}_{2}$ nanoparticles as is the ability of Ce to transition between the two valence states. This transitional ability is hindered following doping since the Ce nanoparticles are forced toward one valence state, and due to the stability of Gd in the lattice structure, unable to transition as easily to the other state [85]. This decreased antioxidant effect was most notable in the cellular EPR model, where $\mathrm{CeO}_{2} 20 \% \mathrm{Gd}$ was significantly different in its scavenging abilities when compared to the pure $\mathrm{CeO}_{2}$ and $\mathrm{CeO}_{2} 10 \% \mathrm{Gd}$ (Figures 3.8 and 3.9). Differences in scavenging ability also existed between the two cell lines; specifically, $\mathrm{CeO}_{2} 20 \% \mathrm{Gd}$ had no significant effect on induced free radicals in NR8383 cells whereas it was able to significantly reduce hydroxyl radical formation in RLE-6TN cells. While this was unexpected, discrepancies between cell lines are not unusual, especially in $\mathrm{CeO}_{2}$ nanoparticle toxicity studies, and may be the result of differences in cellular physiology and function [88, 134]. Thus, in these studies it appears that $\mathrm{CeO}_{2}$ is a less efficient antioxidant in NR8383 cells and that doping has a more pronounced effect on responses of macrophages than those of epithelial cells. The $\mathrm{Gd}_{2} \mathrm{O}_{3}$ had no significant effects on ROS in either EPR model, implying that the antioxidant abilities of the $\mathrm{CeO}_{2}$ are due to the presence of $\mathrm{Ce}^{3+}, \mathrm{Ce}^{4+}$, or oxygen vacancies, and not the dopant.

To ensure that differences in cellular-reactivity were not due to differences in association between the particles and the cells, enhanced dark field microscopy was utilized. All of the nanoparticles were capable of associating with both cell types in a matter of minutes (Figure 3.5), suggesting that the cells would be capable of responding in the short time course conducted in EPR studies, and further, that measured EPR differences were not due to differences in 
cellular association. These results were anticipated based on zeta-potential (Table 3.2), and imply that the presence of Gd did not alter important surface chemistry necessary for interaction of $\mathrm{CeO}_{2}$ with cells. Increased concentrations of $\mathrm{Gd}$ also did not alter the observed size of the nanoparticles (data not shown), implying that differences in reactivity are not a result of differences in size. The hydrodynamic diameters of the $\mathrm{CeO}_{2} 10 \% \mathrm{Gd}$ and $\mathrm{CeO}_{2} 20 \% \mathrm{Gd}$ particles in DM were smaller than the pure $\mathrm{CeO}_{2}$; this difference in hydrodynamic size compared to measured size from SEM is attributed to the sonication of the particle suspensions prior to DLS measurement. Agglomeration is central in nanoparticle-cellular interactions and reactivity [135] and may therefore be important in differences in antioxidant potential; however, differences in toxicity did not exists between the particles as would be expected if agglomeration were important in determining reactivity. This suggests that the differences in antioxidant abilities are due to valence state and transitional ability rather than variances in nanoparticle agglomeration.

None of the three $\mathrm{CeO}_{2}$ nanoparticles induced significant changes in overall cell viability and did not induce apoptosis or necrosis at 24 hours (Figures 3.10 and 3.11). While the lack of differences between the $\mathrm{CeO}_{2}$ nanoparticles was unexpected, numerous studies have shown a lack of $\mathrm{CeO}_{2}$ reactivity at similar doses $[83,89]$ and have accounted this non-toxic effect to $\mathrm{CeO}_{2}$ transitional ability and presence of $\mathrm{Ce}^{3+/ 4+}$. In agreement, Celardo et al., [83] also reported that doping had no effect on cellular viability, again implying that changes in viability measured in other $\mathrm{CeO}_{2}$ nanoparticle studies is not likely a result of valence state.

To further elucidate the effect of $\mathrm{Gd}_{2} \mathrm{O}_{3}$ on differences in $\mathrm{CeO}_{2}$ toxicity, annexin V/ PI dual staining was completed and implied that at a concentration equivalent to the quantity of $\mathrm{Gd}_{2} \mathrm{O}_{3}$ in the $50 \mu \mathrm{g} / \mathrm{ml}$ dose of $\mathrm{CeO}_{2} 20 \% \mathrm{Gd}$, the pure $\mathrm{Gd}_{2} \mathrm{O}_{3}$ caused significant apoptosis at 24 
hours in both cell lines (Figures 3.10 and 3.11). In fact, all three $\mathrm{CeO}_{2}$ nanoparticles did not elicit apoptosis. This implies that Gd did not separate from the doped nanoparticles and interact with the cells to yield the observed effects.

Previous studies have suggested that the valence state of $\mathrm{Ce}$ in $\mathrm{CeO}_{2}$ nanoparticles is important in toxicity and ROS production [82, 122]; however, attempts to elucidate which valence state is important for biological effects are lacking. This study attempted to confirm, through alterations in $\mathrm{CeO}_{2}$ valence state ratio, a specific valence state is a less important determinant of $\mathrm{CeO}_{2}$ reactivity than the presence of mixed valence state and transitional ability. Overall our initial findings suggest that doping does not increase toxicity but appears to inhibit $\mathrm{CeO}_{2}$ antioxidant potential in a rapid cellular exposure in support of our hypothesis. Since $\mathrm{CeO}_{2}$ toxicity results greatly differ between in vitro and in vivo models [39, 82, 90, 136], further studies will need to be completed to determine the effect of valence state on toxicity in vivo. 
Table 3.1. XPS analysis of $\mathrm{Ce}^{3+}$ and $\mathrm{Ce}^{4+}$ ion concentration.

\begin{tabular}{|c|c|c|c|c|c|c|c|}
\hline Samples & $\begin{array}{c}\text { Binding } \\
\text { Energy }(\mathrm{eV})\end{array}$ & $\begin{array}{l}\text { Peak } \\
\text { Height }\end{array}$ & $\begin{array}{l}\text { Peak } \\
\text { Area }\end{array}$ & & {$\left[\mathrm{Ce}^{4+}\right]$} & {$\left[\mathrm{Ce}^{3+}\right]$} & $\mathrm{Ce}^{3+} / \mathrm{Ce}^{4+}$ \\
\hline \multirow{5}{*}{$\mathrm{CeO}_{2}$} & 881.96 & 1382 & 4717 & $\mathrm{Ce}^{4+}$ & \multirow{5}{*}{13981} & \multirow{5}{*}{2363} & \multirow{5}{*}{0.169} \\
\hline & 885.3 & 683 & 2363 & $\mathrm{Ce}^{3+}$ & & & \\
\hline & 888.57 & 625 & 2166 & $\mathrm{Ce}^{4+}$ & & & \\
\hline & 80766 & 1184 & 2085 & $\mathrm{Ce}^{4+}$ & & & \\
\hline & 900.06 & $\begin{array}{l}1104 \\
899\end{array}$ & 3113 & $\mathrm{Ce}^{4+}$ & & & \\
\hline \multirow{6}{*}{$\begin{array}{c}\mathrm{CeO}_{2} \\
10 \% \mathrm{Gd}\end{array}$} & 881.49 & 781 & 1944 & $\mathrm{Ce}^{3+}$ & \multirow{6}{*}{13790} & \multirow{6}{*}{5892} & \multirow{6}{*}{0.427} \\
\hline & 883.02 & 1512 & 4306 & $\mathrm{Ce}^{4+}$ & & & \\
\hline & 886.13 & 1096 & 3948 & $\mathrm{Ce}^{3+}$ & & & \\
\hline & & & & & & & \\
\hline & 889.55 & 838 & 3134 & $\mathrm{Ce}^{4+}$ & & & \\
\hline & 898.42 & 1616 & 6350 & $\mathrm{Ce}^{4+}$ & & & \\
\hline \multirow{6}{*}{$\begin{array}{c}\mathrm{CeO}_{2} \\
20 \% \mathrm{Gd}\end{array}$} & 881.6 & 563 & 1401 & $\mathrm{Ce}^{3+}$ & \multirow{6}{*}{7525} & \multirow{6}{*}{3301} & \multirow{6}{*}{0.439} \\
\hline & 883.33 & 876 & 2181 & $\mathrm{Ce}^{4+}$ & & & \\
\hline & 886.42 & 527 & 1900 & $\mathrm{Ce}^{3+}$ & & & \\
\hline & & & & & & & \\
\hline & 889.92 & 538 & 1938 & $\mathrm{Ce}^{4+}$ & & & \\
\hline & 898.4 & 946 & 3406 & $\mathrm{Ce}^{4+}$ & & & \\
\hline
\end{tabular}


Table 3.2. Characteristic data of pure and doped $\mathrm{CeO}_{2}$ nanoparticles.

\begin{tabular}{lccc}
\multicolumn{1}{c}{ Sample } & $\begin{array}{c}\text { Hydrodynamic } \\
\text { diameter }(\mathrm{nm})\end{array}$ & $\begin{array}{c}\text { Zeta } \\
\text { Potential }\end{array}$ & Surface Area \\
\hline $\mathrm{CeO}_{2}$ & $875 \pm 58$ & $-10.6 \pm 2.4$ & $204.8 \pm 14.6$ \\
$\mathrm{CeO}_{2} 10 \% \mathrm{Gd}$ & $201 \pm 5$ & $-16.3 \pm 2.6$ & $225.4 \pm 34.1$ \\
$\mathrm{CeO} 220 \% \mathrm{Gd}$ & $176 \pm 8$ & $-12.8 \pm 1.6$ & $135.6 \pm 5.6$
\end{tabular}




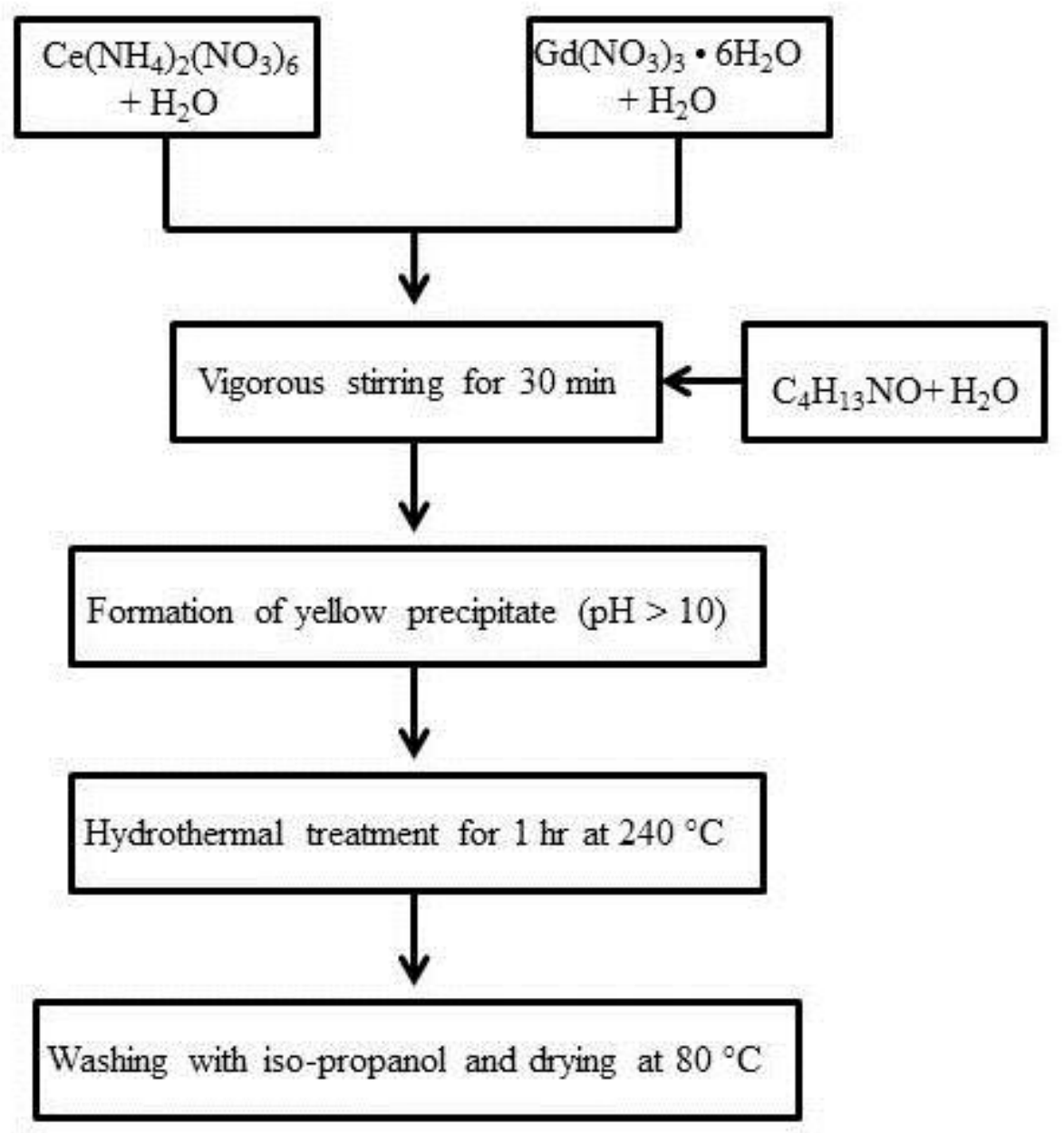

Figure 3.1. Synthesis of $\mathrm{CeO}_{2}$ nanoparticles by a hydrothermal method. 


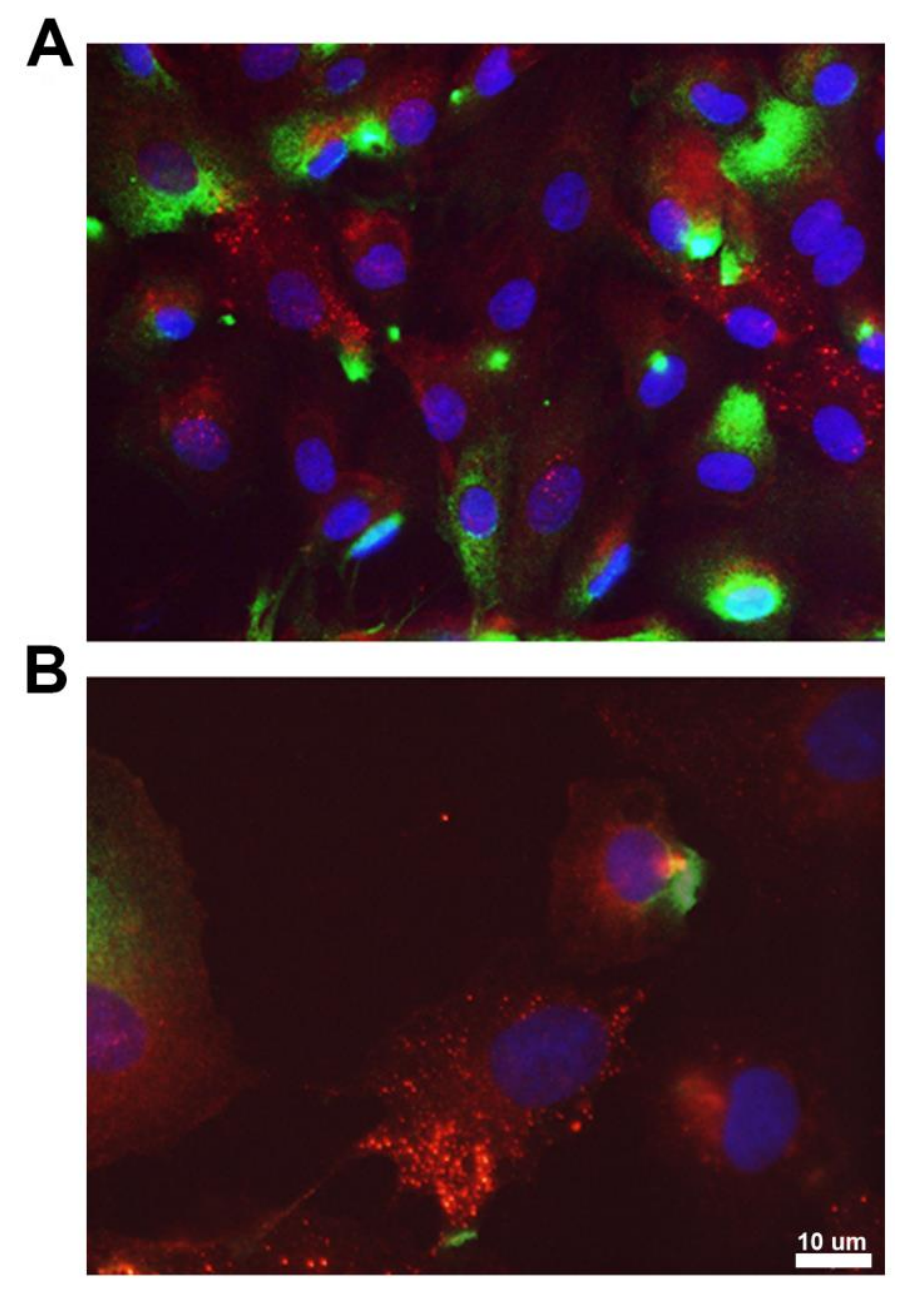

Figure 2. Immunocytochemistry staining of RLE-6TN cells. RLE-6TN cells were grown on coverslips until $80 \%$ confluent, then fixed and stained with antibodies against P180 (Red) and P2RX7 (Green). Coverslips were mounted on slides with Fluoromount G (Dapi) and sealed with nail polish. Cells were imaged at A. 20x and then B. 40x. Scale bar, $10 \mu \mathrm{m}$. 

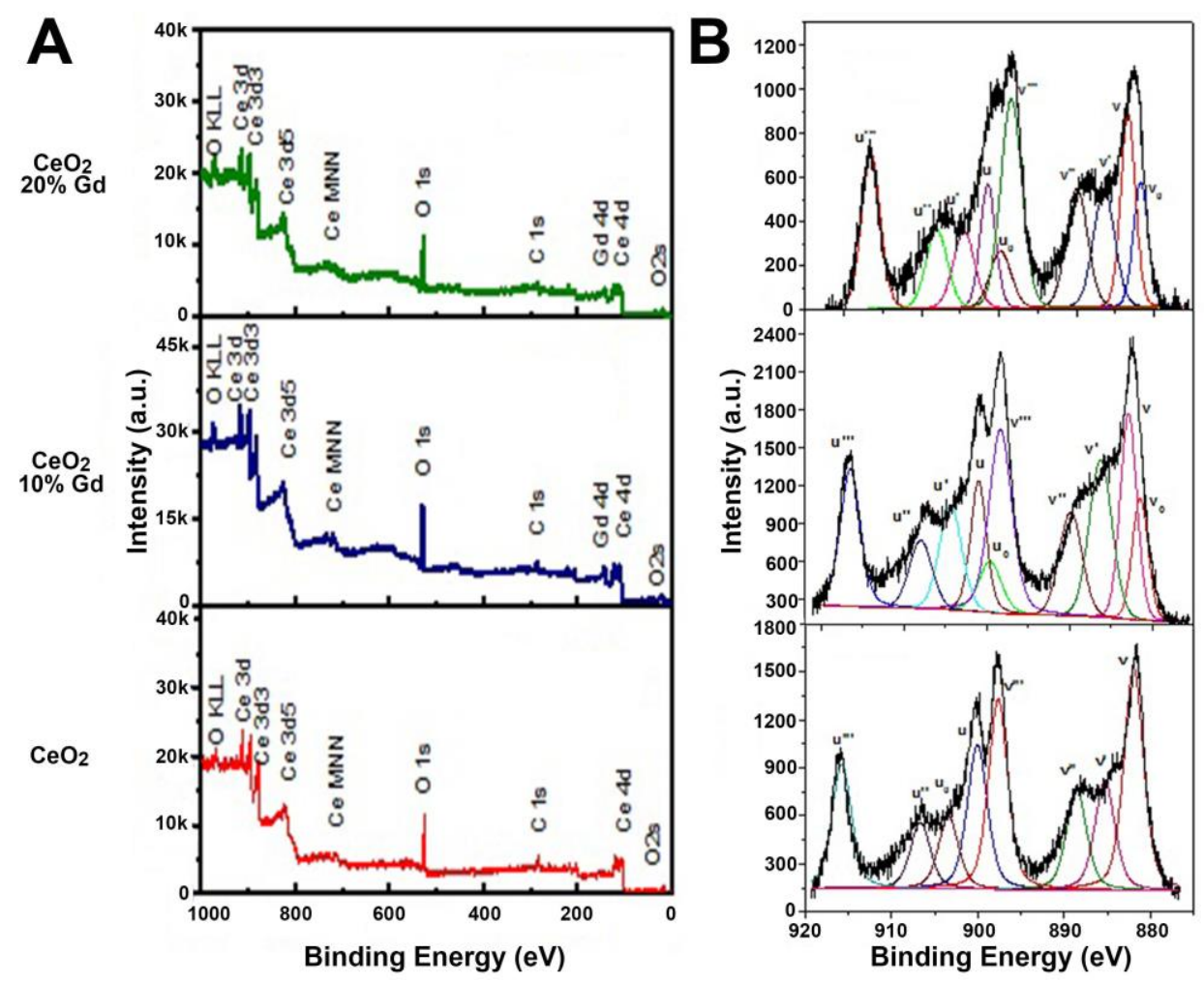

Figure 3.3. XPS survey of $\mathrm{CeO}_{2}$ nanoparticles. A. Wide-scan XPS survey scan spectrum of $\mathrm{CeO}_{2} 20 \% \mathrm{Gd}, \mathrm{CeO}_{2} 10 \% \mathrm{Gd}$, and pure $\mathrm{CeO}_{2}$. B. High resolution XPS spectrum of $\mathrm{CeO}_{2} 20 \%$ $\mathrm{Gd}, \mathrm{CeO}_{2} 10 \% \mathrm{Gd}$, and pure $\mathrm{CeO}_{2}$. 


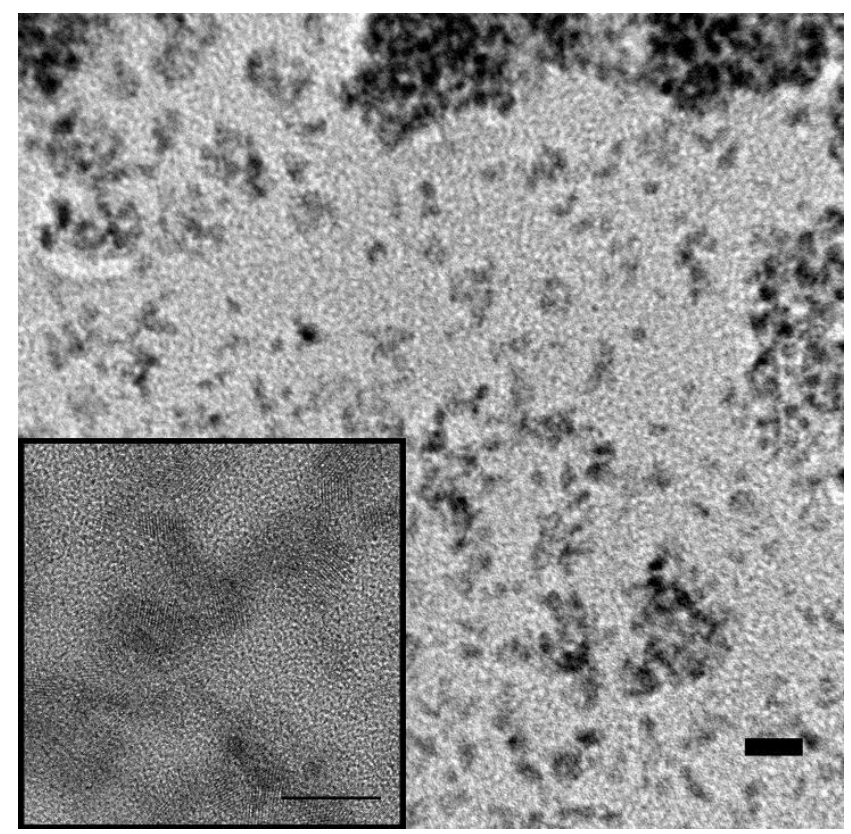

Figure 3.4. TEM images of pure $\mathrm{CeO}_{2}$ nanoparticles. Scale bar, $10 \mathrm{~nm}$. 


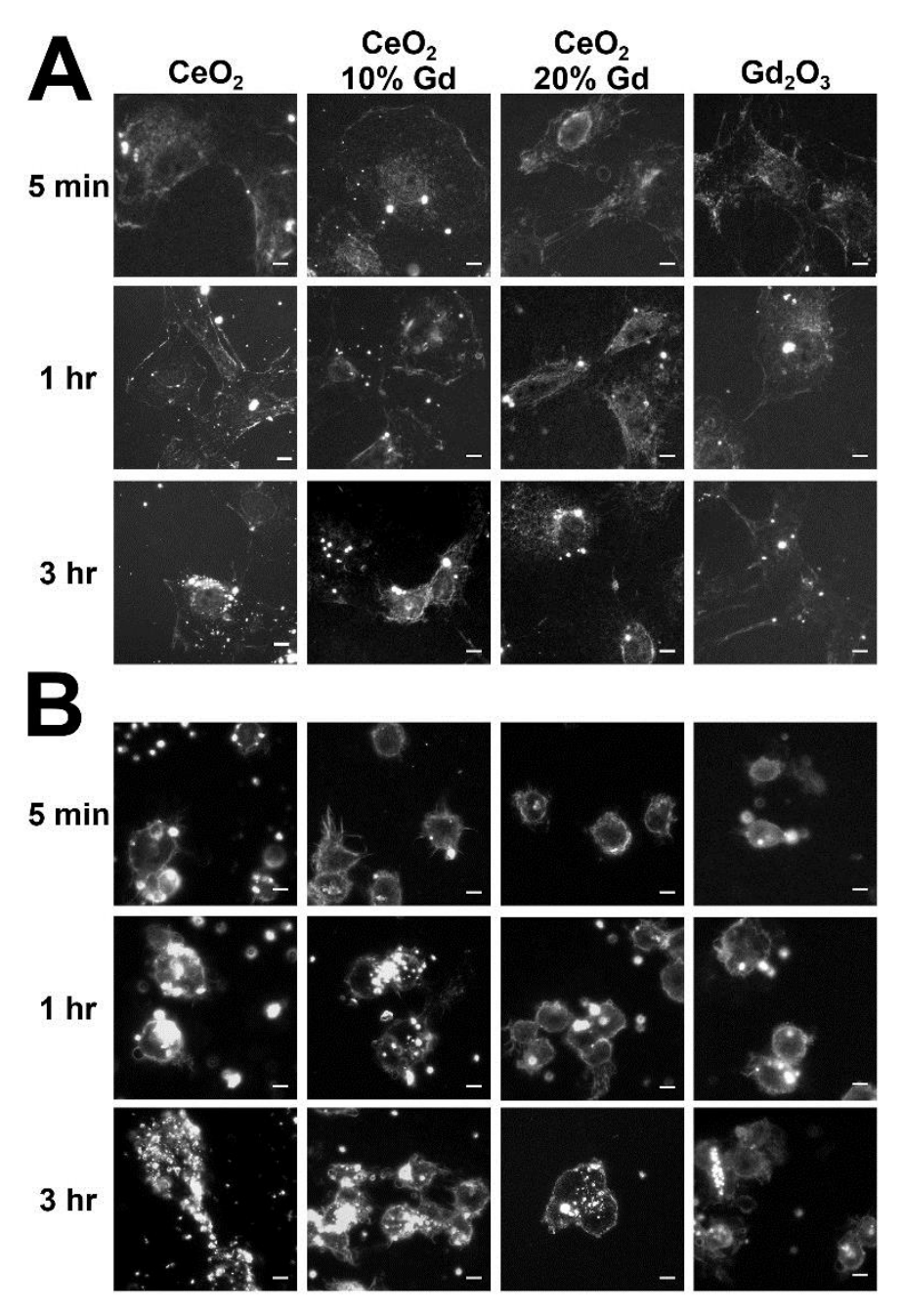

Figure 3.5. Epithelial and macrophage cells associate with $\mathrm{CeO}_{2}$ nanoparticles over a time course. A CytoViva enhanced dark-field microscopy system provides images of high-contrast $\mathrm{CeO}_{2}$ nanoparticles (bright spots) against a dark background of cells. Cells were exposed to $\mathrm{CeO}_{2}$ nanoparticles for 5 minutes, 1 hour, or 3 hours. A. Representative images of RLE-6TN cells associated with $\mathrm{CeO}_{2}$ nanoparticles. B. As in A., except images are representative of NR8383 cells. Scale bar, $5 \mu \mathrm{m}$. 


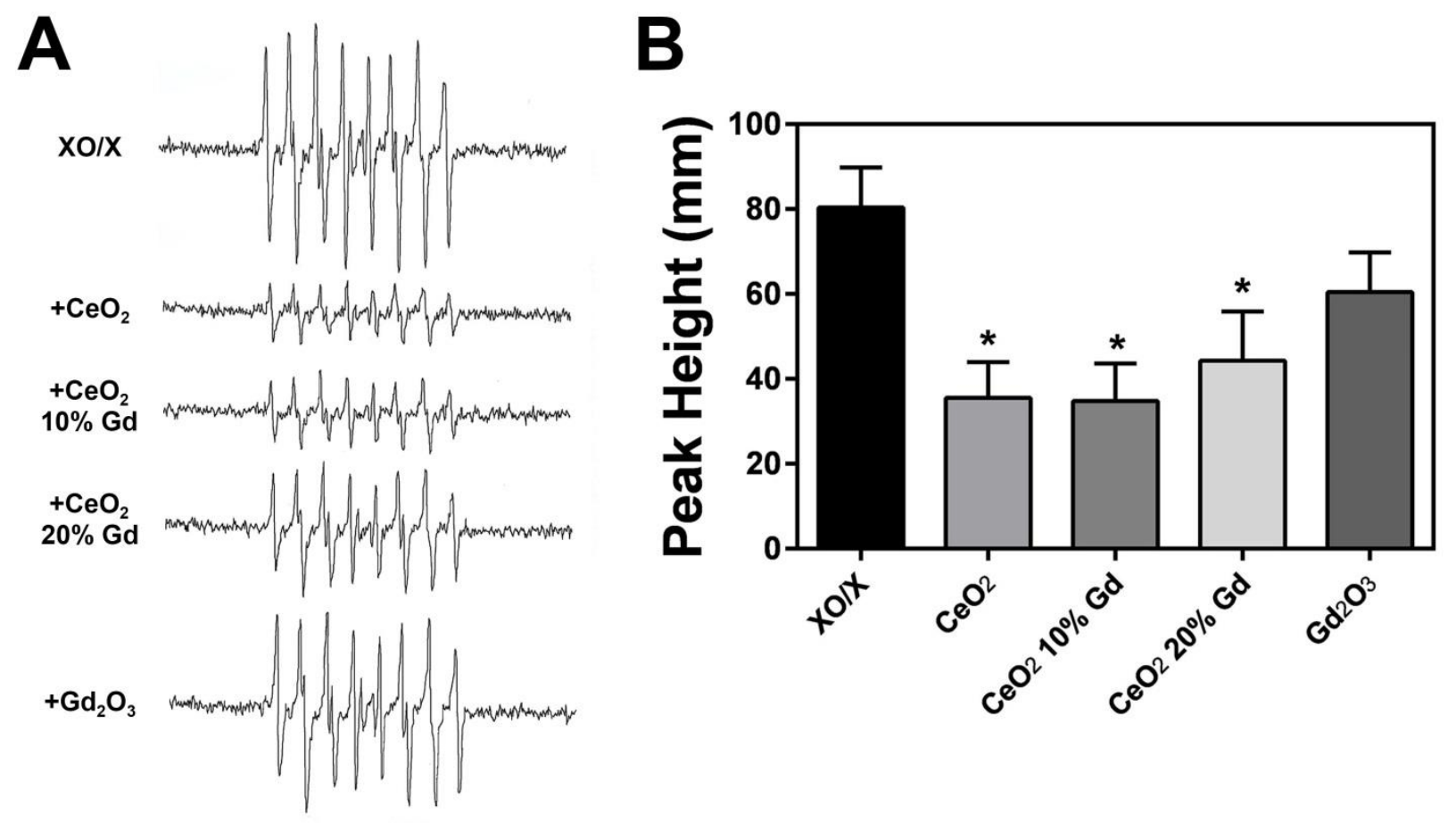

Figure 3.6. $\mathrm{CeO}_{2}$ nanoparticles reduce superoxide radicals. $\mathrm{A}$. $\mathrm{CeO}_{2}$ nanoparticles at $1 \mathrm{mg} / \mathrm{ml}$ $\left(\mathrm{Gd}_{2} \mathrm{O}_{3}\right.$ at $\left.179 \mu \mathrm{g} / \mathrm{ml}\right)$ were combined with50 $\mathrm{mM}$ DEPMPO, $3.5 \mathrm{mM}$ xanthine and $2 \mathrm{U} / \mathrm{ml}$ xanthine oxidase (XO/X) for 3 minutes. EPR setting were: center field, $3490 \mathrm{G}$; scan width, 200 G; time constant, 0.41 s; modulation amplitude, $1 \mathrm{G}$; receiver gain, $2.5 \times 10^{4}$; frequency, 9.8 GHz; and power, $63 \mathrm{~mW}$. Representative spectra for each sample are shown. B. The first, fourth, fifth and eighth peaks were used for measurement of superoxide radical production. Signal intensity was measured in millimeters. Error bars represent the mean \pm standard deviation. $*, p$ $<0.05$ compared to $\mathrm{XO} / \mathrm{X}$. 


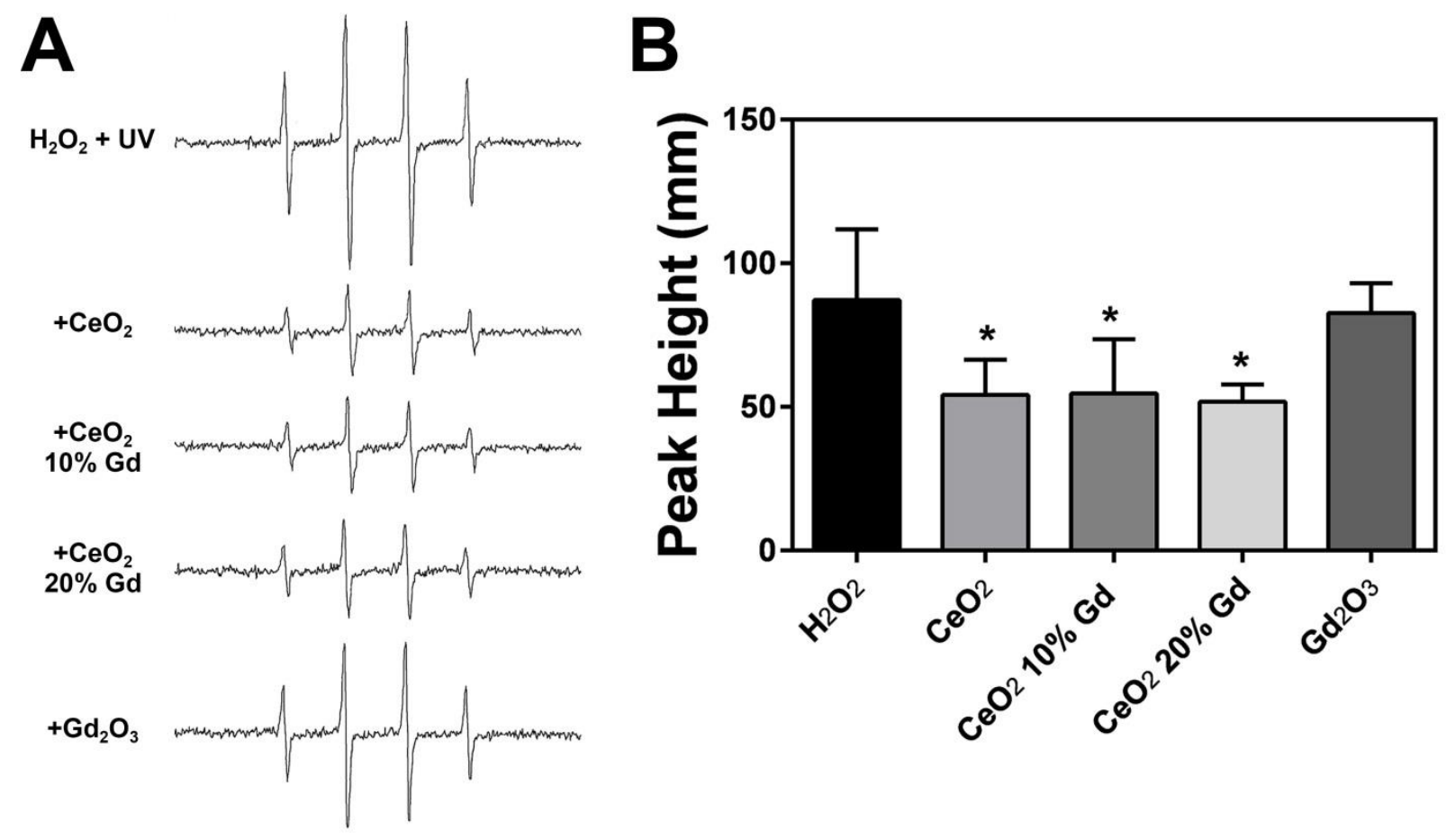

Figure 3.7. $\mathrm{CeO}_{2}$ nanoparticles reduce hydroxyl radicals. $\mathrm{A} . \mathrm{CeO}_{2}$ nanoparticles at $1 \mathrm{mg} / \mathrm{ml}$ $\left(\mathrm{Gd}_{2} \mathrm{O}_{3}\right.$ at $\left.179 \mu \mathrm{g} / \mathrm{ml}\right)$ were combined with $100 \mathrm{mM}$ DMPO and $1 \mathrm{mM} \mathrm{H}_{2} \mathrm{O}_{2}$ then exposed to UV light for 1 minute. EPR setting were: center field, $3487 \mathrm{G}$; scan width, $100 \mathrm{G}$; time constant, 0.41s; modulation amplitude, $1 \mathrm{G}$; receiver gain, $2.5 \times 10^{4}$; frequency, $9.8 \mathrm{GHz}$; and power, 63 $\mathrm{mW}$. Representative spectra for each sample are shown. B. The second and third peaks were used for measurement of hydroxyl radical production. Signal intensity was measured in millimeters. Error bars represent the mean \pm standard deviation. *, $\mathrm{p}<0.05$ compared to $\mathrm{H}_{2} \mathrm{O}_{2}$. 


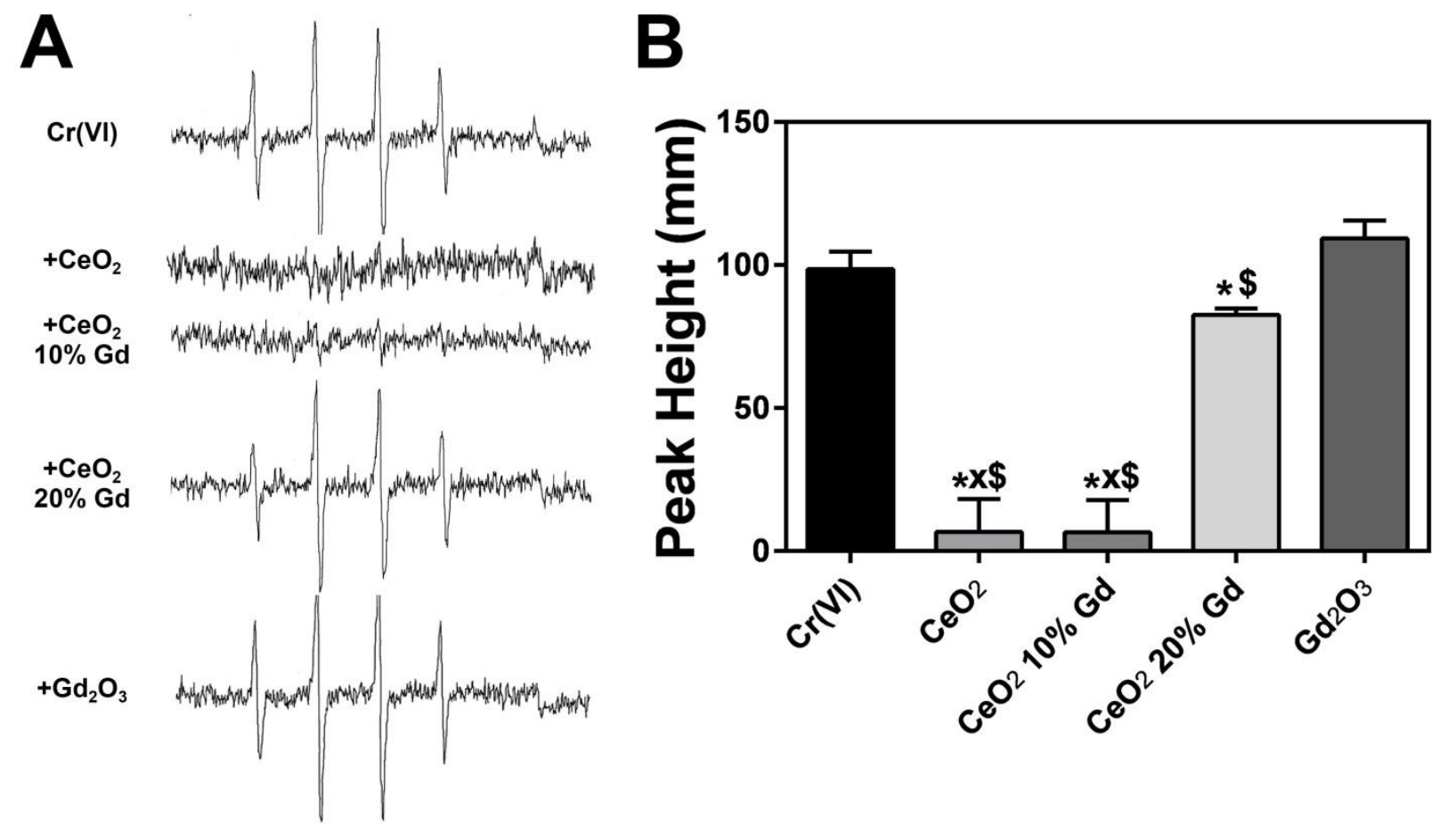

Figure 3.8. $\mathrm{CeO}_{2}$ nanoparticles reduce induced hydroxyl radicals in RLE-6TN cells. A. $\mathrm{CeO}_{2}$ nanoparticles at $1 \mathrm{mg} / \mathrm{ml}\left(\mathrm{Gd}_{2} \mathrm{O}_{3}\right.$ at $\left.179 \mu \mathrm{g} / \mathrm{ml}\right)$ were combined with $200 \mathrm{mM}$ DMPO and $2 \times 10^{6}$ cells $/ \mathrm{ml}$ then incubated for 3 minutes at $37^{\circ} \mathrm{C}$. EPR setting were: center field, $3495 \mathrm{G}$; scan width, $100 \mathrm{G}$; time constant, $0.41 \mathrm{~s}$; modulation amplitude, $1 \mathrm{G}$; receiver gain, $6.3 \times 10^{2}$; frequency, $9.8 \mathrm{GHz}$; and power, $126 \mathrm{~mW}$. Representative spectra for each sample are shown. B. The second and third peaks were used for measurement of hydroxyl radical production. Signal intensity was measured in millimeters. Error bars represent the mean \pm standard deviation. $*, p$ $<0.05$ compared to control, $\mathrm{x}, \mathrm{p}<0.05$ compared to $\mathrm{CeO}_{2} 20 \% \mathrm{Gd}, \$, \mathrm{p}<0.05$ compared to $\mathrm{Gd}_{2} \mathrm{O}_{3}$. 


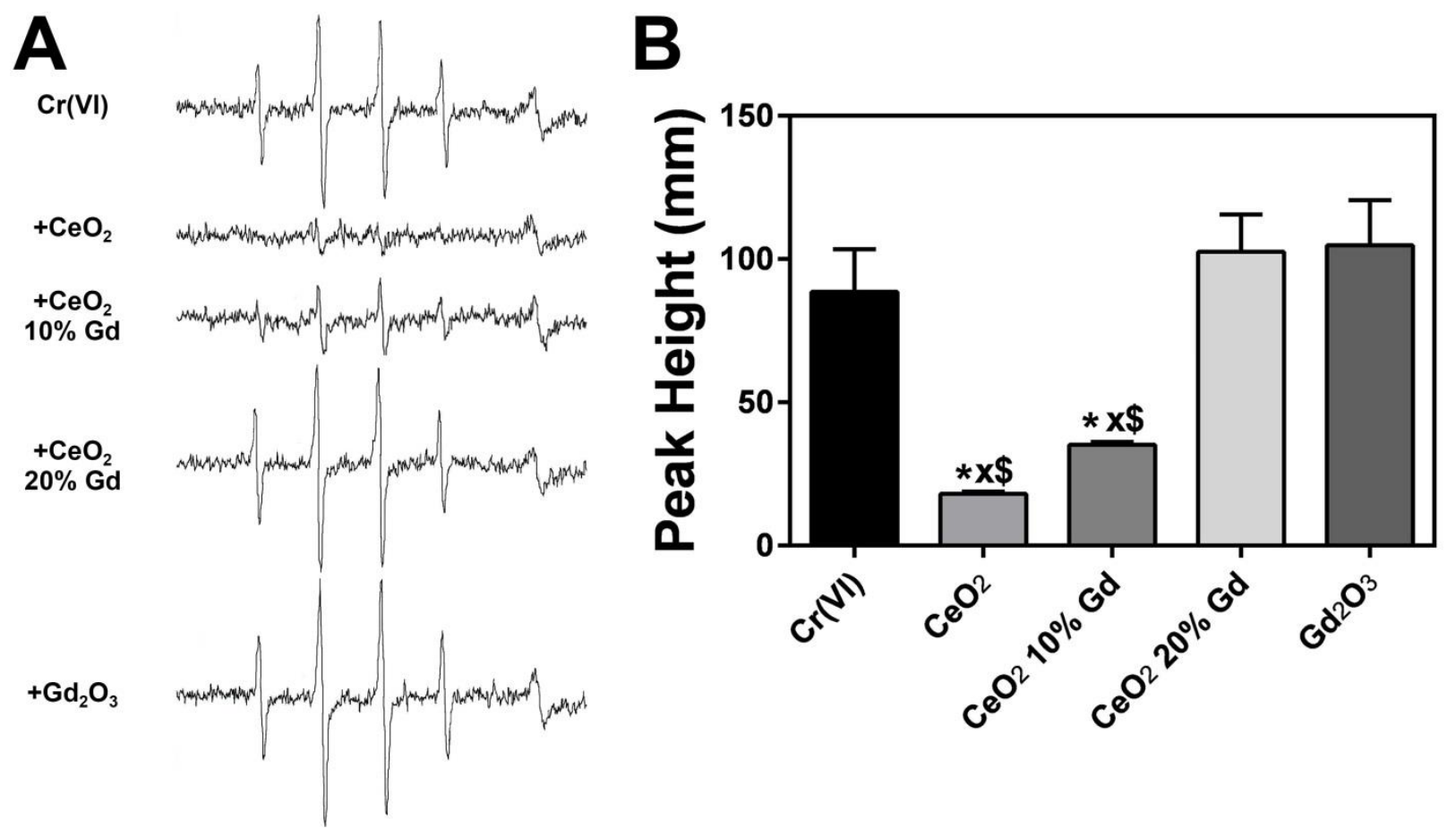

Figure 3.9. $\mathrm{CeO}_{2}$ nanoparticles reduce induced hydroxyl radicals in $\mathbf{N R 8 3 8 3}$ cells. $\mathbf{A} \cdot \mathrm{CeO}_{2}$ nanoparticles at $1 \mathrm{mg} / \mathrm{ml}\left(\mathrm{Gd}_{2} \mathrm{O}_{3}\right.$ at $\left.179 \mu \mathrm{g} / \mathrm{ml}\right)$ were combined with $200 \mathrm{mM}$ DMPO and $2 \times 10^{6}$ cells $/ \mathrm{ml}$ then incubated for 3 minutes at $37^{\circ} \mathrm{C}$. EPR setting were: center field, $3495 \mathrm{G}$; scan width, $100 \mathrm{G}$; time constant, 0.41s; modulation amplitude, $1 \mathrm{G}$; receiver gain, 6.3 x 10²; frequency, $9.8 \mathrm{GHz}$; and power, $126 \mathrm{~mW}$. Representative spectra for each sample are shown. B. The second and third peaks were used for measurement of hydroxyl radical production. Signal intensity was measured in millimeters. Error bars represent the mean \pm standard deviation. *, p $<0.05$ compared to control, $\mathrm{x}, \mathrm{p}<0.05$ compared to $\mathrm{CeO}_{2} 20 \% \mathrm{Gd}, \$, \mathrm{p}<0.05$ compared to $\mathrm{Gd}_{2} \mathrm{O}_{3}$. 

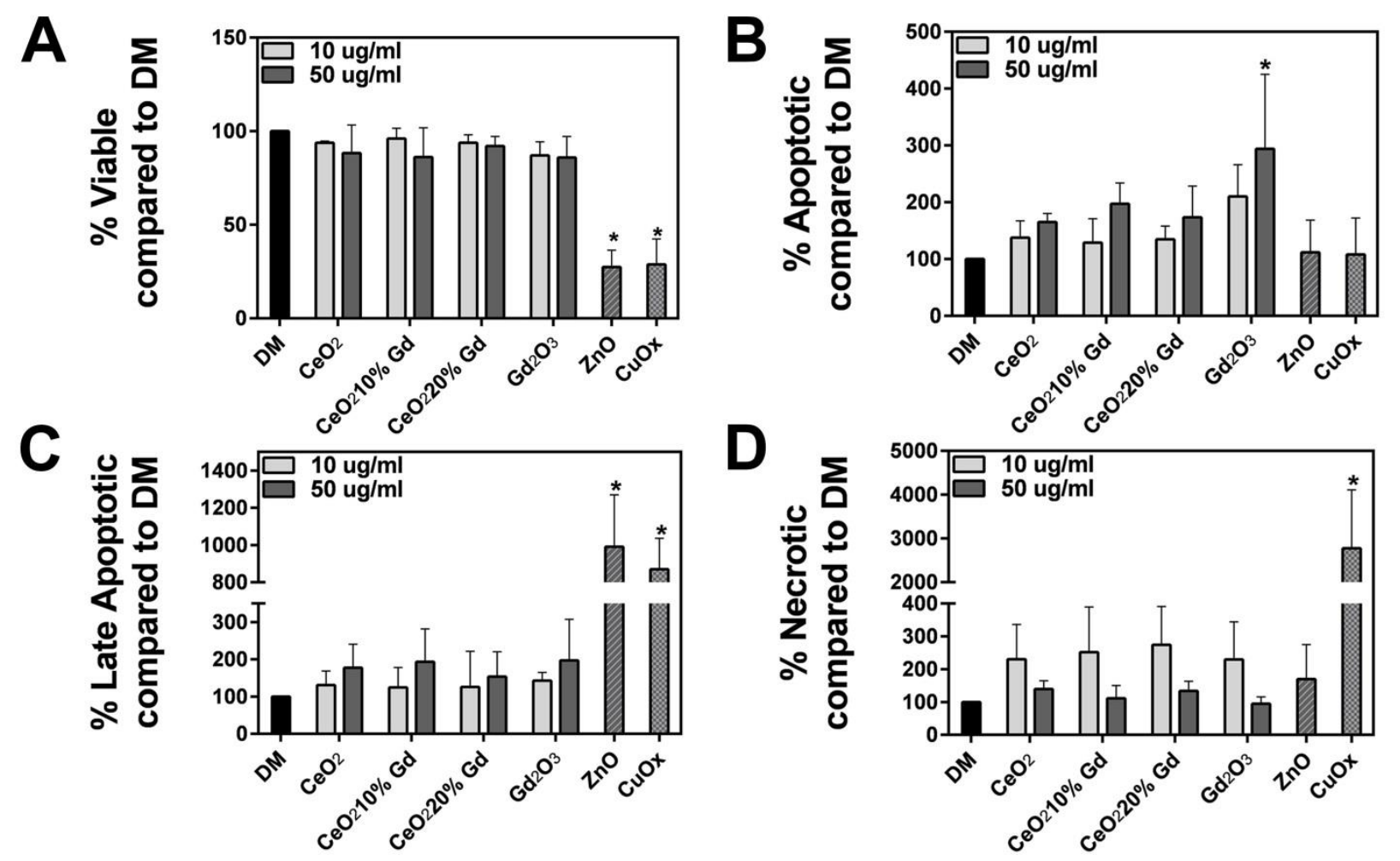

Figure 3.10. $\mathrm{CeO}_{2}$ nanoparticles cause no significant changes in RLE-6TN cell viability at

24 hours. A. RLE-6TN cells were exposed to $\mathrm{CeO}_{2}$ at $10 \mu \mathrm{g} / \mathrm{ml}$ or $50 \mu \mathrm{g} / \mathrm{ml}$ for 24 hours $\left(\mathrm{Gd}_{2} \mathrm{O}_{3}\right.$ at $1.79 \mu \mathrm{g} / \mathrm{ml}$ or $8.95 \mu \mathrm{g} / \mathrm{ml})$. Collected cells were incubated with annexin $\mathrm{V} /$ propidium iodide on ice for 15 minutes then run and 10,000 events were measured. Graph represents cells that were viable after 24 hours. $\mathrm{ZnO}$ and $\mathrm{CuOx}$, at $50 \mu \mathrm{g} / \mathrm{ml}$, were used as positive controls for apoptosis and necrosis respectively and DM was used as a negative control. Error bars represent mean \pm standard deviation. *, $\mathrm{p}<0.05$ compared to control. B. Cells stained positive for annexin V. C. Cells stained positive for both annexin V and propidium iodide. C. Cells stained positive for propidium iodide. 

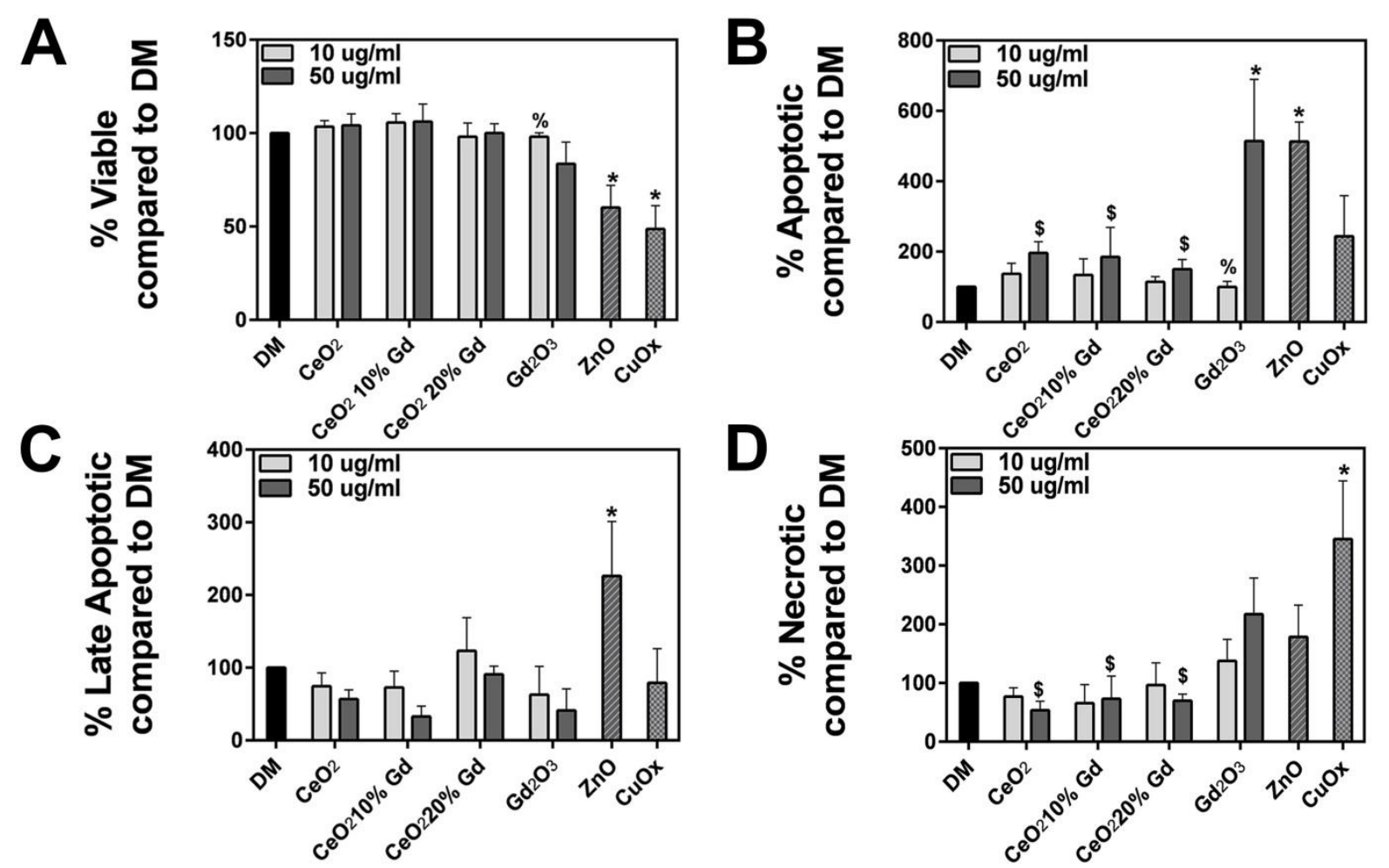

Figure 3.11. $\mathrm{CeO}_{2}$ nanoparticles cause no significant changes in NR8383 cell viability at 24

hours. A. NR8383 cells were exposed to $\mathrm{CeO}_{2}$ at $10 \mu \mathrm{g} / \mathrm{ml}$ or $50 \mu \mathrm{g} / \mathrm{ml}$ for 24 hours $\left(\mathrm{Gd}_{2} \mathrm{O}_{3}\right.$ at $1.79 \mu \mathrm{g} / \mathrm{ml}$ or $8.95 \mu \mathrm{g} / \mathrm{ml})$. Collected cells were incubated with annexin $\mathrm{V} /$ propidium iodide on ice for 15 minutes then run and 10,000 events were measured. Graph represents cells that were viable after 24 hours. $\mathrm{ZnO}$ and $\mathrm{CuOx}$, at $50 \mu \mathrm{g} / \mathrm{ml}$, were used as positive controls for apoptosis and necrosis respectively and DM was used as a negative control. Error bars represent mean \pm standard deviation. *, p <0.05 compared to control, $\%, \mathrm{p}<0.05$ compared to $50 \mu \mathrm{g} / \mathrm{ml}, \$, \mathrm{p}<0.05$ compared to $\mathrm{Gd}_{2} \mathrm{O}_{3}$ at equivalent dose. B. Cells stained positive for annexin V. C. Cells stained positive for both annexin $\mathrm{V}$ and propidium iodide. D. Cells stained positive for propidium iodide. 


\title{
Chapter 4
}

The Effect of Valence State on Cerium Oxide Nanoparticle Toxicity in

\author{
Rats
}




\begin{abstract}
Cerium (Ce), a member of the lanthanide series, is becoming a popular metal oxide for use in mechanical engineering. When in the form of cerium oxide $\left(\mathrm{CeO}_{2}\right)$, Ce can exist in both a $3+$ and 4+ valence state. This makes the particle an ideal catalyst as a result of improved oxygen storage and releasing capacity. For this reason, an increase in the number of consumer products containing $\mathrm{CeO}_{2}$ nanoparticles is expected; thus, understanding the potential toxicity of $\mathrm{CeO}_{2}$ nanoparticles during manufacturing is crucial. Previous in vitro and in vivo evidence has demonstrated that $\mathrm{CeO}_{2}$ has either antioxidant or oxidant-like properties, which is postulated to be due to the nanoparticles ability to transition between $3+$ and $4+$ valence states. Therefore, we chose to chemically modify the nanoparticles through doping in order to shift the valence state toward 3+. Pure $\mathrm{CeO}_{2}$ and two doped nanoparticles, 10 mol\% gadolinium (Gd) and $20 \mathrm{~mol} \% \mathrm{Gd}$, were used for this study. Preliminary characteristics indicated that doping results in minimal size and zeta potential changes but drastic changes in valence state. Following characterization of the nanoparticles, male, Sprague-Dawley rats were exposed to 0.5 and $1.0 \mathrm{mg} / \mathrm{kg}$ nanoparticles via intratracheal instillation. Animals were sacrificed, bronchoalveolar lavage fluid was collected and lung sections were prepared, to determine the effect of valence state on toxicity 1,7 , or 84 days post-exposure. Preliminary results demonstrate that damage, as measured by elevation in lactate dehydrogenase, occurred within 1 day post-exposure and was sustained 7 days postexposure, but subsided to control animal levels 84 days post-exposure. Further, no inflammatory signaling or lipid peroxidation occurred following exposure to any of the nanoparticles. Thus, our results implicate that valence state has a minimal effect on $\mathrm{CeO}_{2}$ nanoparticle toxicity in vivo.
\end{abstract}

Key words: Cerium oxide, nanoparticles, nanotoxicity, intratracheal instillation, valence state 


\section{Introduction}

$\mathrm{Ce}$, the most abundant rare earth metal and a member of the lanthanide series, has been implicated in Ce pneumoconiosis, a restrictive lung disease characterized by severe pulmonary fibrosis and emphysema [137, 138]. Ce-containing rare earth metal dusts, which are used in industry for glass polishing and photoengraving have been associated with severe fibrosis and extensive Ce particle accumulation following medical examination of industry workers. In fact, studies have shown Ce remains within workers' lungs for more than 20 years [139]. Thus, the production of new materials containing $\mathrm{Ce}$, such as cerium oxide $\left(\mathrm{CeO}_{2}\right)$ nanoparticles, necessitates toxicity studies to evaluate potential worker exposure risks and determine ways to improve the safety of Ce-containing products while furthering their use in industry. Previous studies have been completed in vitro and in vivo to determine the potential toxic effects of $\mathrm{CeO}_{2}$ nanoparticles as a means to prevent future human health hazards; however, to date, the literature on $\mathrm{CeO}_{2}$ nanoparticle toxicity is conflicted. Due to the variety of uses for $\mathrm{CeO}_{2}$ nanoparticles, including use in catalysts, solar cells, and gas sensors, as well as use as a diesel fuel additive to reduce emissions and increase engine efficiency [120], toxicity screenings of this nanomaterial and determination of $\mathrm{CeO}_{2}$ pulmonary effects is essential.

Previous in vitro studies of $\mathrm{CeO}_{2}$ nanoparticle toxicity have shown conflicting toxicity results. For example, studies completed in immune cells have reported $\mathrm{CeO}_{2}$ protects against induced apoptosis in U937 cells [83] or acts as an antioxidant under conditions of induced oxidative stress in RAW 264.7 cells [93]. Further, studies conducted in colon cells, indicate $\mathrm{CeO}_{2}$ nanoparticles were capable of preventing radiation induced damage through antioxidantlike properties [136]. Conversely, studies completed in various epithelial cell lines, have implicated that $\mathrm{CeO}_{2}$ either exerts toxicity through ROS production [87, 88, 123] or elicits only 
mild ROS and has antioxidant like properties [93]. These results imply that $\mathrm{CeO}_{2}$ toxicity varies between cell type and within similar cell types. The conflicting in vitro data is theorized to be a result of the ability of Ce to easily transition between $3+$ and $4+$ valence states [82]. When Ce is in the $3+$ valence state, it is hypothesized that it has antioxidant potential, while in the $4+$ valence state it produces free radicals and causes oxidative damage [82, 83, 88]. To assess the importance of valence state in determining $\mathrm{CeO}_{2}$ reactivity and toxicity, a technique known as doping was employed to modulate the electrical properties of the nanoparticles and force them toward a greater $3+/ 4+$ ratio using gadolinium (III) oxide $\left(\mathrm{Gd}_{2} \mathrm{O}_{3}\right)$ [85]. Two doped $\mathrm{CeO}_{2}$ nanoparticles were prepared and used for this study, a 10 and $20 \mathrm{~mol} \% \mathrm{Gd}$ in $\mathrm{CeO}_{2}$. Pure, unaltered $\mathrm{CeO}_{2}$ nanoparticles were also tested in addition to a $\mathrm{Gd}_{2} \mathrm{O}_{3}$ control to ensure any effects seen between compounds were due to valence state and oxygen vacancies rather than the presence of $\mathrm{Gd}_{2} \mathrm{O}_{3}$ [140]. Initial tests were conducted in vitro to determine valence state effects in both RLE-6TN alveolar epithelial and NR8383 alveolar macrophage rat cells [141]. Preliminary in vitro studies, showed valence state had no effect on toxicity, but as doping increased, the antioxidant potential of the nanoparticles decreased [124]. However, due to the lack of differences seen between nanoparticles reactivity, in vivo studies were required to understand if altering valence state affects $\mathrm{CeO}_{2}$ pulmonary toxicity.

While previous studies have been conducted to determine the toxicity of $\mathrm{CeO}_{2}$ nanoparticles following deposition in the lungs of rats, this is the first study to chemically alter the valence state of the nanoparticles and assess changes in reactivity. In vivo studies have shown that $\mathrm{CeO}_{2}$ nanoparticles cause substantial pulmonary damage, induce inflammation, and initiate fibrosis at a range of doses using a variety of exposure methods, including intratracheal (IT) instillation and inhalation. For example, at doses ranging from $0.15 \mathrm{mg} / \mathrm{kg}$ to $7 \mathrm{mg} / \mathrm{kg}$, rats 
presented with markers of fibrosis within 28 days post-IT exposure [40]. A study that exposed rats to $\mathrm{CeO}_{2}$ nanoparticles via mouth/nose inhalation showed similar toxicity results and inflammatory cytokine activation, also presented data that $\mathrm{CeO}_{2}$ significantly increased reactive oxygen species (ROS) production and disrupted antioxidant system. This change in ROS was not detected in comparable in vivo studies $[89,90]$. Based on these discrepancies, both within in vivo and in vitro systems as well as between the two models, understanding how valence state may affect $\mathrm{CeO}_{2}$ toxicity is imperative to ensure safe use in manufacturing.

To determine the effect of valence state and oxygen vacancies on $\mathrm{CeO}_{2}$ reactivity in vivo, Sprague Dawley rats were exposed to pure $\mathrm{CeO}_{2}, 10 \mathrm{~mol} \% \mathrm{Gd}$, or $20 \mathrm{~mol} \% \mathrm{Gd}$ nanoparticles via IT. Rats were sacrificed 1, 7, or 84 days post-one time nanoparticle exposure and overall pulmonary toxicity, ROS, inflammation, and pulmonary changes were assessed.

\section{Materials and Methods}

\section{$\mathrm{CeO}_{2}$ Nanoparticle Production and Characterization}

$\mathrm{CeO}_{2}$ nanoparticle production and characterization was completed by Dr. Ed Sabolsky and Dr. Aleks Stefaniak. Gd-doped $\mathrm{CeO}_{2}$ nanopowder was prepared as previously described [141]. Briefly, a hydrothermal method was used in which cerium (IV) ammonium nitrate and gadolinium nitrate hexa-hydrate were dissolved in deionized water and mixed together. Tetramethyl ammonium hydroxide was added to the mixture until the $\mathrm{pH}$ reached 10 , followed by precipitate formation. The precipitate was washed and hydrothermally treated at $240{ }^{\circ} \mathrm{C}$ for 1 hour to obtain the final nanoparticles.

To determine the relative size of the nanoparticles in phosphate buffered saline (PBS), dynamic light scattering (DLS) was performed using a Nano ZS90 instrument (Malvern 
Instrument; Worcestershire, UK). Prior to sample measurement, sample cells were cleaned, rinsed, and pre-wetted with PBS. Samples were exposed to ultrasonic agitation for 10 minutes using a probe tip to produce a uniform dispersion.

Zeta potential of $\mathrm{CeO}_{2}$ and $\mathrm{Gd}$-doped $\mathrm{CeO}_{2}$ nanoparticles in PBS were determined using a Nano ZS90 instrument (Malver Instruments; Worcestershire, UK). The viscosity of the PBS was determined at room temperature using a VS-10 viscometer (Malvern Instruments) for use in determining zeta potential. Each nanoparticle suspension was sonicated for 10 minutes using a probe tip to produce a uniform dispersion. The Smoluchowski approximation of 1.5 was used for Henry's function and a $\mathrm{pH}$ of 7.5 was determined for the PBS.

\section{Animal Exposures}

Animal IT exposures were completed by Mr. Mark Barger. Male Sprague-Dawley (Hla: SDCVF) rats (6 weeks old) were purchased from Hilltop Laboratories (Scottsdale, PA) and housed in an animal facility accredited by the American Association for Accreditation of Laboratory Animal Care in duplicate in cages individually ventilated with HEPA-filtered air. All animals were exposed and euthanized according to a National Occupational Institute for Occupational Safety and Health approved protocol that complied with the Guidelines for the Care and Use of Laboratory Animals. Following a one week acclimation period, rats were anesthetized with 40 $\mathrm{mg} / \mathrm{kg}$ sodium methohexital (Brevital, Eli Lily and Co.; Indianapolis IN) weighed, and placed on an inclined restraint board. $\mathrm{CeO}_{2}$ nanoparticles, both pure and doped, were exposed to ultrasonic agitation for 5 minutes prior to animal exposure. Nanoparticles were administered via intratracheal instillation at a final concentration of $0.5 \mathrm{mg} / \mathrm{kg} \mathrm{BW}$ or $1.0 \mathrm{mg} / \mathrm{kg} \mathrm{BW}$. PBS was 
administered by intratracheal instillation to control rats. At least 6 animals were treated per group and sacrificed at 1,7 , or 84 days post-exposure.

Because $\mathrm{CeO}_{2}$ nanoparticle exposure does not have a set permissible exposure limit (PEL), animal dosages were selected based on other in vivo studies [39]. Importantly, the doses of $0.5 \mathrm{mg} / \mathrm{kg}$ and $1 \mathrm{mg} / \mathrm{kg}$ represent levels well below PEL levels for nuisance dusts, which $\mathrm{CeO}_{2}$ would be categorized as until a PEL is set for the nanomaterial. In fact, the dosages represent a 3.1 (high dose) or 6.2 (low dose) year worker exposure based on the PEL of $5 \mathrm{mg} / \mathrm{m}^{3}$ for nuisance dusts and deposition rate of 0.8 [142].

\section{Bronchoalveolar lavage}

At 1, 7, and 84 ( $\mathrm{n}=6-7 /$ treatment group) days post-exposure, bronchoalveolar lavage (BAL) was performed to assess lung injury and inflammation. Animals were deeply anesthetized with sodium pentobarbital (>100 mg/kg) and exsanguinated by cutting the abdominal aorta. The lungs

were first lavaged with $6 \mathrm{mls} \mathrm{Ca}^{2+}, \mathrm{Mg}^{2+}$-free PBS, $\mathrm{pH}$ 7.4.The lungs were further lavaged with aliquots of $8 \mathrm{mls}$ PBS until $40 \mathrm{~mL}$ were collected. Lavages were centrifuged at $3000 \mathrm{x} g$ for 10 minutes at $4^{\circ} \mathrm{C}$. Supernatant from the first lavage was collected for lactate dehydrogenase (LDH) and cytokine analysis, while the supernatant from the second lavage was discarded. Cell pellets were then re-suspended in $1 \mathrm{ml}$ PBS and evaluated as described below.

\section{Cellular evaluation}

Total cells numbers were determined using a Beckman Coulter Multisizer 4 Analyzer (Beckman Coulter; Indianapolis, IN). Further, amounts of polymorphonuclear leukocytes (PMN) and alveolar macrophages (AM) were also determined. Cells were differentiated using a Cytospin 4 
centrifuge (Shandon Life Sciences International; Cheshire, England). Briefly, cell suspensions $\left(2 \times 10^{5}\right)$ were spun for 5 minutes at $800 \mathrm{rpm}$ and pelleted onto a slide. 200 cells/rat were then counted following staining with modified Wright-Giemsa stain and the relative abundance of lung AMs, PMNs, lymphocytes, and eosinophils were determined.

Lactate dehydrogenase ( $L D H)$, chemiluminescence $(C L)$, and Electron Paramagnetic Resonance $(E P R)$

LDH measurements were collected by Dr. Melissa Badding, CL measurements were collected by Ms. Anna Morris, and ESR was completed by Dr. Stephen Leonard. Acellular LDH activity from the first BAL fluid was measured to determine general cell damage and toxicity using a COBAS C111 analyzer (Roche Diagnostic Systems; Montclair, NJ). Luminol-dependent CL was completed using cells from the second BAL. CL is a measurement of ROS formation, specifically a measurement of macrophage activity, which was monitored using a Berthold LB953 Luminometer (Berthold; Wildbad, Germany). BAL cell $\left(1 \times 10^{6} \mathrm{AM} / \mathrm{ml}\right)$ luminescence was measured prior and following zymosan ( $2 \mathrm{mg} / \mathrm{ml}$; Sigma Chemical Company; St Louis, MO) stimulation. Zymosan was used for its ability to stimulate and be readily engulfed by activated phagocytic cells [143]. Results are presented as Zymosan-stimulated minus unstimulated cell CL production.

A 5, 5'dimethylpryrroline N-oxide (DMPO) spin trap technique was implemented to form long-lived free radicals that could be detected via EPR to assess the reactivity of the cells from the second lavage. EPR measurements were collected using a flat cell assembly and Bruker EMX spectrometer (Billerica, MA). Second BAL cells $\left(1 \times 10^{6} \mathrm{AM} / \mathrm{ml}\right)$ were combined with 200 mM DMPO (Sigma Aldrich), and $2 \mathrm{mM} \mathrm{Cr}$ (VI) for 3 minutes at $37^{\circ} \mathrm{C}$ prior to hydroxyl radical 
measurement. Instrument settings are indicated in the legend for Figure 4.3. Signal intensity (peak height) was used to measure the relative amount of superoxide radicals produced and is measured in millimeters. All data is presented as peak height fold change above control animal AM response to $\mathrm{Cr}(\mathrm{VI})$

\section{Lipid peroxidation measurements (LPO)}

Following lavage, a segment of the left lung was removed from each animal and immediately placed at $-80^{\circ} \mathrm{C}$ until completion of assay. LPO values were determined according to the manufacturer's protocol (OxisResearch; Beverly Hills, CA) and samples were run in duplicate. Briefly, lung tissue $(100 \mathrm{mg} / \mathrm{ml})$ was combined with ice-cold PBS and butylated hydroxytoluene (50 $\mathrm{mM})$, then homogenized for 30 seconds. Following homogenization, samples were centrifuged at $2500 \mathrm{~g}$ for 10 minutes at $4^{\circ} \mathrm{C}$, then $200 \mu \mathrm{l}$ of clear supernatant was removed and placed in a clean glass tube. After addition of kit-specific reagents and an incubation at $45^{\circ} \mathrm{C}$ for 1 hour, samples were centrifuged at $2500 \mathrm{~g}$ for 10 minutes at room temperature and a clear supernatant was collected and transferred to a glass plate. Absorbance was measured at $586 \mathrm{~nm}$.

\section{Cytokine measurements}

TNF- $\alpha$, IL-8, and IL-6 were determined from primary BAL fluid using enzyme-linked immunosorbent assays (ELISAs) according to the manufacturers protocol (Life Technologies; Grand Island, NY) and samples were run in duplicate. Briefly, lavage fluid was added to an ELISA plate and incubated at room temperature for 1 to 2 hours. Following a wash step, biotinylated antibody was incubated for 1 hour at room temperature. The plate was washed again prior to the addition of the streptavidin HRP for 30 minutes at room temperature. After an 
incubation with the TMB solution, stop solution was added to the plate and absorbance was measured at $450 \mathrm{~nm}$ minus $550 \mathrm{~nm}$.

\section{Pulmonary Collagen Accumulation}

To determine the effect of $\mathrm{CeO}_{2}$ nanoparticles on collagen build-up in the lungs as a marker of fibrosis initiation, a Sir-Col assay (Biocolor Life Science Assays; United Kingdom) was used according to company protocol. Briefly, pulmonary lung tissue was homogenized using a tissue tearor for 30 seconds in a pepsin- $(0.1 \mathrm{mg} / \mathrm{ml})$ acid $(0.5 \mathrm{M}$ acetic acid) solution to help extract collagen from the tissue. The tissue was then incubated overnight in the solution at $4{ }^{\circ} \mathrm{C}$. Following incubation, $100 \mu \mathrm{l}$ of each sample was combined with Sir-Col collagen dye and placed on a shaker for 30 minutes to form a collagen-dye complex. Samples were then centrifuged at 12,000 RPM for 10 minutes and the unbound dye was removed. Following a wash step with an acid-salt solution, samples were centrifuged again, and the excess liquid was removed. An alkali reagent was then added to the samples to solubilize the collagen dye and 100 $\mu 1$ of sample was transferred to a 96 well plate. Absorbance was measured at $555 \mathrm{~nm}$.

\section{Histopathological Examination}

Histopathological examination was performed on lungs, liver, and kidney sections from 84-day post $\mathrm{CeO}_{2}$ nanoparticle or PBS exposed animals using hematoxylin-eosin (H\&E) staining on formalin-fixed tissues. Lung tissue was also stained with Picrosirius Red stain for detection of collagen fibers and fibrosis initiation. Following fixation of tissues in $10 \%$ buffered formalin, tissues were embedded in paraffin wax, sectioned at $5 \mu \mathrm{m}$, mounted on glass slides, and stained. Sections were examined by light microscopy by a board-certified pathologist. 


\section{Statistical analysis}

Data are represented as the mean \pm standard error of the mean (SEM) for each condition. To compare responses between groups, a two-way analysis of variance (ANOVA) and Tukey posttest were performed using GraphPad Prism 6 software (GraphPad Software, Inc.; La Jolla, CA) Statistical significance is shown when $\mathrm{p}<0.05$.

\section{Results}

\section{$\mathrm{CeO}_{2}$ Characteristics}

To determine the relative size of the nanoparticles in PBS, DLS was utilized and showed that all of the nanoparticles agglomerated into micron sized particles (Table 4.1). Previous data showed that these particles were about $5 \mathrm{~nm}$ as-prepared prior to suspension [141], but due to high surface energy of the nanoparticles they quickly agglomerate. Zeta potential results also show a similar trend between the nanoparticle samples, as the values fall within the Riddick category of delicate dispersion [131]. Further, data suggests that doping the nanoparticles drastically altered

their valence state from $16.9 \% \mathrm{Ce}^{3+}$ in pure $\mathrm{CeO}_{2}$ to $42.7 \% \mathrm{Ce}^{3+}$ in $\mathrm{CeO}_{2} 10 \% \mathrm{Gd}$ and $43.9 \%$ $\mathrm{Ce}^{3+}$ in $\mathrm{CeO}_{2} 20 \%$ Gd (Table 3.1).

\section{$\mathrm{CeO}_{2}$ Nanoparticles Effects on Pulmonary Cellular Influx}

To determine the effect of $\mathrm{CeO}_{2}$ nanoparticles on pulmonary cell number, total cell counts, macrophage counts, and PMN counts were completed on primary lavage cells. One day postexposure, all three nanoparticle types induced mild increases in total cells, macrophages, and PMNs, however these increases were not significant. By 7 days post-exposure all three nanoparticle types at both doses caused a significant influx of PMNs into the pulmonary 
environment, while only the low exposure dose resulted in increased macrophage presence. By 84 days post-exposure, all cell counts returned to normal with the exception of the high dose of $\mathrm{CeO}_{2} 20 \%$ Gd (Figure 4.1). Cell differentials showed a similar recovery response and change in pulmonary cellular composition over the 84 day experiment. BAL composition changed from mainly macrophages to greater than $50 \%$ PMNs following exposure to both pure $\mathrm{CeO}_{2}$ nanoparticles and $\mathrm{CeO}_{2} 10 \% \mathrm{Gd}$ (Figure 4.2). $\mathrm{CeO}_{2} 20 \% \mathrm{Gd}$ significantly lowered the amount of macrophages and significantly increased the amount of PMNs relative to PBS control treated animals but had a less severe effect on cellular composition 1 day post-exposure. Cell differentials showed that pure $\mathrm{CeO}_{2}$ nanoparticles had a significantly more pronounced effect on cellular composition compared to both $\mathrm{CeO}_{2} 10 \% \mathrm{Gd}$ and $\mathrm{CeO}_{2} 20 \% \mathrm{Gd} 7$ days-post IT. By 84 days post-exposure, BAL cellular composition returned to normal with the exception of the $\mathrm{CeO}_{2}$ 20\% Gd, which caused a persistent effect on macrophages (Figure 4.2C).

$\mathrm{CeO}_{2}$ Nanoparticle Effects on Pulmonary Toxicity and Phagocytic Cell Activity

To determine the general toxic effects of $\mathrm{CeO}_{2}$ nanoparticle exposure, $\mathrm{LDH}$ levels were measured. Results demonstrate that damage peaked at 7 days-post exposure and returned to baseline damage by 84 days with the exception of $\mathrm{CeO}_{2} 20 \%$, which induced persistent damage (Figure 4.1A).

To determine phagocytic cell responsiveness and ROS production, EPR was utilized. Results indicate that phagocytic cells did not produce hydroxyl radicals in the absence of stimulus following exposure to any of the nanoparticles. However, results implicate that following treatment with $\mathrm{Cr}(\mathrm{VI})$, phagocytic cells from the three $\mathrm{CeO}_{2}$ groups at 7 days postexposure BAL produced significant levels of hydroxyl radicals compared to control treated 
animal BAL cells. Results also indicate that $\mathrm{CeO}_{2} 20 \% \mathrm{Gd}$ significantly affected the ability of the phagocytic cells to respond to $\mathrm{Cr}$ (VI) 84 days-post exposure (Figure 4.3B). To further determine cellular activity a chemiluminescence (CL) assay was also utilized to measure ROS formation [40]. Results implicate that 1 day post-exposure, BAL cells significantly responded to zymosan stimulation, but over time BAL cells produced less ROS, and by 84 days post-exposure minimal ROS production was detected (Figure 4.3A).

$\mathrm{CeO}_{2}$ Nanoparticle Exposure does not Result in Lipid Peroxidation (LPO)

To determine free radical generation following nanoparticle exposure, LPO levels were determined in pulmonary tissue through measurement of MDA as an end product of persistent free radical damage. Results indicate that none of the nanoparticles induced significant LPO following pulmonary exposure, even 84 days post nanoparticle exposure (Figure 4.4).

\section{$\mathrm{CeO}_{2}$ Nanoparticle Effect on Inflammatory Cytokines}

To determine the inflammatory effects of $\mathrm{CeO}_{2}$ nanoparticles following pulmonary exposure, IL6 , TNF- $\alpha$, and IL-1 $\beta$ levels were detected in BAL fluid. Results indicate that all 3 nanoparticles did not induce significant inflammatory cytokines at any of the collected time points (Figure 4.5).

\section{$\mathrm{CeO}_{2}$ Nanoparticle Effect on Collagen Formation in Lung Tissue}

To determine the effect of $\mathrm{CeO}_{2}$ nanoparticles on collagen formation in pulmonary tissue as a measurement of fibrosis initiation, a Sir-Col assay was utilized. Results indicate that nanoparticles caused a slight, but not significant increase in the amount of collagen in the lungs compared to control treated animals after 84 days post-exposure (Figure 4.6). 


\section{$\mathrm{CeO}_{2}$ Nanoparticle Effect on Cellular Influx and Fibrosis in Organs}

To determine the effect of $\mathrm{CeO}_{2}$ on alveolar macrophage and granular material accumulation in airways, $\mathrm{H} \& \mathrm{E}$ staining was utilized in lung sections from animals exposed to $\mathrm{CeO}_{2}$ nanoparticle materials 84 days post-exposure. Results indicate that all $\mathrm{CeO}_{2}$ nanomaterials caused an influx of macrophage (multifocal and diffuse) accumulation in the airways and mononuclear cell infiltration in the alveolar septae at both $0.5 \mathrm{mg} / \mathrm{kg}$ and $1 \mathrm{mg} / \mathrm{kg}$ doses compared to PBS treated animals. Lung lesion severity was generally greater in $\mathrm{CeO}_{2} 20 \% \mathrm{Gd}$ exposed animals, however there was not a consistent difference in the incidence or severity of lung changes among the animals, making determination of Gd impact difficult to interpret. No significant differences were noted between groups at equivalent doses but there was greater severity of lung lesions in animals exposed to $1 \mathrm{mg} / \mathrm{kg}$ compared to those exposed at $0.5 \mathrm{mg} / \mathrm{kg}$ (Figure 4.7A, Table 4.2). Sirius Red staining was also used on lung tissue to determine fibrosis initiation. Due to issues with fixation, the thickening noted by the stain is likely due impart to insufficient fixation and thus results that $\mathrm{CeO}_{2}$ induced fibrosis should be interpreted conservatively (Figure 4.7B, Table 4.2). To determine the potential for $\mathrm{CeO}_{2}$ nanomaterials to cause damage in other organs, kidney and liver sections were stained with $\mathrm{H} \&$ E. No significant changes in liver or kidney were noted (Table 4.2).

\section{Discussion}

As interest in $\mathrm{CeO}_{2}$ nanoparticles increase for industrial use, subsequent worker exposures will also increase. The purpose of this study was to determine if doping, a process which alters the valence state of $\mathrm{Ce}$ from $4+$ to $3+$, could decrease pulmonary toxicity of $\mathrm{CeO}_{2}$ 
nanoparticles. Specifically this study assessed how changes in valence state would affect pulmonary cellular influx, overall damage, inflammation, and fibrosis.

As previously shown, doping substantially altered the $\mathrm{Ce}^{3+} / \mathrm{Ce}^{4+}$ ratio from $16 \%$ in the pure $\mathrm{CeO}_{2}$ nanoparticles to $42 \%$ in the $10 \mathrm{~mol} \%$ doped and to $44 \%$ in the $20 \mathrm{~mol} \%$ doped [141]; however, in disagreement with the hypothesis, valence state did not have dramatic effects on the toxicity and reactivity of $\mathrm{CeO}_{2}$ nanoparticles following pulmonary instillation. While the overall effect of valence state on toxicity is unclear, it did appear that the $\mathrm{CeO}_{2} 20 \%$ had persistent effects on cell influx and pulmonary damage not measured in animals exposed to pure $\mathrm{CeO}_{2}$ or $\mathrm{CeO}_{2} 10 \%$ nanoparticles. Interestingly, $\mathrm{CeO}_{2} 20 \% \mathrm{Gd}$ had less of an immediate effect on $\mathrm{LDH}$ levels and cellular influx compared to pure $\mathrm{CeO}_{2}$ and $\mathrm{CeO}_{2} 10 \% \mathrm{Gd}$ (Figure 4.1). Alternatively, histopathology results indicate no significant difference in alveolar macrophage and granular material accumulation in alveoli between the $\mathrm{CeO}_{2}$ groups as expected from cell counting results (Figure 4.7A). As previously shown in our in vitro studies, valence state may be less important in determining nanoparticle reactivity since the valence states between the doped samples were very similar [141]. Therefore, the process of doping may prevent the nanoparticles from switching between valence states, a trait believed to be necessary for $\mathrm{CeO}_{2}$ to act as an antioxidant, which may affect their reactivity in the pulmonary environment. Further, an additional set of animals were exposed to $\mathrm{Gd}_{2} \mathrm{O}_{3}$ alone to ensure any effects measured were due to valence state or transitional ability, rather than the presence of $\mathrm{Gd}$ in the doped nanoparticle samples. Data implicates that $\mathrm{Gd}_{2} \mathrm{O}_{3}$ at a dose equivalent to the amount of $\mathrm{Gd}$ present in the $\mathrm{CeO}_{2} 20 \% \mathrm{Gd}$ sample $(179 \mu \mathrm{g} / \mathrm{kg})$, did not have significant effects on LDH or pulmonary cell influx by 84 day-exposure (data not shown). This implies that the effects caused by $\mathrm{CeO}_{2} 20 \%$ 
Gd are due to differences in surface reactivity and the nanoparticle's valence state rather than the presence of $\mathrm{Gd}$.

Further, while other studies have shown $\mathrm{CeO}_{2}$ induces inflammatory cytokine activation following IT and inhalation exposure, none of the nanoparticle samples induced any significant inflammatory cytokines over the time course regardless of the severe pulmonary PMN and macrophage influx [40, 90] (Figure 4.5). The lack of cytokine activation may be due to differences in collection procedure, as cytokines from this study were measured directly from BALF rather than measured from media collected from plated BAL cells [40]. Additionally, differences in dose and exposure route may also account for a lack of inflammatory cytokine signaling measured in this study [90].

To determine BAL phagocytic cell activity, EPR and chemiluminescence were implemented. As previously shown by $\mathrm{Ma}$ et al. (2011), $\mathrm{CeO}_{2}$ severely affects AM responsiveness at 1 day post-exposure; however, this response diminishes by 84 days postexposure [40]. To determine if this responsiveness also results in increased ROS production, cells were exposed to $\mathrm{Cr}$ (VI) and free radical production was assessed via EPR. Unlike chemiluminescence results, EPR results implicated that cells were more responsive 7 days postexposure. This may be due to a shift in phagocytic cell population from mainly PMNs to a mixture of PMNs and macrophages (Figure 4.2). Interestingly, by 84 days post-exposure, $\mathrm{CeO}_{2}$ $20 \%$ Gd exposed phagocytic BAL cells were significantly hindered in their ability to respond to Cr (VI) exposure compared to PBS control treated animals. By 84 days post-exposure, the cells in the BAL may be spent due to continued presence of $\mathrm{CeO}_{2} 20 \% \mathrm{Gd}$ nanoparticles, as noted by persistent damage (Figure 4.1), and therefore less responsive to further stimulus. Conversely, at 
1 and 7 days post-exposure, the phagocytic cells are extremely responsive, as noted by chemiluminescence (Figure 4.3).

Due to the effect of $\mathrm{CeO}_{2}$ on ROS, a downstream endpoint of ROS was assessed to determine the effect of valence state on $\mathrm{CeO}_{2}$ oxidative potential in vivo. Previous studies have shown that following $\mathrm{CeO}_{2}$ inhalation in $\mathrm{CD} 1$ mice, significant changes in LPO and glutathione levels occur [144]; however, our study implicates that none of the nanoparticles induced significant oxidative lung injury as measure by LPO formation in lung tissue (Figure 4.4). This is further supported by the lack of free radical production measured by ESR in the absence of $\mathrm{Cr}$ (VI) as a stimulus (data not shown). These differences may be due to the exposure route, dose, and in vivo model system.

To determine fibrosis initiation, a Sir-Col assay was utilized to measure collagen formation in lung tissue 84 days post-exposure as a supplementary assay to histochemical staining. Results implicate that $\mathrm{CeO}_{2}$ nanoparticles caused slight increases in collagen formation in lung tissue; however, these increases were not significant compared to $0 \mathrm{mg} / \mathrm{kg}$ treated control animals (Figure 4.6). Further, Sirius Red staining was used on lung tissue collected from 84 day post-exposure animals to detect changes in collagen[145]. While some thickening was visualized in the parenchyma near the ends of the lung lobes (Figure 4.7B), this is typically due to incomplete inflation during the fixation process rather than true fibrosis. Therefore, diagnoses of the alveolar septal thickening and fibrosis initiation should be interpreted conservatively. Previous in vivo studies, as well as retrospective human studies, have implicated that $\mathrm{CeO}_{2}$ nanoparticles are capable of inducing pulmonary fibrosis $[39,138]$, therefore we anticipated a significant increase in lung collagen following exposure to the various $\mathrm{CeO}_{2}$ nanoparticles in this study. However, it is possible that due to the low doses used in our study compared to previous 
in vivo studies that the animals were able to prevent long-term damage following exposure (Figure 4.1). Further, because human studies have shown that Ce remains in the pulmonary environment for more than 30 years [137], it is possible that an increased post-exposure time would have presented data that overtime the nanoparticles induce changes in collagen production and overall pulmonary health.

Previous studies have suggested that valence state of $\mathrm{CeO}_{2}$ determines the potential toxicity of the nanoparticles; however, our findings do not indicate a direct correlation between valence state and toxicity over an 84 day time course. In fact, initial exposure to pure $\mathrm{CeO}_{2}$ (greater $\mathrm{Ce}^{4+}$ ), induced greater damage initially, but doped $\mathrm{CeO}_{2}\left(\right.$ greater $\mathrm{Ce}^{3+}$ ) caused persistent pulmonary injury. Due to differences between the two doped nanoparticles, it is likely that the transitional ability of $\mathrm{CeO}_{2}$, which is inhibited by $\mathrm{Gd}$ doping, determines its reactivity, rather than a specific valence state. Therefore, further studies are necessary to determine the mechanisms by which doped $\mathrm{CeO}_{2}$ causes less toxicity initially but induces persistent damage overtime. Further, numerous studies have reported that $\mathrm{CeO}_{2}$ has protective effects in vitro and in vivo against induced damage [56, 146, 147], therefore an in vivo study in which damage is induced prior to $\mathrm{CeO}_{2}$ exposure may allow elucidation of differences in reactivity between doped and pure nanoparticles. 
Table 4.1. Nanoparticle characteristics in PBS.

\begin{tabular}{ccc} 
Nanoparticle & $\begin{array}{c}\text { Hydrodynamic } \\
\text { diameter }(\mathrm{nm})\end{array}$ & $\begin{array}{c}\text { Zeta } \\
\text { potential }\end{array}$ \\
\hline $\begin{array}{c}\mathrm{CeO}_{2} \\
\mathrm{CeO}_{2} 10 \%\end{array}$ & $1166 \pm 74$ & $-32.1 \pm 3.0$ \\
$\mathrm{Gd}$ & $2078 \pm 32$ & $-26.9 \pm 4.1$ \\
$\mathrm{CeO}_{2} 20 \%$ & & $-23.4 \pm 1.8$ \\
$\mathrm{Gd}$ & $2436 \pm 56$ & \\
\hline
\end{tabular}




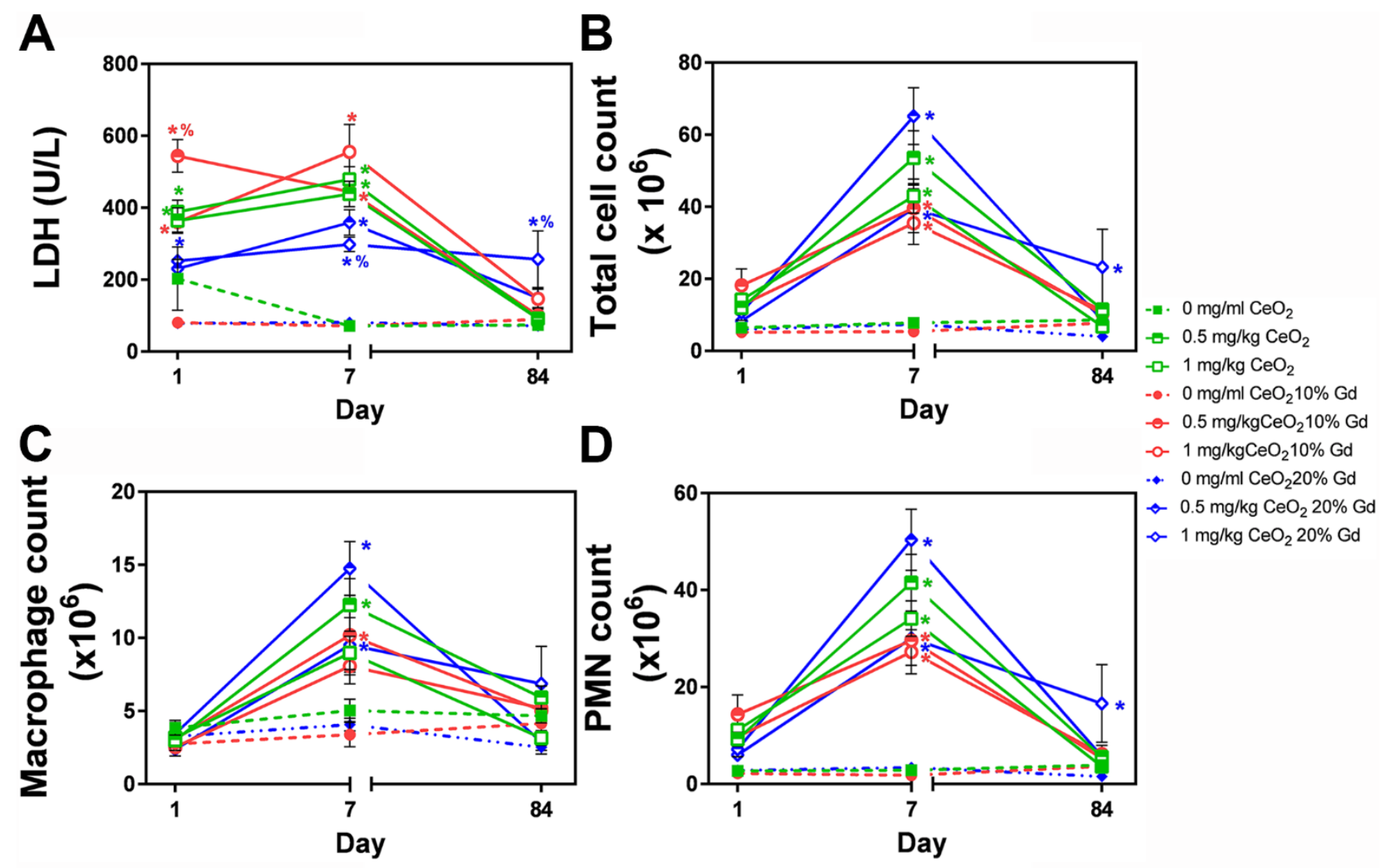

Figure 4.1. Lactate dehydrogenase (LDH) levels and inflammatory cell counts in rat BALF over a time course of 84 days post-IT exposure. A. LDH concentration in BALF 1, 7, and 84 days post-CeO $\mathrm{Ce}_{2}$ nanoparticle exposure. Square $\left(\mathrm{CeO}_{2}\right)$, circle $\left(\mathrm{CeO}_{2} 10 \% \mathrm{Gd}\right)$, triangle $\left(\mathrm{CeO}_{2}\right.$ $20 \%$ ) symbols represent mean \pm SEM $(\mathrm{n}=6-7$ rats/group). PBS vehicle control animals are represented by hashed lines. *, $\mathrm{p}<0.05$ compared to $0 \mathrm{mg} / \mathrm{kg}$ controls on corresponding day, $\%$, $\mathrm{p}<0.05$ compared to pure $\mathrm{CeO}_{2}$ on corresponding day. B. From the BALF in A. total cells at 1 , 7, and 84 days post-exposure. C. As in B, except macrophages were counted. D. As in B, except PMNs were counted. 

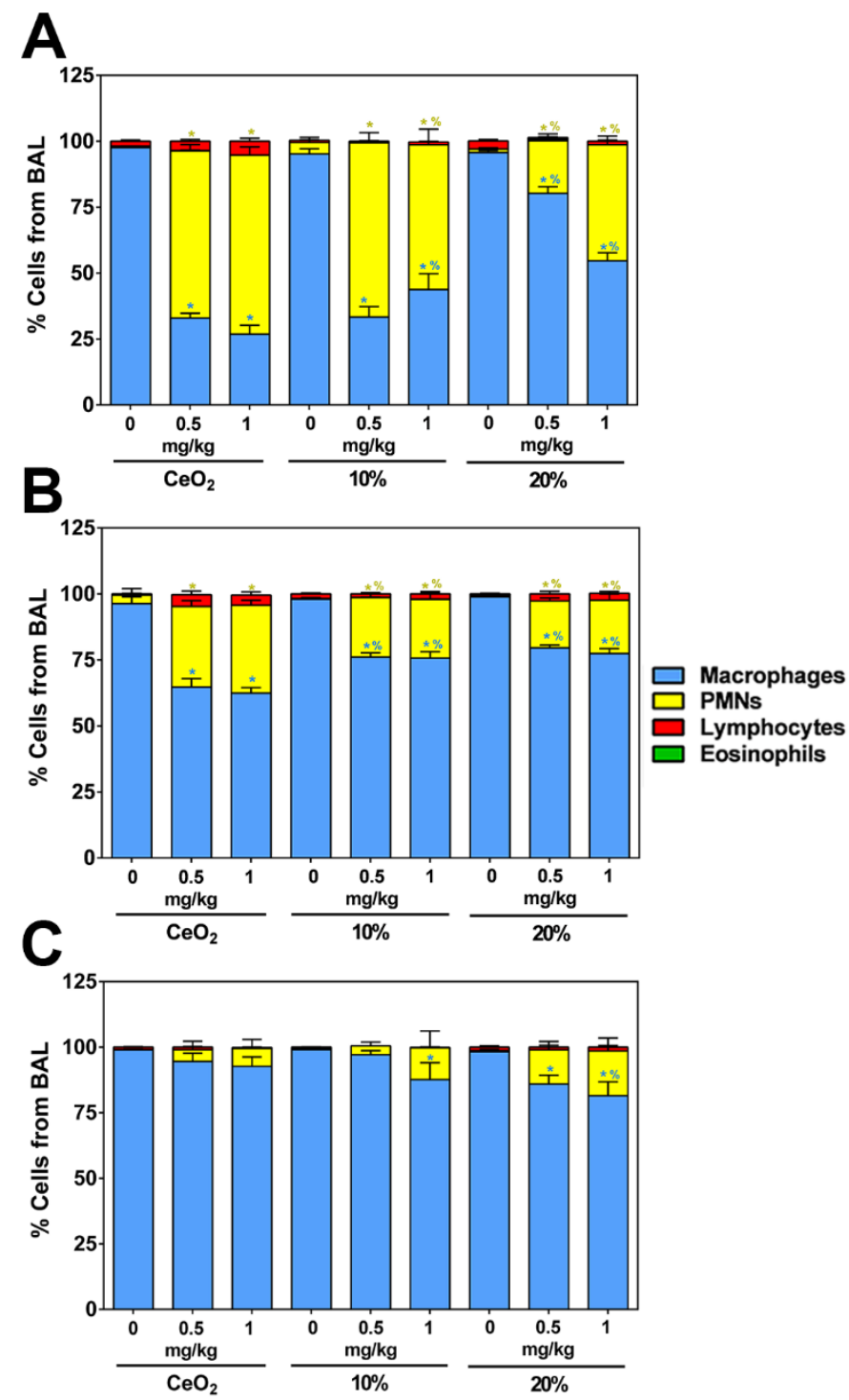

Figure 4.2. Cell differentials from BALF over a time course of 84 days post-IT exposure. A. Cells (200/rat) from day 1 post $-\mathrm{CeO}_{2}$ exposure were designated as macrophages, PMNs, lymphocytes, or eosinophils. Data is represented as percentage of cells and the bars represent the mean percentage $\pm \operatorname{SEM}(\mathrm{n}=6-7$ rats/group). *, $\mathrm{p}<0.05$ compared to $0 \mathrm{mg} / \mathrm{kg}$ controls on corresponding day, \%, p $<0.05$ compared to pure $\mathrm{CeO}_{2}$ on corresponding day. B. As in A. except data represents cells from 7 days post-exposure. C. As in A, except data represents cells from 84 days post-exposure. 

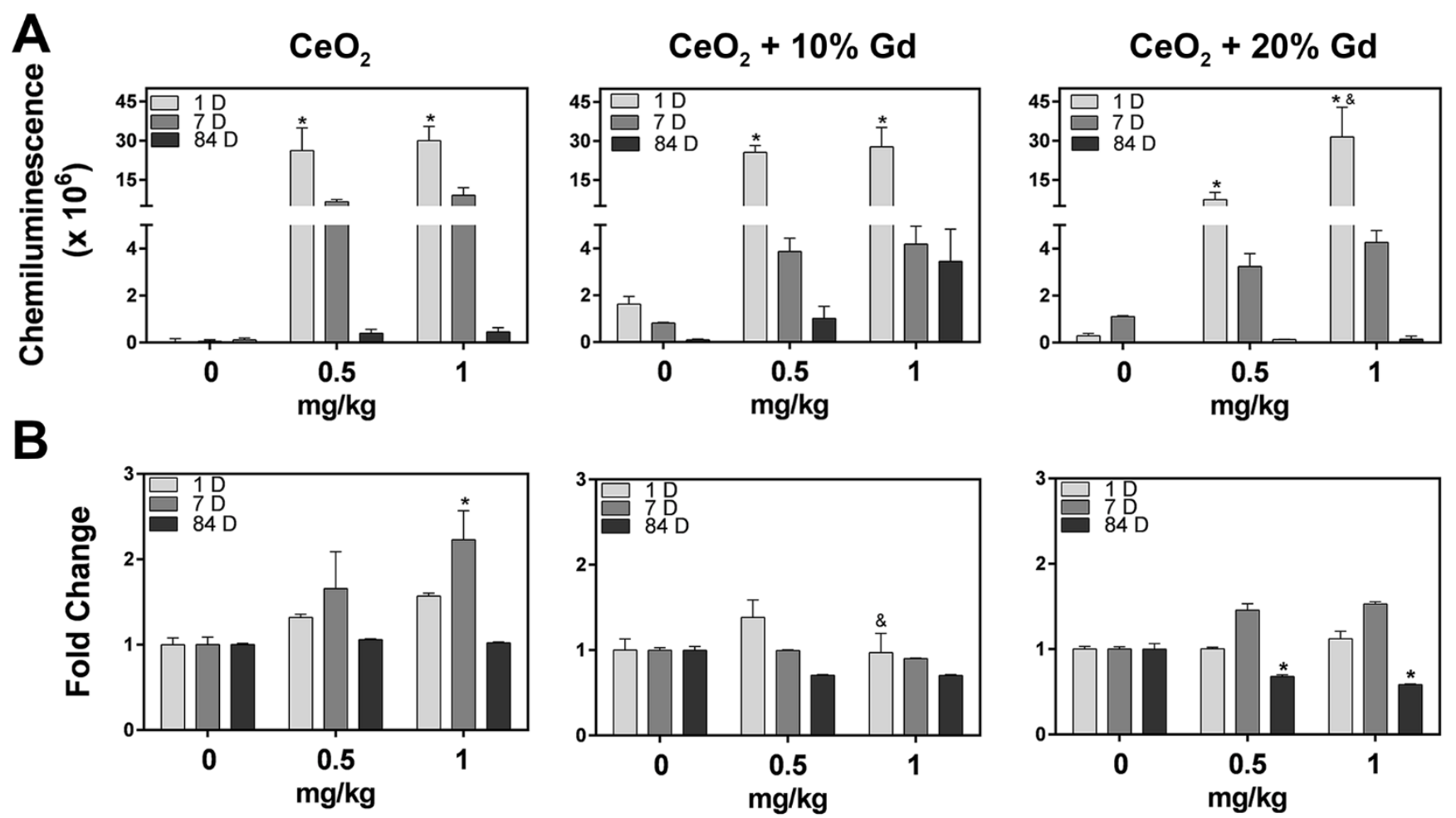

Figure 4.3. Phagocytic pulmonary cell activity over a time course of 84 days post-exposure.

A. Response of AM from BALF over 84 days post exposure to zymosan challenge. ROS production was measured via chemiluminescence. ${ }^{*}, \mathrm{p}<0.05$ compared to $0 \mathrm{mg} / \mathrm{kg}$ controls on corresponding day, \%, p $<0.05$ compared to $0.5 \mathrm{mg} / \mathrm{kg}$ dose of same nanoparticle on corresponding day. B. Phagocytic cell response to $\mathrm{Cr}(\mathrm{VI})$ challenge as measured by free radical production via EPR. BALF cells were combined with $200 \mathrm{mM} \mathrm{DMPO}$, and $2 \mathrm{mM} \mathrm{Cr}$ (VI) for 3 minutes. EPR setting were: center field, $3485 \mathrm{G}$; scan width, $100 \mathrm{G}$; time constant, 0.41s; modulation amplitude, $1 \mathrm{G}$; receiver gain, 1 x 104; frequency, $9.8 \mathrm{GHz}$; and power, $126.9 \mathrm{~mW}$. 

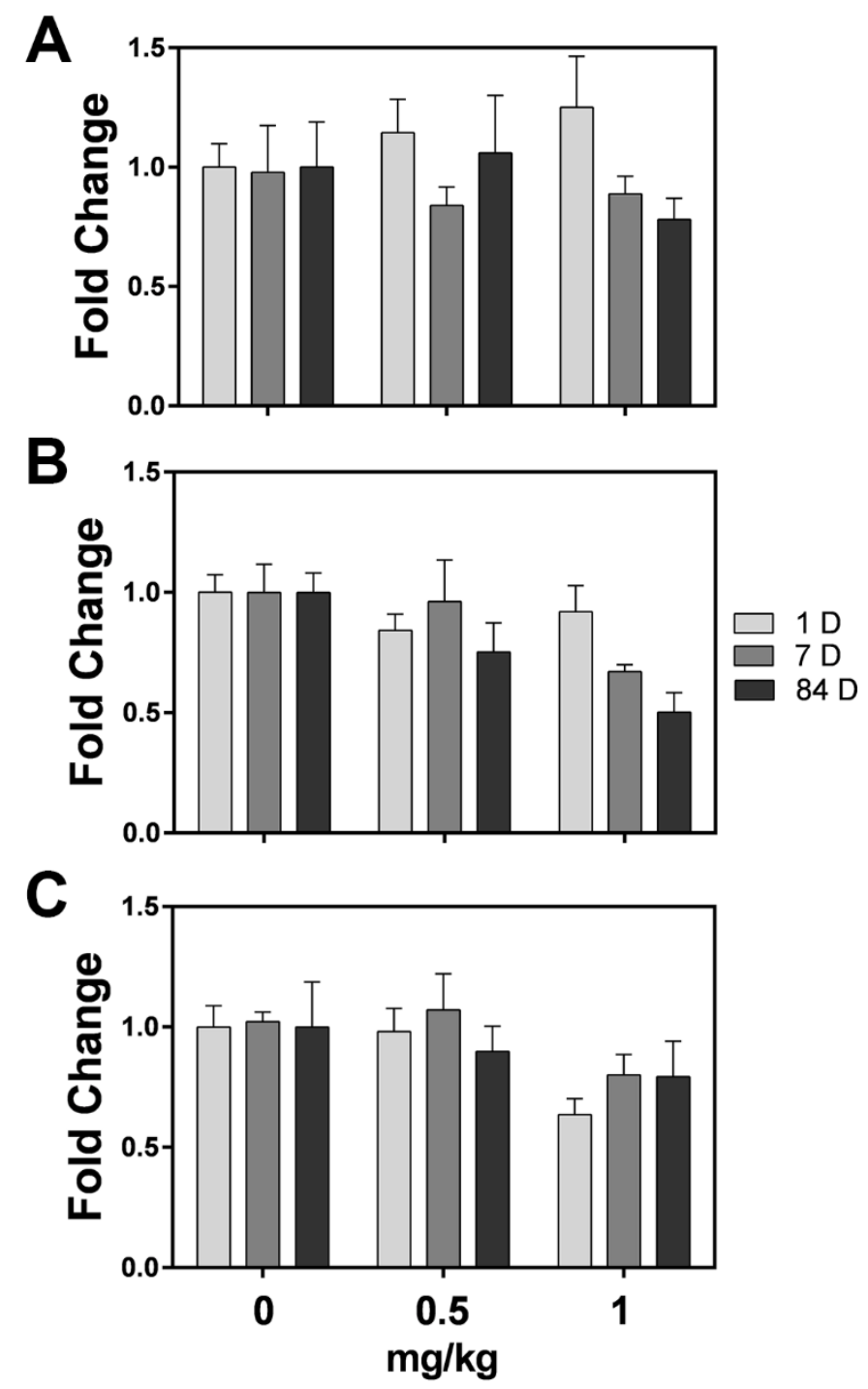

Figure 4.4. Lipid peroxidation (LPO) production in pulmonary homogenates. A. LPO production, measured from lung homogenates from day 1 post-exposure pulmonary tissue. B. As in $\mathbf{A}$, except pulmonary tissue from day 7 post-exposure. $\mathbf{C}$. As in $\mathbf{A}$, except pulmonary tissue from day 84 post-exposure. 

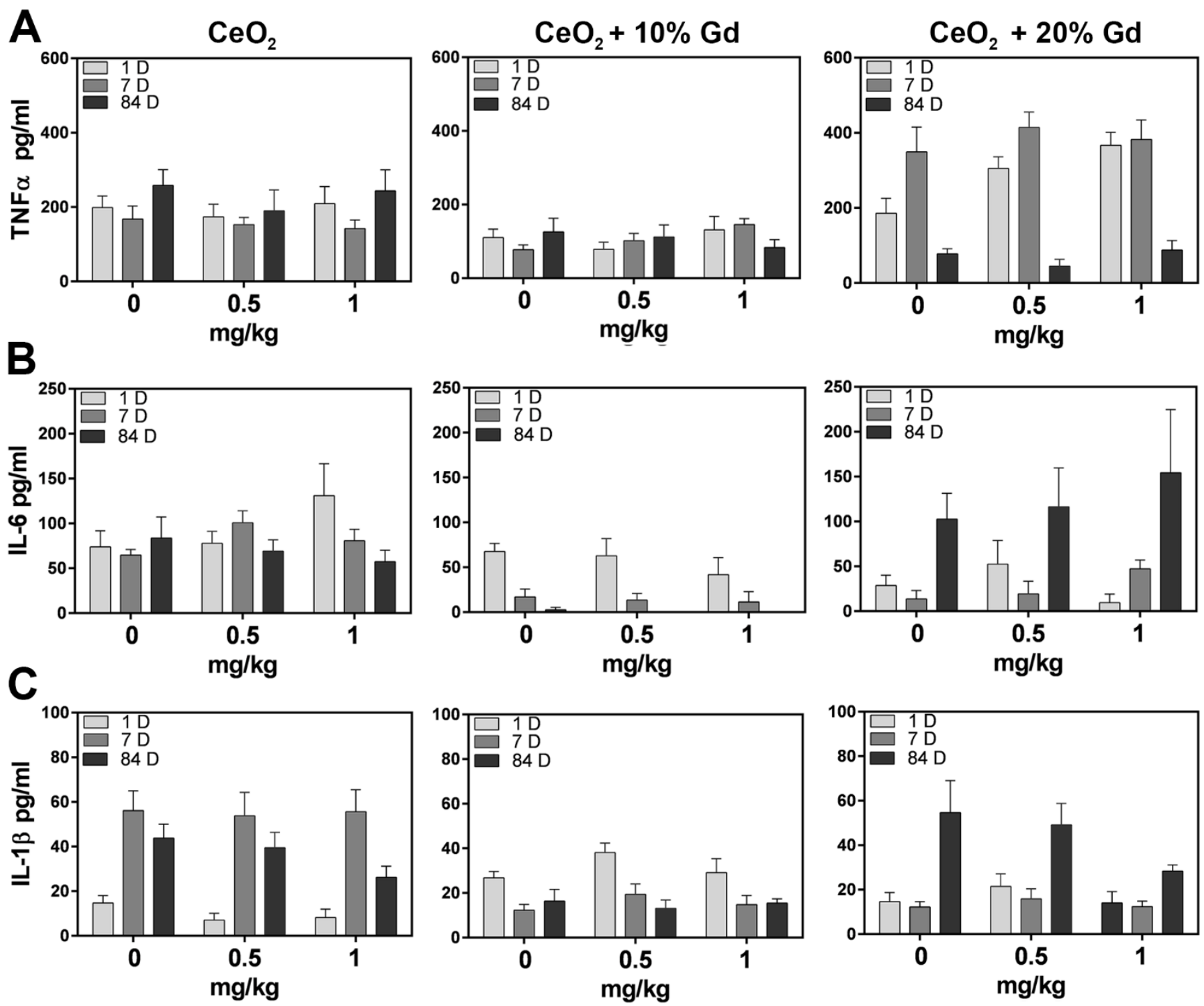

Figure 4.5. Cytokine concentration in BALF over a time course of 84 days post-exposure.

A. Concentrations of TNF- $\alpha$ in BALF from $\mathrm{CeO}_{2}$ nanoparticle treated rats were quantified. B. As in A. except IL-6 concentrations were measured. C. As in A. except IL-1 $\beta$ concentrations were measured. 


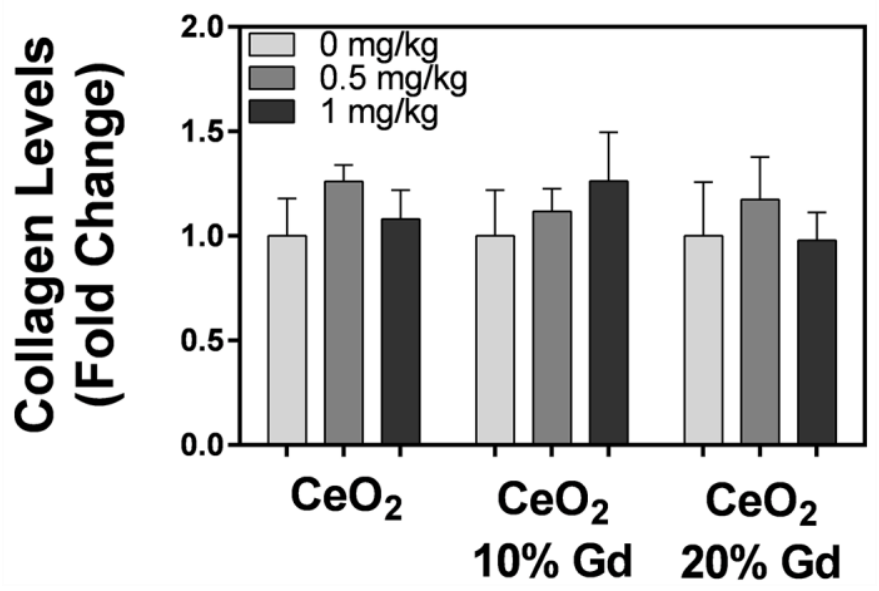

Figure 4.6. Collagen concentration in lung tissue 84 days post-nanoparticle exposure. Collagen levels were measured using a Sir-Col assay and are presented as fold change compared to $0 \mathrm{mg} / \mathrm{kg}$ control animals. 


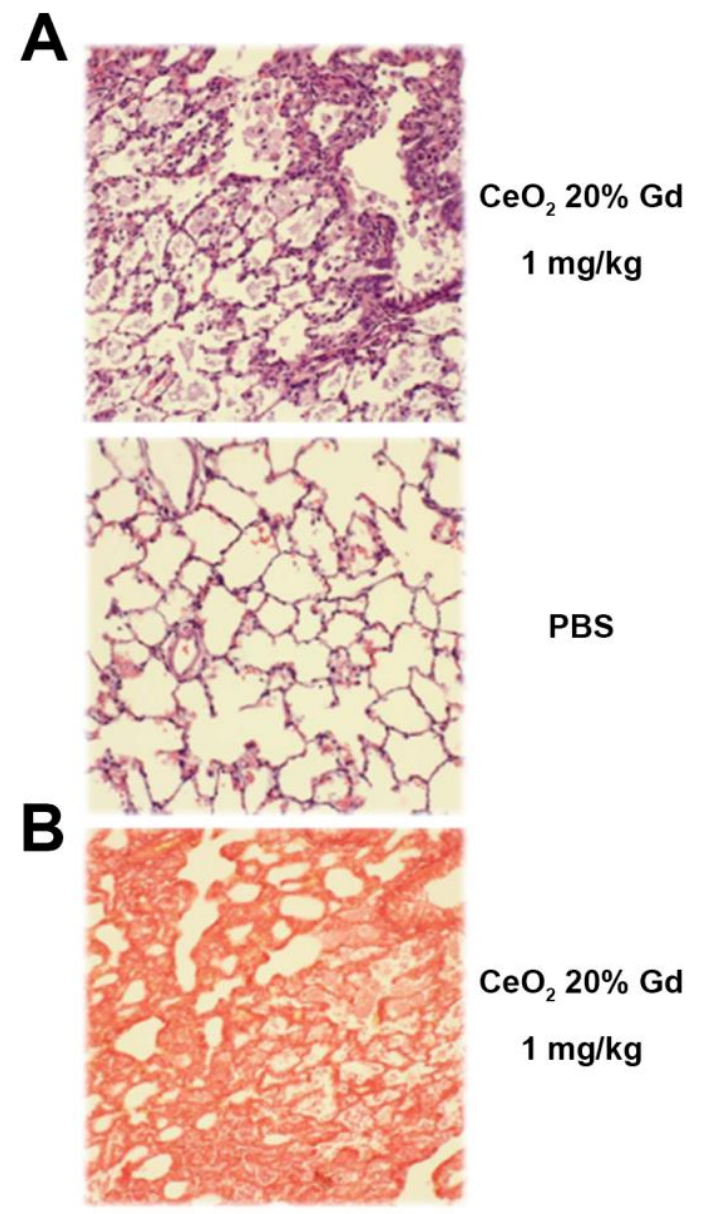

Figure 4.7. Histopathology results for pulmonary tissue after 84 day exposure to $\mathrm{CeO}_{2} 20 \%$

Gd. A. H \& E staining on pulmonary tissue showing alveolar macrophage and granular material in alveolar space. 20x. B. Sirius Red staining on pulmonary tissue to examine changes in collagen levels. 20x. Due to issues with inflation with fixative, interpretation of fibrosis initiation and septal thickening should be done conservatively. 


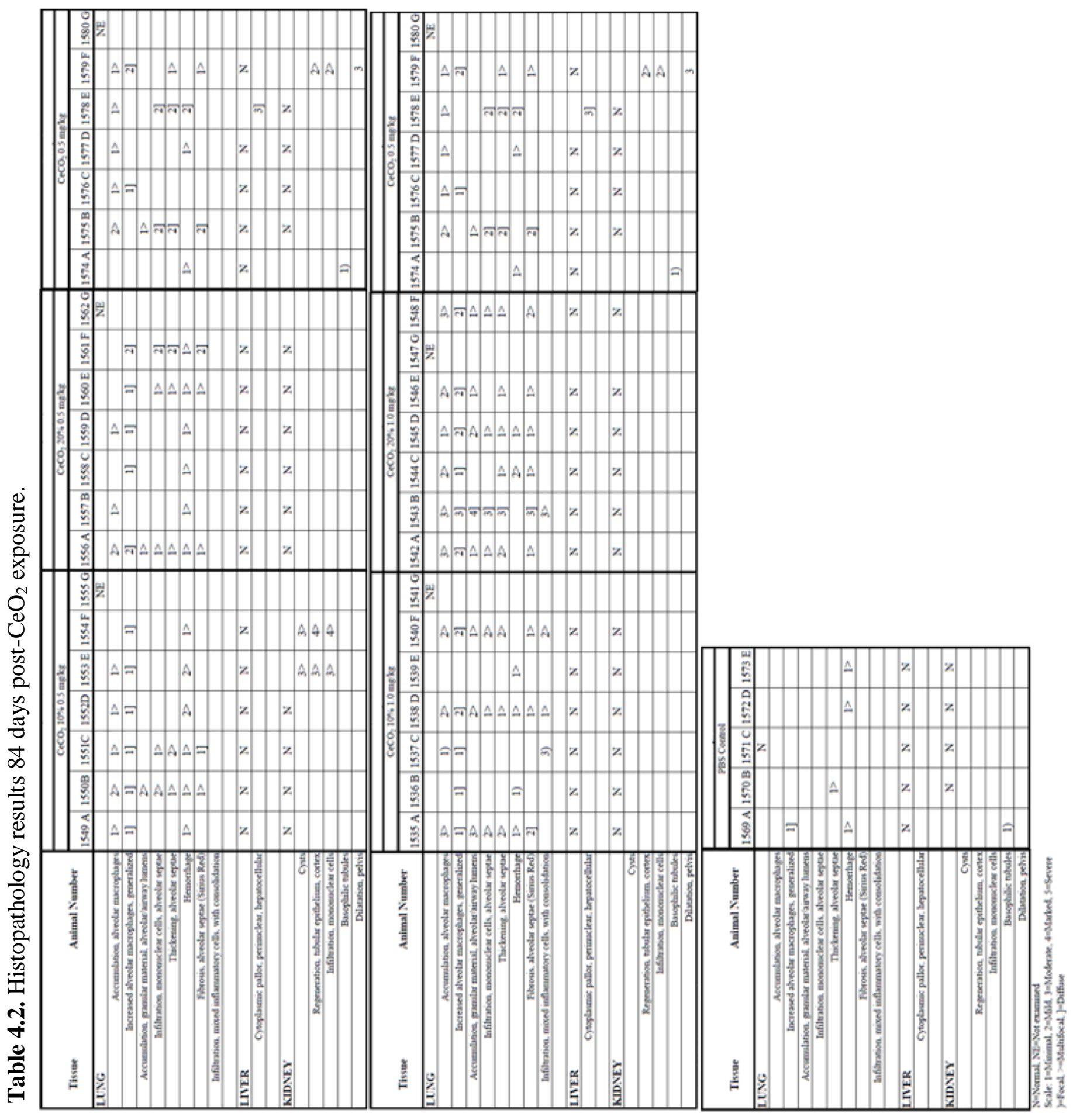




\section{Chapter 5}

Conclusions and Future Directions 


\subsection{Conclusions}

Overall these results demonstrate that shape, size, chemical composition, and valence state significantly alters the reactivity of tungstate and $\mathrm{CeO}_{2}$ nanoparticles in vitro. Altering the shape of the tungstate nanoparticles from sphere to wire had the greatest effect on cellular activity, specifically the ability of wires to induce ROS in RAW 264.7 cells (Figures 2.5 and 2.7). The shape also dramatically affected the particle-cellular interaction, as spheres were visualized within RAW 264.7 cells and spheres were only visualized clumped on the cell surface (Figures 2.3 and 2.4). Further, wires caused significantly more cell death as measured by an MTT assay, while spheres caused a trend toward increased viability, possibly cellular proliferation. Surprisingly, altering the chemical composition from $\mathrm{Ca}$ to $\mathrm{Sr}$ or $\mathrm{Br}$ did not dramatically alter the reactivity of the nanoparticles as originally predicted with the exception of the ability of the nanomaterials to interact with cells. Specifically, Ba containing tungstate nanoparticles did not associate as well or as rapidly as the other tungstate nanomaterials (Figure 2.2). This may have been due to differences in size and therefore overall surface area of the different spheres, or may be due to differences in reactivity of Ba compared to $\mathrm{Ca}$ or $\mathrm{Sr}[26]$. Further, the sizes of the nanowires were relatively similar, thus no differences in toxicity were measured between wire samples, whereas the size of the spheres were substantially different, yet no differences in toxicity were measured either (Figure 2.9). Our results support previous literature that shape of nanomaterials can dramatically affect toxicity, yet the study did not indicate that size or chemical composition affected reactivity as anticipated $[1,110]$.

While the study of shape and size of nanomaterials is a heavily studied field of research to determine the properties that may provide novel safe nanomaterials for use in consumer products, determining how chemical composition, specifically altering the valence state, is an 
under studied field. Our in vitro results implicate that altering the valence state of $\mathrm{CeO}_{2}$ nanoparticles, which would potentially make them more suitable for engineering purposes [127], significantly altered their antioxidant abilities in both rat macrophage and epithelial cells (Figures 3.7 and 3.8). While the initial hypothesis was that doping would decrease antioxidant abilities due to a change in valence state, the findings demonstrate that transitional ability of $\mathrm{CeO}_{2}$ nanoparticles is more important in determining their protective effect. This was concluded based on the similarities between the valence state of the two doped samples and the statistically significant differences between their antioxidant potential measured via EPR. Further, the characterization data of the $\mathrm{CeO}_{2}$ nanoparticles implies that the process of doping did not alter the size or zeta potential of the nanoparticles in DM but did significantly alter the valence state. However, there was a type of saturation affect with doping as the difference in valence state between the $10 \%$ and $20 \%$ doped $\mathrm{CeO}_{2}$ only changed by approximately $1 \%$ (Table 3.1). Also, doping did appear to affect the agglomeration of the nanoparticles in DM as measured by DLS, possibly due to changes in surface properties of the nanomaterial (Tables 3.1 and 3.2). Our overall findings suggest that doping the nanomaterials decreases their antioxidant potential in vitro but does not affect their overall effects on RLE-6TN and NR8383 cell viability.

Our in vivo $\mathrm{CeO}_{2}$ nanoparticle study indicates that altering the valence state and subsequent transitional ability of the nanomaterial significantly alters the pulmonary effect. Preliminary data suggests that pure $\mathrm{CeO}_{2}$ and $\mathrm{CeO}_{2} \quad 10 \% \mathrm{Gd}$ nanoparticles induced greater toxicity and cell influx compared to $\mathrm{CeO}_{2} 20 \%$ Gd after initial exposure. However, by 84 days post-exposure, pulmonary effects induced by $\mathrm{CeO}_{2}$ and $\mathrm{CeO}_{2} 10 \% \mathrm{Gd}$ were minimal and $\mathrm{CeO}_{2}$ $20 \% \mathrm{Gd}$ induced significantly greater pulmonary influx than the other nanomaterials (Figure 4.1). Surprisingly, none of the nanomaterials significantly induced ROS as measured via EPR 
and downstream lipid peroxidation production (Figures 4.3 and 4.4) as expected from previous studies [144]. Further, because rare earth metals are known to induce rare earth metal pneumoconiosis and fibrosis $[138,148]$, pathology was completed on lung tissue collected from animals exposed to the various $\mathrm{CeO}_{2}$ nanoparticles and results showed no significant difference in cellular influx or fibrosis initiation between $\mathrm{CeO}_{2}$ groups. However, there was significant alveolar macrophage accumulation and granular material visualized in alveoli compared to PBS treated animals (Figure 4.7). Unfortunately, due to fixation of tissues, determination of fibrosis initiation was hindered (Figure 4.7B). Surprisingly, no damage was noted in liver and kidney sections as would have been expected due to potential nanomaterial translocation [149].

Unfortunately, differences in reactivity between the nanomaterials was not pronounced in an in vivo model as anticipated, thus further studies must be conducted to determine the effect of valence state on $\mathrm{CeO}_{2}$ toxicity in order to manufacture $\mathrm{CeO}_{2}$ containing products safely.

Overall, the data suggests that altering the size, shape, chemical composition, and valence state of nanomaterials may provide alternative, safe materials for use in consumer products. Additionally, since the process of doping increases the efficiency of materials for use in industry [127]but had minor effects on overall in vivo reactivity in these studies, this may provide a novel attribute that can be altered to improve nanomaterial efficiency while not affecting toxicity which may prove important as the use of nanomaterials in consumer products continues to grow. Specifically, the use of $\mathrm{CeO}_{2}$ nanoparticles in both biomedical applications [150] and as a diesel fuel additive [151] will increase the potential risk for human exposures, making determination of properties (size, shape, valence state) important in nanoparticle toxicity crucial. 


\subsection{Future Studies}

While the tungstate data indicates that these nanomaterials cause mild toxicity in vitro, it is known that in vivo results can often differ $[152,153]$. Therefore, it is important to determine the effect of size, shape, and chemical composition of tungstate nanoparticles on toxicity in either an animal model or a more complex in vitro system. For example, co-culture in vitro models are seeing an increase in use due to their ability to more closely recapitulate an in vivo system. The co-culture models allow for cellular signaling between different cell types, potentially amplifying the cellular response to nanoparticles and modeling the effects recorded in vivo [154]. Further, our results indicated that wires were more reactive than spheres, most likely due to differences in cellular-interactions as discussed in chapter 2. Differences in reactivity between spheres and wires has been recorded with numerous other nanomaterials, as wires often penetrate cell walls and if long enough, are unsuccessfully phagocytosed, promoting continuous damage and cellular responses [155]. However, neither shape induced inflammatory cytokine activation, potentially due to the in vitro model utilized for the study as the wires were expected to promote inflammation. In vivo models may allow for better characterization of differences between these two nanomaterials, as it would be anticipated that the nanowires would induce more inflammation in vivo, transverse the pulmonary interstitial space, and cause toxicity as has been noted with other wire or belt shaped nanomaterials [156].

Furthermore, studies to determine the effect of valence state on $\mathrm{CeO}_{2}$ antioxidant potential in different cell lines should be conducted. RLE-6TN and NR8383 cells, while providing a unique model for the rat pulmonary environment, do not respond well to induced ROS, making study of $\mathrm{CeO}_{2}$ potential antioxidant-like effects difficult. Therefore, RAW 264.7 cells may represent an adequate in vitro model to determine antioxidant potential beyond the 3 
minute EPR studies. In vitro studies have indicated that $\mathrm{CeO}_{2}$ is capable of reducing $\mathrm{ROS}$ through various mechanisms, including scavenging free radicals or upregulating cellular antioxidant systems $[157,158]$. Thus, future studies should consider studying cellular antioxidant systems, such as superoxide dismutase, catalase, and glutathione reductase. Determining the role of valence state in oxidative or antioxidant potential of $\mathrm{CeO}_{2}$ nanoparticles may help develop safer materials for use in manufacturing of consumer products.

Additionally, future studies should be conducted to further examine the effect of valence state on $\mathrm{CeO}_{2}$ nanoparticle toxicity, as our in vivo results were inconclusive. One potential method to test valence state would be in an animal model with high basal levels of oxidative stress or animals in which oxidative stress is induced. For example, Colon et al. (2010) presented data in which $\mathrm{CeO}_{2}$ nanoparticles protected gastrointestinal epithelium from radiation induced damage through antioxidant-like methods as well as inducing superoxide dismutase [136]. Further, Hirst et al. (2013) implicated that $\mathrm{CeO}_{2}$ nanoparticles acted similarly to $\mathrm{N}$-acetyl cysteine, a known antioxidant, when mice were treated with carbon tetrachloride [159]. Therefore, a study in which damage was intentionally induced in the pulmonary environment prior to $\mathrm{CeO}_{2}$ nanoparticle exposure may allow for elucidation of the effect of valence state on potential toxicity or antioxidant potential in vivo. Further, because rare earth metals are known to induce rare earth metal pneumoconiosis and fibrosis $[138,148]$, pathology will be completed on lung tissue collected from animals exposed to the various $\mathrm{CeO}_{2}$ nanoparticles. Additionally, liver and kidney damage will be assessed as nanomaterials are known to translocate from the lungs following pulmonary exposure [149]. 


\section{REFERENCES}

1. Nel, A., et al., Toxic potential of materials at the nanolevel. Science, 2006. 311(5761): p. 622-627.

2. Love, S.A., et al., Assessing Nanoparticle Toxicity, in Annu Rev Anal Chem, R.G. Cooks and E.S. Yeung, Editors. 2012, Annual Reviews: Palo Alto. p. 181-205.

3. Agency, U.S.E.P. Particulate Matter (PM). 3/18/13 08/18/15]; Available from: http://www.epa.gov/pm/.

4. $\quad$ Monteiro-Riviere, N.A., et al., Safety Evaluation of Sunscreen Formulations Containing Titanium Dioxide and Zinc Oxide Nanoparticles in UVB Sunburned Skin: An In Vitro and In Vivo Study. Toxicol. Sci., 2011. 123(1): p. 264-280.

5. Comini, E., Metal oxide nano-crystals for gas sensing. Anal. Chim. Acta, 2006. 568(12): p. 28-40.

6. Espinoza, V.S., et al., Material flow analysis of carbon nanotube lithium-ion batteries used in portable computers. ACS Sustainable Chemistry \& Engineering, 2014. 2(7): p. 1642-1648.

7. Zhang, F., et al., Exploring the Room-Temperature Synthesis and Properties of Multifunctional Doped Tungstate Nanorods. J. Phys. Chem. C., 2008. 112(38): p. 1481614824.

8. Zhao, J. and V. Castranova, Toxicology of Nanomaterials Used in Nanomedicine. J Toxicol Env Heal B, 2011. 14(8): p. 593-632.

9. Nowack, B. and T.D. Bucheli, Occurrence, behavior and effects of nanoparticles in the environment. Environmental pollution, 2007. 150(1): p. 5-22.

10. Koyama, S., et al., Medical Application of Carbon-Nanotube-Filled Nanocomposites: The Microcatheter. Small, 2006. 2(12): p. 1406-1411.

11. Liang, F. and B. Chen, A review on biomedical applications of single-walled carbon nanotubes. Curr Med Chem, 2010. 17(1): p. 10-24.

12. Krätschmer, W., et al., C60: a new form of carbon. Nature, 1990. 347(6291): p. 354-358.

13. Magrez, A., et al., Cellular toxicity of carbon-based nanomaterials. Nano letters, 2006. 6(6): p. 1121-1125.

14. Mihalchik, A.L., et al., Effects of nitrogen-doped multi-walled carbon nanotubes compared to pristine multi-walled carbon nanotubes on human small airway epithelial cells. Toxicology, 2015. 333: p. 25-36. 
15. Poland, C., et al., Carbon nanotubes introduced into the abdominal cavity of mice show asbestos-like pathogenicity in a pilot study. Nat Nanotechnol, 2008. 3: p. 423 - 428.

16. Palomäki, J., et al., Long, needle-like carbon nanotubes and asbestos activate the NLRP3 inflammasome through a similar mechanism. Acs Nano, 2011. 5(9): p. 6861-6870.

17. Silvestre, C., D. Duraccio, and S. Cimmino, Food packaging based on polymer nanomaterials. Prog Polym Sci, 2011. 36(12): p. 1766-1782.

18. Gref, R., et al., Biodegradable long-circulating polymeric nanospheres. Science, 1994. 263(5153): p. 1600-1603.

19. Lucarelli, M., et al., Innate defence functions of macrophages can be biased by nanosized ceramic and metallic particles. Eur Cytokine Netw, 2004. 15(4): p. 339-346.

20. Zhang, J., et al., Related mechanism of transparency in MgAl2O4 nano-ceramics prepared by sintering under high pressure and low temperature. J Phys D Appl Phys, 2009. 42(5): p. 052002.

21. Peter, M., et al., Novel biodegradable chitosan-gelatin/nano-bioactive glass ceramic composite scaffolds for alveolar bone tissue engineering. Chem Eng J, 2010. 158(2): p. 353-361.

22. Park, E.-J. and K. Park, Oxidative stress and pro-inflammatory responses induced by silica nanoparticles in vivo and in vitro. Toxicol. Lett., 2009. 184(1): p. 18-25.

23. Schrand, A.M., et al., Metal-based nanoparticles and their toxicity assessment. Wiley interdisciplinary reviews: Nanomedicine and Nanobiotechnology, 2010. 2(5): p. 544-568.

24. Hainfeld, J.F., R.D. Powell, and F.R. Furuya, Microscopic Uses of Nanogold® 6. Gold and silver staining: techniques in molecular morphology, 2002: p. 85.

25. Dreaden, E.C., et al., Beating cancer in multiple ways using nanogold. Chem Soc Rev, 2011. 40(7): p. 3391-3404.

26. Alkilany, A.M. and C.J. Murphy, Toxicity and cellular uptake of gold nanoparticles: what we have learned so far? J Nanopart Res, 2010. 12(7): p. 2313-2333.

27. Fernández-García, M. and J.A. Rodriguez, Metal oxide nanoparticles. Encyclopedia of Inorganic and Bioinorganic Chemistry, 2011.

28. Chang, Y.-N., et al., The toxic effects and mechanisms of $\mathrm{CuO}$ and $\mathrm{ZnO}$ nanoparticles. Materials, 2012. 5(12): p. 2850-2871.

29. De Berardis, B., et al., Exposure to $\mathrm{ZnO}$ nanoparticles induces oxidative stress and cytotoxicity in human colon carcinoma cells. Toxicol Appl Pharm, 2010. 246(3): p. 116127. 
30. Gojova, A., et al., Induction of Inflammation in Vascular Endothelial Cells by Metal Oxide Nanoparticles: Effect of Particle Composition. Environmental Health Perspectives, 2007. 115(3): p. 403-409.

31. Zhang, H., et al., Use of metal oxide nanoparticle band gap to develop a predictive paradigm for oxidative stress and acute pulmonary inflammation. ACS Nano, 2012. 6(5): p. 4349-4368.

32. Fondevila, M., et al., Silver nanoparticles as a potential antimicrobial additive for weaned pigs. Animal Feed Science and Technology, 2009. 150(3): p. 259-269.

33. Bergin, I.L. and F.A. Witzmann, Nanoparticle toxicity by the gastrointestinal route: evidence and knowledge gaps. International journal of biomedical nanoscience and nanotechnology, 2013. 3(1-2): p. 10.1504/IJBNN.2013.054515.

34. Wu, J., et al., Toxicity and penetration of TiO2 nanoparticles in hairless mice and porcine skin after subchronic dermal exposure. Toxicology Letters, 2009. 191(1): p. 1-8.

35. Crosera, M., et al., Nanoparticle dermal absorption and toxicity: a review of the literature. International Archives of Occupational and Environmental Health, 2009. 82(9): p. 1043-1055.

36. Liu, T., et al., Single and repeated dose toxicity of mesoporous hollow silica nanoparticles in intravenously exposed mice. Biomaterials, 2011. 32(6): p. 1657-1668.

37. Yang, S.-T., et al., Long-term accumulation and low toxicity of single-walled carbon nanotubes in intravenously exposed mice. Toxicology Letters, 2008. 181(3): p. 182-189.

38. Sharifi, S., et al., Toxicity of nanomaterials. Chemical Society Reviews, 2012. 41(6): p. 2323-2343.

39. Ma, J.Y., et al., Induction of pulmonary fibrosis by cerium oxide nanoparticles. Toxicol Appl Pharm, 2012. 262(3): p. 255-264.

40. Ma, J.Y., et al., Cerium oxide nanoparticle-induced pulmonary inflammation and alveolar macrophage functional change in rats. Nanotoxicology, 2011. 5(3): p. 312-325.

41. Yang, W., J.I. Peters, and R.O. Williams Iii, Inhaled nanoparticles-A current review. Int J Pharm, 2008. 356(1-2): p. 239-247.

42. Gojova, A., et al., Induction of inflammation in vascular endothelial cells by metal oxide nanoparticles: effect of particle composition. Environ Health Persp, 2007. 115(3): p. 403.

43. Chen, H.-W., et al., Titanium dioxide nanoparticles induce emphysema-like lung injury in mice. The FASEB journal, 2006. 20(13): p. 2393-2395. 
44. Karlsson, H.L., et al., Copper Oxide Nanoparticles Are Highly Toxic: A Comparison between Metal Oxide Nanoparticles and Carbon Nanotubes. Chem Res Toxicol, 2008. 21(9): p. 1726-1732.

45. Sharma, V., et al., DNA damaging potential of zinc oxide nanoparticles in human epidermal cells. Toxicol Lett, 2009. 185(3): p. 211-218.

46. Benameur, L., et al., DNA damage and oxidative stress induced by CeO2 nanoparticles in human dermal fibroblasts: Evidence of a clastogenic effect as a mechanism of genotoxicity. Nanotoxicology, 2014(0): p. 1-10.

47. Mohamed, H.R.H., Estimation of TiO 2 nanoparticle-induced genotoxicity persistence and possible chronic gastritis-induction in mice. Food Chem Toxicol, 2015. 83: p. 76-83.

48. Shukla, R.K., et al., ROS-mediated genotoxicity induced by titanium dioxide nanoparticles in human epidermal cells. Toxicol In Vitro, 2011. 25(1): p. 231-241.

49. Ahamed, M. and H.A. Alhadlaq, Nickel nanoparticle-induced dose-dependent cytogenotoxicity in human breast carcinoma MCF-7 cells. Onco Targets and therapy, 2014. 7: p. 269.

50. Kyjovska, Z.O., et al., DNA damage following pulmonary exposure by instillation to low doses of carbon black (Printex 90) nanoparticles in mice. Environ Mol Mutagen, 2015. 56(1): p. 41-49.

51. Bartosz, G., Reactive oxygen species: destroyers or messengers? Biochem pharmacol, 2009. 77(8): p. 1303-1315.

52. Fukui, H., et al., Association of zinc ion release and oxidative stress induced by intratracheal instillation of ZnO nanoparticles to rat lung. Chem-Biol Interact, 2012. 198(1): p. 29-37.

53. Sharma, V., D. Anderson, and A. Dhawan, Zinc oxide nanoparticles induce oxidative DNA damage and ROS-triggered mitochondria mediated apoptosis in human liver cells (HepG2). Apoptosis, 2012. 17(8): p. 852-870.

54. Fahmy, B. and S.A. Cormier, Copper oxide nanoparticles induce oxidative stress and cytotoxicity in airway epithelial cells. Toxicol In Vitro, 2009. 23(7): p. 1365-1371.

55. Onizawa, S., et al., Platinum nanoparticle antioxidants inhibit pulmonary inflammation in mice exposed to cigarette smoke. Pulm Pharmacol Ther, 2009. 22(4): p. 340-349.

56. Hashem, R.M., et al., Cerium oxide nanoparticles alleviate oxidative stress and decreases Nrf-2/HO-1 in D-GALN/LPS induced hepatotoxicity. Biomedicine \& Pharmacotherapy, 2015. 73: p. 80-86. 
57. Dunnick, K., et al., The effect of tungstate nanoparticles on reactive oxygen species and cytotoxicity in RAW 264.7 mouse monocyte macrophage cells. J Toxicol Env Heal A, 2014. 77(20): p. 1251-1268.

58. Elmore, S., Apoptosis: A Review of Programmed Cell Death. Toxicol Pathol, 2007. 35(4): p. 495-516.

59. Meyer, K., et al., $\mathrm{ZnO}$ nanoparticles induce apoptosis in human dermal fibroblasts via p53 and p38 pathways. Toxicol In Vitro, 2011. 25(8): p. 1721-1726.

60. Pan, Y., et al., Gold nanoparticles of diameter $1.4 \mathrm{~nm}$ trigger necrosis by oxidative stress and mitochondrial damage. Small, 2009. 5(18): p. 2067-2076.

61. Jeng, H.A. and J. Swanson, Toxicity of Metal Oxide Nanoparticles in Mammalian Cells. J. Toxicol. Environ. Health, A, 2006. 41(12): p. 2699-2711.

62. Foldbjerg, R., D.A. Dang, and H. Autrup, Cytotoxicity and genotoxicity of silver nanoparticles in the human lung cancer cell line, A549. Archives of toxicology, 2011. 85(7): p. 743-750.

63. Foldbjerg, R., et al., PVP-coated silver nanoparticles and silver ions induce reactive oxygen species, apoptosis and necrosis in THP-1 monocytes. Toxicol Lett, 2009. 190(2): p. $156-162$.

64. Misra, S.K., et al., Comparative study using spheres, rods and spindle-shaped nanoplatelets on dispersion stability, dissolution and toxicity of $\mathrm{CuO}$ nanomaterials. Nanotoxicology, 2014. 8(4): p. 422-432.

65. Yang, K. and Y.-Q. Ma, Computer simulation of the translocation of nanoparticles with different shapes across a lipid bilayer. Nat Nanotechnol, 2010. 5(8): p. 579-583.

66. Limbach, L.K., et al., Oxide Nanoparticle Uptake in Human Lung Fibroblasts: Effects of Particle Size, Agglomeration, and Diffusion at Low Concentrations. Environ SciTechnol, 2005. 39(23): p. 9370-9376.

67. Park, M.V., et al., The effect of particle size on the cytotoxicity, inflammation, developmental toxicity and genotoxicity of silver nanoparticles. Biomaterials, 2011. 32(36): p. 9810-9817.

68. Carlson, C., et al., Unique cellular interaction of silver nanoparticles: size-dependent generation of reactive oxygen species. J Phys Chem B, 2008. 112(43): p. 13608-13619.

69. Kim, T.H., et al., Size-dependent cellular toxicity of silver nanoparticles. J Biomed Mater Res A, 2012. 100(4): p. 1033-1043.

70. Hsiao, I.-L. and Y.-J. Huang, Effects of various physicochemical characteristics on the toxicities of $\mathrm{ZnO}$ and $\mathrm{TiO} 2$ nanoparticles toward human lung epithelial cells. Sci Total Environ, 2011. 409(7): p. 1219-1228. 
71. Pan, Y., et al., Size-dependent cytotoxicity of gold nanoparticles. Small, 2007. 3(11): p. 1941-1949.

72. Warheit, D.B., et al., Pulmonary instillation studies with nanoscale TiO2 rods and dots in rats: toxicity is not dependent upon particle size and surface area. Toxicol Sci, 2006. 91(1): p. 227-236.

73. Zhang, X.-D., et al., Size-dependent in vivo toxicity of PEG-coated gold nanoparticles. Int J Nanomed, 2011. 6: p. 2071.

74. Grassian, V.H., et al., Inflammatory response of mice to manufactured titanium dioxide nanoparticles: comparison of size effects through different exposure routes. Nanotoxicology, 2007. 1(3): p. 211-226.

75. Cho, M., et al., The impact of size on tissue distribution and elimination by single intravenous injection of silica nanoparticles. Toxicol Lett, 2009. 189(3): p. 177-183.

76. Chithrani, B.D., A.A. Ghazani, and W.C. Chan, Determining the size and shape dependence of gold nanoparticle uptake into mammalian cells. Nano Lett, 2006. 6(4): p. 662-668.

77. Heng, B., et al., Evaluation of the cytotoxic and inflammatory potential of differentially shaped zinc oxide nanoparticles. Arch. Toxicol., 2011. 85(12): p. 1517-1528.

78. Jia, G., et al., Cytotoxicity of carbon nanomaterials: single-wall nanotube, multi-wall nanotube, and fullerene. Environ SciTechnol, 2005. 39(5): p. 1378-1383.

79. Zhang, Y., et al., Cytotoxicity effects of graphene and single-wall carbon nanotubes in neural phaeochromocytoma-derived PC12 cells. Acs Nano, 2010. 4(6): p. 3181-3186.

80. Limbach, L.K., et al., Exposure of engineered nanoparticles to human lung epithelial cells: influence of chemical composition and catalytic activity on oxidative stress. Environ SciTechnol, 2007. 41(11): p. 4158-4163.

81. Dahle, J. and Y. Arai, Environmental Geochemistry of Cerium: Applications and Toxicology of Cerium Oxide Nanoparticles. Int J Environ Res Pub Health, 2015. 12(2): p. 1253-1278.

82. Das, M., et al., Auto-catalytic ceria nanoparticles offer neuroprotection to adult rat spinal cord neurons. Biomaterials, 2007. 28(10): p. 1918-1925.

83. Celardo, I., et al., Ce $e^{3+}$ Ions Determine Redox-Dependent Anti-apoptotic Effect of Cerium Oxide Nanoparticles. ACS Nano, 2011. 5(6): p. 4537-4549.

84. Auffan, M., et al., Relation between the redox state of iron-based nanoparticles and their cytotoxicity toward Escherichia coli. Environ SciTechnol, 2008. 42(17): p. 6730-6735. 
85. Wang, Z., et al., Comparative Study of CeO2 and Doped CeO2 with Tailored Oxygen Vacancies for CO Oxidation. Chem Phys Chem, 2011. 12(15): p. 2763-2770.

86. Zhang, F., et al., Room-temperature preparation, characterization, and photoluminescence measurements of solid solutions of various compositionally-defined single-crystalline alkaline-earth-metal tungstate nanorods. Chem. Mater., 2008. 20(17): p. 5500-5512.

87. Lin, W., et al., Toxicity of cerium oxide nanoparticles in human lung cancer cells. Int J Toxicol, 2006. 25(6): p. 451-457.

88. Park, E.-J., et al., Oxidative stress induced by cerium oxide nanoparticles in cultured BEAS-2B cells. Toxicology, 2008. 245(1-2): p. 90-100.

89. Demokritou, P., et al., An in vivo and in vitro toxicological characterisation of realistic nanoscale CeO2 inhalation exposures. Nanotoxicology, 2013. 7(8): p. 1338-1350.

90. Srinivas, A., et al., Acute inhalation toxicity of cerium oxide nanoparticles in rats. Toxicol Lett, 2011. 205(2): p. 105-115.

91. Cho, W.-S., et al., Zeta Potential and Solubility to Toxic Ions as Mechanisms of Lung Inflammation Caused by Metal/Metal Oxide Nanoparticles. Toxicol Sci, 2012. 126(2): p. 469-477.

92. Chung, H.E., et al., Toxicokinetics of zinc oxide nanoparticles in rats. J. Phys.: Conf. Ser., 2013. 429(1): p. 012037.

93. Xia, T., et al., Comparison of the Mechanism of Toxicity of Zinc Oxide and Cerium Oxide Nanoparticles Based on Dissolution and Oxidative Stress Properties. ACS Nano, 2008. 2(10): p. 2121-2134.

94. Karlsson, H.L., et al., Size-dependent toxicity of metal oxide particles-A comparison between nano- and micrometer size. Toxicol. Lett., 2009. 188(2): p. 112-118.

95. Rushton, E.K., et al., Concept of assessing nanoparticle hazards considering nanoparticle dosemetric and chemical/biological response metrics. J. Toxicol. Environ. Health A, 2010. 73(5-6): p. 445-461.

96. Yang, H., et al., Comparative study of cytotoxicity, oxidative stress and genotoxicity induced by four typical nanomaterials: the role of particle size, shape and composition. J. Appl. Toxicol., 2009. 29(1): p. 69-78.

97. Kang, J.L., et al., Comparison of the Biological Activity Between Ultrafine and Fine Titanium Dioxide Particles in RAW 264.7 Cells Associated with Oxidative Stress. J. Toxicol. Environ. Health, A, 2008. 71(8): p. 478-485. 
98. Thongtem, T., et al., Luminescence and absorbance of highly crystalline CaMoO4, SrMoO4, CaWO4 and SrWO4 nanoparticles synthesized by co-precipitation method at room temperature. J. Alloys Compound, 2010. 506(1): p. 475-481.

99. Porter, D., et al., A biocompatible medium for nanoparticle dispersion. Nanotoxicology, 2008. 2(3): p. 144-154.

100. Gibbs-Flournoy, E., et al., Darkfield-Confocal Microscopy detection of nanoscale particle internalization by human lung cells. Part. Fibre Toxicol., 2011. 8(1): p. 2.

101. Leonard, S., et al., Comparison of stainless and mild steel welding fumes in generation of reactive oxygen species. Part. Fibre Toxicol., 2010. 7(1): p. 32.

102. Collins, A.R., et al., The comet assay: topical issues. Mutagenesis, 2008. 23(3): p. 143151.

103. Schneider, C.A., W.S. Rasband, and K.W. Eliceiri, NIH Image to ImageJ: 25 years of image analysis. Nat. Methods, 2012. 9(7): p. 671-675.

104. Koenigsmann, C., et al., Highly Enhanced Electrocatalytic Oxygen Reduction Performance Observed in Bimetallic Palladium-Based Nanowires Prepared under Ambient, Surfactantless Conditions. Nano Lett., 2012. 12(4): p. 2013-2020.

105. Koenigsmann, C., et al., Size-Dependent Enhancement of Electrocatalytic Performance in Relatively Defect-Free, Processed Ultrathin Platinum Nanowires. Nano Lett., 2010. 10(8): p. 2806-2811.

106. Koenigsmann, C., et al., Ambient Surfactantless Synthesis, Growth Mechanism, and SizeDependent Electrocatalytic Behavior of High-Quality, Single Crystalline Palladium Nanowires. ACS Nano, 2011. 5(9): p. 7471-7487.

107. Ji, Z., et al., Designed Synthesis of CeO2 Nanorods and Nanowires for Studying Toxicological Effects of High Aspect Ratio Nanomaterials. ACS Nano, 2012. 6(6): p. 5366-5380.

108. Applerot, G., et al., Enhanced Antibacterial Activity of Nanocrystalline ZnO Due to Increased ROS-Mediated Cell Injury. Adv. Funct. Mater., 2009. 19(6): p. 842-852.

109. Fairbairn, D.W., P.L. Olive, and K.L. O'Neill, The comet assay: a comprehensive review. Mutat. Res-Genet. Toxicol., 1995. 339(1): p. 37-59.

110. Simon-Deckers, A.1., et al., Size-, Composition-and Shape-Dependent Toxicological Impact of Metal Oxide Nanoparticles and Carbon Nanotubes toward Bacteria. Environ. Sci. Technol., 2009. 43(21): p. 8423-8429.

111. Chen, J., et al., Evaluating Cytotoxicity and Cellular Uptake from the Presence of Variously Processed TiO2 Nanostructured Morphologies. Chem. Res. Toxicol., 2010. 23(5): p. 871-879. 
112. Zhao, X., et al., In vitro assessment of cellular responses to rod-shaped hydroxyapatite nanoparticles of varying lengths and surface areas. Nanotoxicology, 2011. 5(2): p. 182194.

113. O'Neill, L.A., IMMUNOLOGY: How Frustration Leads to Inflammation. Sci. Signaling, 2008. 320(5876): p. 619.

114. Donaldson, K., et al., Asbestos, carbon nanotubes and the pleural mesothelium: a review of the hypothesis regarding the role of long fibre retention in the parietal pleura, inflammation and mesothelioma. Part. Fibre Toxicol., 2010. 7(1): p. 5.

115. Hussain, S., et al., Cerium Dioxide Nanoparticles Induce Apoptosis and Autophagy in Human Peripheral Blood Monocytes. ACS Nano, 2012. 6(7): p. 5820-5829.

116. Wörle-Knirsch, J.M., et al., Nanoparticulate Vanadium Oxide Potentiated Vanadium Toxicity in Human Lung Cells. Environ. Sci. Technol., 2006. 41(1): p. 331-336.

117. Lu, S., et al., Efficacy of simple short-term in vitro assays for predicting the potential of metal oxide nanoparticles to cause pulmonary inflammation. Environ. Health Persp., 2009. 117(2): p. 241-247.

118. Hussain, S.M., et al., In vitro toxicity of nanoparticles in BRL $3 A$ rat liver cells. Toxicol. In Vitro, 2005. 19(7): p. 975-983.

119. Huang, S., et al., Disturbed mitotic progression and genome segregation are involved in cell transformation mediated by nano-TiO2 long-term exposure. Toxicol. Appl. Pharmacol., 2009. 241(2): p. 182-194.

120. Cassee, F.R., et al., Exposure, Health and Ecological Effects Review of Engineered Nanoscale Cerium and Cerium Oxide Associated with its Use as a Fuel Additive. Crit Rev Toxicol, 2011. 41(3): p. 213-229.

121. Minarchick, V.C., et al., Pulmonary Cerium Dioxide Nanoparticle Exposure Differentially Impairs Coronary and Mesenteric Arteriolar Reactivity. Cardiovasc Toxicol, 2013: p. 1-15.

122. Skorodumova, N., et al., Quantum origin of the oxygen storage capability of ceria. Phys Rev Lett, 2002. 89(16): p. 166601.

123. Eom, H.-J. and J. Choi, Oxidative stress of $\mathrm{CeO}_{2}$ nanoparticles via p38-Nrf-2 signaling pathway in human bronchial epithelial cell, BEAS-2B. Toxicol Lett, 2009. 187(2): p. 7783.

124. Korsvik, C., et al., Superoxide dismutase mimetic properties exhibited by vacancy engineered ceria nanoparticles. Chem Commun, 2007(10): p. 1056-1058.

125. Hirano, S. and K.T. Suzuki, Exposure, metabolism, and toxicity of rare earths and related compounds. Environ Health Persp, 1996. 104(Suppl 1): p. 85-95. 
126. Ward, H. and T. Nicholas, Alveolar type I and type II cells. Australian and New Zealand journal of medicine, 1984. 14(s5): p. 731-734.

127. Hornés, A., et al., Structural, catalytic/redox and electrical characterization of systems combining $\mathrm{Cu}-\mathrm{Ni}$ with $\mathrm{CeO}_{2}$ or $\mathrm{Ce}_{1-x} \mathrm{M}_{x} \mathrm{O}_{2-\delta}(\mathrm{M}=\mathrm{Gd}$ or $\mathrm{Tb})$ for direct methane oxidation. J Power Sources, 2009. 192(1): p. 70-77.

128. ASTM B922-02: Standard test method for metal powder specific surface area by physical adsorption in ASTM International2002, American Society for Testing and Materials: West Consohocken, PA.

129. Kumar, A., et al., Luminescence properties of europium-doped cerium oxide nanoparticles: role of vacancy and oxidation states. Langmuir, 2009. 25(18): p. 1099811007.

130. Kuntaiah, K., et al., Nanocrystalline $\mathrm{Ce}_{1-x} \mathrm{Sm}_{x} \mathrm{O}_{2-\delta}(x=0.4)$ solid solutions: structural characterization versus CO oxidation. RSC Advances, 2013. 3(21): p. 7953-7962.

131. Riddick, T., Control of colloid stability through zeta potential: With a closing chapter on its relationship to cardiovascular disesase. 1968.

132. Cheng, G., et al., Cerium oxide nanoparticles induce cytotoxicity in human hepatoma SMMC-7721 cells via oxidative stress and the activation of MAPK signaling pathways. Toxicol In Vitro, 2013. 27(3): p. 1082-1088.

133. Acharya, S.A., et al., Gd/Sm dopant-modified oxidation state and defect generation in nano-ceria. Solid State Ionics, 2014. 260(0): p. 21-29.

134. Li, N., et al., Comparison of the Pro-Oxidative and Proinflammatory Effects of Organic Diesel Exhaust Particle Chemicals in Bronchial Epithelial Cells and Macrophages. J Immunol, 2002. 169(8): p. 4531-4541.

135. Tedja, R., et al., Biological impacts of TiO on human lung cell lines A549 and H1299: particle size distribution effects. J Nanopart Res, 2011. 13(9): p. 3801-3813.

136. Colon, J., et al., Cerium oxide nanoparticles protect gastrointestinal epithelium from radiation-induced damage by reduction of reactive oxygen species and upregulation of superoxide dismutase 2. Nanomed-Nanotechnol, 2010. 6(5): p. 698-705.

137. Pairon, J.-C., et al., Biopersistence of cerium in the human respiratory tract and ultrastructural findings. Am J Ind Med, 1995. 27(3): p. 349-358.

138. Vocaturo, G., et al., Human exposure to heavy metals. Rare earth pneumoconiosis in occupational workers. CHEST Journal, 1983. 83(5): p. 780-783.

139. Pairon, J., et al., Lung retention of cerium in humans. Occup Environ Med, 1994. 51(3): p. 195-199. 
140. Yoneda, S., et al., Effects of gadolinium chloride on the rat lung following intratracheal instillation. Fund Appl Toxicol, 1995. 28(1): p. 65-70.

141. Dunnick, K., et al., The Effect of Cerium Oxide Nanoparticle Valence State on Reactive Oxygen Species and Toxicity. Biological Trace Element Research, 2015. 166(1): p. 96107.

142. Labor, U.S.D.o. Occupational Safety \& Health Administration. Particulates Not Otherwise Regulated (Total Dust) 08/24/2015]; Available from:

https://www.osha.gov/dts/chemicalsampling/data/CH_259640.html.

143. Gantner, B.N., et al., Collaborative induction of inflammatory responses by dectin-1 and Toll-like receptor 2. J Exp Med, 2003. 197(9): p. 1107-1117.

144. Aalapati, S., et al., Toxicity and bio-accumulation of inhaled cerium oxide nanoparticles in CD1 mice. Nanotoxicology, 2014. 8(7): p. 786-798.

145. Malkusch, W., B. Rehn, and J. Bruch, Advantages of Sirius Red staining for quantitative morphometric collagen measurements in lungs. Experimental lung research, 1995. 21(1): p. 67-77.

146. Rubio, L., et al., Antioxidant and anti-genotoxic properties of cerium oxide nanoparticles in a pulmonary-like cell system. Archives of toxicology, 2015: p. 1-10.

147. Zhang, Q., et al., Cerium oxide nanoparticles protect primary mouse bone marrow stromal cells from apoptosis induced by oxidative stress. J Nanopart Res, 2014. 16(11): p. $1-12$.

148. McDonald, J.W., et al., Rare earth (cerium oxide) pneumoconiosis: analytical scanning electron microscopy and literature review. Modern Pathol 1995. 8(8): p. 859-865.

149. Card, J.W., et al., Pulmonary applications and toxicity of engineered nanoparticles. Am J Physiol-Lung C, 2008. 295(3): p. L400-L411.

150. Karakoti, A.S., et al., Nanoceria as antioxidant: Synthesis and biomedical applications. JOM, 2008. 60(3): p. 33-37.

151. Park, B., et al., Hazard and risk assessment of a nanoparticulate cerium oxide-based diesel fuel additive-a case study. Inhalation toxicology, 2008. 20(6): p. 547-566.

152. Sayes, C.M., K.L. Reed, and D.B. Warheit, Assessing toxicity of fine and nanoparticles: comparing in vitro measurements to in vivo pulmonary toxicity profiles. Toxicol Sci, 2007. 97(1): p. 163-180.

153. Fischer, H.C. and W.C. Chan, Nanotoxicity: the growing need for in vivo study. Curr Opin Biotech, 2007. 18(6): p. 565-571. 
154. Snyder-Talkington, B.N., et al., New perspectives for in vitro risk assessment of multiwalled carbon nanotubes: application of coculture and bioinformatics. $\mathrm{J}$ Toxicol Env Heal B, 2012. 15(7): p. 468-492.

155. Stoehr, L.C., et al., Shape matters: effects of silver nanospheres and wires on human alveolar epithelial cells. Part Fibre Toxicol, 2011. 8(36): p. 3-15.

156. Jr, R.F.H., et al., Particle length-dependent titanium dioxide nanomaterials toxicity and bioactivity. Part Fibre Toxicol, 2009. 6: p. 35.

157. Colon, J., et al., Protection from radiation-induced pneumonitis using cerium oxide nanoparticles. Nanomed-Nanotechnol, 2009. 5(2): p. 225-231.

158. Schubert, D., et al., Cerium and yttrium oxide nanoparticles are neuroprotective. Biochem Bioph Res Co, 2006. 342(1): p. 86-91.

159. Hirst, S.M., et al., Bio-distribution and in vivo antioxidant effects of cerium oxide nanoparticles in mice. Environ Toxicol, 2013. 28(2): p. 107-118. 


\section{KATHERINE M. DUNNICK}

kdunnick@mix.wvu.edu

2204 Chateau Royale Ct

(W) 304-285-6145

Morgantown, WV 26505

(C) 360-513-3492

\section{OBJECTIVE}

Seeking a position in which I can use my experience in toxicology, nanoparticle safety studies, and cell based assays to advance my career in the field of toxicity.

\section{EDUCATION}

2015

Ph.D. in Pharmaceutical and Pharmacological Sciences (GPA: 3.7), West Virginia University, Morgantown, WV

2011 B.S. in Biology (GPA: 3.375), Lebanon Valley College, Annville, PA Minors: Chemistry, Psychology

\section{RESEARCH EXPERIENCE}

2011-2015

Ph.D. Candidate, Pharmaceutical and Pharmacological Sciences, West Virginia University / Health Effects Laboratory Division, National Institute for Occupational Safety and Health (NIOSH), Centers for Disease Control and Prevention, Morgantown, WV (research advisor: Dr. Stephen Leonard)

\section{Research focus and duties:}

- Perform in vitro and in vivo laboratory research in an occupational pulmonary toxicology lab to determine how valence state of cerium oxide nanoparticles affects reactive oxygen species and general cytotoxicity

- Perform in vitro laboratory research to determine how size, shape, and chemical composition of tungstate metal oxide nanoparticles affects toxicity

- Conduct experiments and develop techniques, such as electron paramagnetic resonance, flow cytometry, ELISAs, western blotting, and fluorescent microscopy

- Interpretation and statistical analysis of data

- Written and oral communication of research findings

- Assist in training other lab members on laboratory techniques and equipment

- Collaboration as part of multidisciplinary teams

2010-2011

Undergraduate Researcher, Psychology Department Lebanon Valley College, (research advisor: Dr. Michelle Niculescu)

Research focus: Examination of the genetic underpinnings of risk taking behaviors. 


\section{PUPLICATIONS}

Dunnick KM, Pillai R, Pisane KL, Stefaniak AB, Sabolsky EM, Leonard SS. The effect of cerium oxide nanoparticle valence state on reactive oxygen species production and toxicity. Biological Trace Element Research. Published online March 17, 2015; 166(1): 96-107. doi: 10.1007/s12011-015-0297-4

Dunnick KM, Badding MA, Schwegler-Berry D, Patete JM, Koenigsmann C, Wong SS, and Leonard SS. The effects of tungstate nanoparticles on reactive oxygen species and cytotoxicity in RAW 264.7 mouse monocyte macrophage cells. Journal of Toxicolology and Environmental Health, Part A. 2014; 77(20):1251-1268. doi: 10.1080/15287394.2014.897490.

Badding MA, Fix NR, Orandle MS, Barger MW, Dunnick KM, Cummings KJ, Leonard SS. Pulmonary toxicity of indium-tin oxide production facility particles in rats. Journal of Applied Toxicology. In Press.

\section{In preparation}

Dunnick KM, Morris AM, Badding MA, Barger M, Stefaniak AB, Sabolsky EM, Leonard SS. The effect of valence state on cerium oxide nanoparticle toxicity in rats.

Selected Abstracts and Presentations (* abstract chosen for podia presentation)

*Dunnick KM, Barger M, Badding MA, Morris A, Stefaniak A, Sabolsky E, Leonard SS. Effect of valence state on $\mathrm{CeO}_{2}$ nanoparticle toxicity in rats. - Allegheny-Erie Society of Toxicology Conference, 2015 June, Morgantown, W.

Dunnick KM, Sabolsky E, Leonard SS. The role of valence state in cerium oxide nanoparticle toxicity. Toxicologist 2015 Mar.

- Society of Toxicology Conference, 2015 Mar, San Diego, CA.

*Dunnick KM, Sabolsky E, Leonard SS. Effects of doped cerium oxide nanoparticles on reactive oxygen species production.

- $8^{\text {th }}$ Conference on Metal Toxicity \& Carcinogenesis, 2014 Oct, Albuquerque, NM.

*Dunnick KM, Sabolsky E, Leonard SS. Effects of valence state on cerium oxide nanoparticle toxicity.

- American Association of Pharmaceutical Scientists Pittsburgh Regional Research Forum, 2014 Sep, Pittsburgh, PA.

Dunnick KM, Badding MA, Schwegler-Berry D, N. Marshall, E. Sabolsky and Leonard SS. Role of tungstate nanoparticles in the production of ROS and induction of cellular damage.

- Allegheny-Erie Society of Toxicology Conference, 2014 May, Morgantown, WV.

Dunnick KM, Badding MA, Schwegler-Berry D, Fix NR, Wong SS, and Leonard SS. Evaluation of tungstate nanoparticle cytotoxicity. Toxicologist 2014 Mar; 138(1): 517. 
- Society of Toxicology Conference, 2014 Mar, Phoenix, AZ.

Dunnick KM, Badding MA, Fix NR, JM Patete Wong SS, and Leonard SS. Effect of size and shape of tungstate nanoparticles on cytotoxicity and ROS.

- American Association of Pharmaceutical Scientists WVU Regional Conference, 2013

June, Morgantown, $W V$.

Dunnick KM, Badding MA, Fix NR, Wong SS, Castranova V, Leonard SS [2013]. Role of tungstate nanoparticles in the production of ROS and induction of cellular damage. Toxicologist 132:371:1747.

- Society of Toxicology Conference, 2013 Mar, San Antonio, TX

Fix NR, Dunnick KM, Badding MA, Cummings KJ, Castranova V, and Leonard SS. Generation of reactive oxygen species by process materials from indium-tin oxide production. Toxicologist 2013 Mar; 132(1):429.

- Society of Toxicology Conference, 2013 Mar, San Antonio, TX

Badding MA, Fix NR, Dunnick KM, Cummings KJ, Castranova V, and Leonard SS. Macrophage toxicity in response to particles collected from indium-tin oxide production company. Toxicologist 2013 Mar; 132(1):427.

- Society of Toxicology Conference, 2013 Mar, San Antonio, TX

\section{LEADERSHIP ROLES}

2015-2016

2015

2014-2015

2014

2008-2011
Society of Toxicology, Nanotoxicology Student Representative Outside Speaker Committee, IGERT Program, WVU

Society of Toxicology, Nanotoxicology Vice-Student Representative

- Mentor-Mentee Match Program Committee member

- Specialty Section Awards Committee

- Specialty Section Proposal Review Committee member

Committee member; Science on Tap WVU outreach program

Committee member; Student Alumni Association

HONORS AND AWARDS

2014

2014

2014

2014

2014

2013, 2014

2013, 2014

2013 $8^{\text {th }}$ Conference on Metal Toxicity \& Carcinogenesis Student Travel Award The Rho Chi Academic Honor Society in Pharmacy

Requires a minimum GPA of 3.0 in Pharmacy course work

Nanotoxicology Outstanding Graduate Student Award

(Society of Toxicology)

Regulatory and Safety Evaluation Specialty Graduate Student Award

(Society of Toxicology)

WVU Dean Foundation Graduate Student Travel Award

National Science Foundation, IGERT fellowship recipient

WVU School of Pharmacy Graduate Student Travel Award

Society of Toxicology Graduate Student Travel Award 
2010- 2011

Dean's List

Requires a minimum GPA of 3.0 in Biology major

2007-2011

Requires a minimum GPA of 3.33

Vickroy Award (Annual award)

The college's highest scholarship, which is given to high school seniors graduating in the top $10 \%$ of their class

\section{SERVICE AND VOLUNTEER EXPERIENCE}

2015, June

2015, Feb

2015, Jan

2015

2014, Dec

2014, May

2014-2015

2014, Apr

2010

2005-2011
Camp Muffly, Childrens Day Camp, Volunteer

WV Science Bowl Volunteer

Trinity Christian School Science Fair Judge

Ad Hoc reviewer, J. Toxicology and Environmental Health, part A

Ronald McDonald House volunteer

Boys and Girls club volunteer

Children's Discovery Museum of WV NanoDays Volunteer

WV Science Bowl Volunteer

Freshman biology tutor

American Cancer Society

Yearly Relay for Life Team Captain

\section{PROFESSIONAL ORGANIZATION MEMBERSHIPS}

2012-present

2012-present

2012-present
Society of Toxicology

Member of: Nanotoxicology Specialty Section, Inhalation and Respiratory Specialty Section, Women in Toxicology Special Interest Group

Allegheny-Erie Regional Chapter, Society of Toxicology

American Association of Pharmaceutical Scientists 